NBER WORKING PAPER SERIES

\title{
DOES INCOMPLETE SPANNING IN INTERNATIONAL FINANCIAL MARKETS HELP TO EXPLAIN EXCHANGE RATES?
}

\author{
Hanno Lustig \\ Adrien Verdelhan \\ Working Paper 22023 \\ http://www.nber.org/papers/w22023 \\ NATIONAL BUREAU OF ECONOMIC RESEARCH \\ 1050 Massachusetts Avenue \\ Cambridge, MA 02138 \\ February 2016
}

\begin{abstract}
We are grateful to Emmanuel Farhi, Jack Favilukis, Bob Hodrick, Robert Richmond, and Alexandros Vardoulakis for their discussions and detailed comments, and we would like to thank Bob Hodrick for conversations that led to this paper. We are grateful to Bernard Dumas, Ana Fostel, Xavier Gabaix, Francisco Gomes, Leonid Kogan, Sylvain Leduc, Matteo Maggiori, Jonathan Parker, Anna Pavlova, Carolin Pflueger, Anders Trolle, Raman Uppal and seminar participants at different institutions and conferences for their comments. The views expressed herein are those of the authors and do not necessarily reflect the views of the National Bureau of Economic Research.
\end{abstract}

NBER working papers are circulated for discussion and comment purposes. They have not been peer-reviewed or been subject to the review by the NBER Board of Directors that accompanies official NBER publications.

(C) 2016 by Hanno Lustig and Adrien Verdelhan. All rights reserved. Short sections of text, not to exceed two paragraphs, may be quoted without explicit permission provided that full credit, including $\odot$ notice, is given to the source. 
Does Incomplete Spanning in International Financial Markets Help to Explain Exchange Rates?

Hanno Lustig and Adrien Verdelhan

NBER Working Paper No. 22023

February 2016, Revised March 2016

JEL No. F31,G12

\begin{abstract}
Compared to the predictions of complete market models, actual exchange rates are puzzlingly smooth and only weakly correlated with macro-economic fundamentals, suggesting that market incompleteness plays a key role in exchange rate dynamics. Incompleteness in international financial markets introduces a stochastic wedge between the growth rates of marginal utility at home and abroad, and the change in the exchange rate. We derive a preference-free upper bound on the effects of the FX wedges. Even if domestic agents can invest only in the foreign risk-free asset, incomplete spanning fails to simultaneously match the exchange rate volatility, cyclicality and the FX risk premia in the data.
\end{abstract}

\author{
Hanno Lustig \\ Stanford Graduate School of Business \\ 655 Knight Way \\ Stanford, CA 94305 \\ and NBER \\ hlustig@stanford.edu \\ Adrien Verdelhan \\ MIT Sloan School of Management \\ 100 Main Street, E62-621 \\ Cambridge, MA 02142 \\ and NBER \\ adrienv@mit.edu
}


Starting with the seminal work of Lucas (1982), many models in international economics assume that the menu of contingent claims spans all states of the world. Given complete spanning, the rate of appreciation of the real exchange rate equals the difference between the marginal utility growth rates of the foreign and domestic stand-in investor in each state of the world: $\Delta s=m^{*}-m$. Everyone agrees, however, that, in reality, financial markets certainly do not span all possible states of the world. Departures from complete spanning introduce stochastic FX wedges between $\Delta s$ and $m^{*}-m$. Can these FX wedges help us understand the puzzling features of exchange rates? Our paper addresses this question. We assume that domestic agents invest only in the foreign risk-free asset and thus derive an upper bound on the effects of the FX wedges. We find that this extreme departure from complete spanning can help to match the volatility and cyclicality of exchange rates in the data, but only at the cost of eliminating currency risk premia and restoring uncovered interest rate parity.

Our paper focuses on three key exchange rate puzzles: the volatility puzzle of Brandt, Cochrane, and Santa-Clara (2006), the cyclicality puzzle of Backus and Smith (1993), and the forward premium puzzle of Fama (1984). These three puzzles highlight the limits of most international economics models, and they are the subject of a very large literature, with literally hundreds of contributions published in the last thirty years. (i) Hansen and Jagannathan (1991) show that stochastic discount factors have to be highly volatile in order to reproduce observed equity premia across the globe. As Brandt, Cochrane, and Santa-Clara (2006) point out, stochastic discount factors must be almost perfectly correlated in order to match the comparatively low exchange rate volatility in the data. But macroeconomic variables exhibit low correlations across countries. (ii) When markets are complete and agents have constant relative risk aversion preferences, changes in exchange rates must be perfectly correlated with relative consumption growth rates in the domestic and foreign economies. As was first pointed out by Kollmann (1991) and Backus and Smith (1993), the low correlation in the data is therefore surprising. (iii) As documented by Tryon (1979), Hansen and Hodrick (1980) and Fama (1984), interest rate differences do not predict subsequent changes in exchange rates, thus giving rise to large deviations from the uncovered interest rate parity condition and currency carry trade 
returns. The size of currency risk premia represents a challenge for many models in international economics.

In this paper, we study whether departures from complete spanning in international securities trading can help address the three key exchange rate puzzles. There is a wealth of empirical evidence that investors act as if they face an incomplete menu of assets abroad, either because of explicit transactions and capital controls, or because of other frictions (Lewis, 1995). To derive an upper bound on the effects of incomplete spanning in international financial markets on exchange rates, we focus on the case in which investors can only invest abroad in the risk-free asset, or equivalently, investors only have access to forward currency markets.

We show that even this dramatic deviation from complete spanning cannot help us to simultaneously make progress on the three main exchange rate puzzles. Incomplete spanning always lowers the volatility of exchange rates, and in some cases the correlation between macro fundamentals and exchange rate changes, but, in doing so, incomplete spanning also restores uncovered interest rate parity and reduces the carry trade risk premium well below its empirical value.

To study the exchange rate puzzles, we adopt the perspective of an econometrician who commits to a model for the log domestic and foreign stochastic discount factors, $m$ and $m^{*}$, taking allocations (e.g., aggregate consumption growth, the market return) as given. These stochastic discount factors may depend on agents' preferences and may, for example, vary with consumption, real money balances, and work hours. They may also depend on intermediaries' wealth, collateral or liquidity and may reflect the impact of market incompleteness. But the economic variables are what they are in the data, independently from their theoretical interpretation. An econometrician would start from the time-series of these variables in the data and look for the best-fitting model that can reproduce the empirical exchange rate and risk-free rates, testing for example different preference parameters. We do not commit to any class of models in particular and we let the econometrician choose any possible model. Once the model is chosen, we define the projection of the stochastic discount factor in the space of traded assets as our initial $m$.

In order to derive model-free results, we build on Backus, Foresi, and Telmer's (2001) insight 
that incomplete spanning introduces a FX wedge $\eta$ between the change in exchange rates and the domestic and foreign stochastic discount factors: $\Delta s=\eta+m^{*}-m$. These stochastic FX wedges can be interpreted as ratios of tax rates on exchange rate transactions that mimic the effects of market incompleteness in a complete markets world. Similar approaches have been used in the macroeconomics literature, most notably in Chari, Kehoe, and McGrattan (2007). Our theoretical results rely on two key assumptions: 1) the existence of a stochastic discount factor in the space of traded assets in one country, 2) the existence of a domestic and a foreign risk-free rate in which the other country's investors can invest. ${ }^{1}$

We analyze the effect of the FX wedges $\eta$ while enforcing the foreign investors' Euler equation only in the domestic risk-free bond market, but not in other domestic securities markets. This is equivalent to assuming that foreign investors have unconstrained access to one-period ahead forward currency markets, but perhaps not to other asset markets. Similarly, domestic investors have access to foreign risk-free bonds. We find that the Euler equation restrictions imply that the FX wedges need to be pro-cyclical, causing the real exchange rate to appreciate less when marginal utility growth is high, and hence always reduce the volatility of exchange rates relative to the complete markets benchmark.

To bring the volatility of exchange rates in line with the data, the volatility of the FX wedges needs to match the maximum Sharpe ratio in the economy. These FX wedges act as a reduction of the representative agent's risk aversion in currency markets, thus solving the excess volatility puzzle. But these FX wedges also shrink currency risk premia and move the model towards the uncovered interest rate parity.

We start by analyzing the log-normal case. Our quantitative assessment relies on two empirical assumptions: (i) the stochastic discount factors $m$ and $m^{*}$ are volatile, as implied by the Hansen and Jagannathan (1991) bounds; and (ii) the conditional correlation between the

\footnotetext{
${ }^{1}$ Our assumptions are reasonable but not trivial. If the law of one price holds in financial markets and investors can form portfolios freely, then a unique stochastic discount factor exists in the space of traded assets (see Ross, 1978; Cochrane, 2005, for a textbook exposition). From the stochastic discount factor in one country, one can then construct a second one using the change in exchange rate. But there are cases when investors cannot form portfolios freely (e.g., in the presence of short-selling constraints) or when the law of one price in financial markets fails, and thus the existence of a stochastic discount factor is not guaranteed. Likewise, risk-free assets may not exist. Assuming that a stochastic discount factor exists in the space of traded assets and that risk-free rates exist allows us to derive model-free results.
} 
domestic and foreign log stochastic discount factors is at most 0.5 , a large value considering the low cross-country correlation of any macroeconomic variable in the data. The log normality assumption allows us to focus on the first two moments of stochastic discount factors and FX wedges and jointly address the volatility, cyclicality, and risk premium puzzles.

Our results, however, are not a simple rejection of lognormality. We relax this assumption, and we derive restrictions on FX wedges in terms of their entropy and co-entropy with the pricing kernels. Even in this general case, increases in the volatility of the exchange rate changes go hand in hand with decreases in currency risk premia. ${ }^{2}$ In a calibrated version of the benchmark Merton (1976) and consumption disaster model, we find that the introduction of incomplete spanning of the consumption disasters cannot address the three puzzles simultaneously.

Sofar we have assumed that all moments of the FX wedge $\eta$ are free parameters, the best case scenario for incomplete market models. Yet, in a large class of dynamic asset pricing models, the higher-order moments of the FX wedge are related to its first moment by no arbitrage restrictions, further restraining the ability of incomplete market models to match the data. Imposing dynamic no-arbitrage restrictions worsens the trade-off we have described thus far. We show that the FX wedges always lower currency market risk premia and Sharpe ratios in this class of models. A given percentage decrease in the volatility of exchange rates relative to the complete markets case implies the same percentage decrease in the currency markets' Sharpe ratio relative to the complete markets benchmark, while the uncovered interest rate parity slope regression coefficient is always pushed towards unity. In a version of the Consumption-CAPM model with heteroskedasticity in consumption growth, we show that the effect of incompleteness is equivalent to lowering the coefficient of risk aversion of the representative agent by the same percentage for the pricing of currency risk.

Given that incomplete spanning alone cannot address the main exchange rate puzzles, what avenues may work? The literature suggests several paths. Colacito and Croce (2011), Bansal and Shaliastovich (2012), Farhi and Gabaix (2015), and Gabaix and Maggiori (2015) address the

\footnotetext{
${ }^{2}$ The only way to counteract the decrease of the risk premium brought about by the decrease in exchange rate volatility is to impute a large non-stationary component in the exchange rate changes through a large drift in the stochastic FX wedge. While one cannot rule out the existence of a non-Gaussian model that would match the three exchange rate puzzles simultaneously thanks to incomplete spanning, we do not know of such a model.
} 
aforementioned puzzles in models respectively based on long-run risk preferences, rare disaster risk, or segmented markets. The long-run risk models assume that the slow moving components of consumption growth are perfectly correlated across countries. The disaster risk model assumes that exchange rates exhibit a low probability of a large depreciation. The segmented market models assume a very large correlation between exchange rate changes and the consumption growth of the market participants. While we find these assumptions plausible, we recognize that more empirical work is needed to directly validate them. There is yet no widely accepted solution to the exchange rate puzzles. Since we find that incomplete spanning can only go so far in explaining exchange rate puzzles, our paper implicitly argue in favor of more empirical work along the lines suggested by the recent contributions to the international finance literature.

Building on Brandt, Cochrane, and Santa-Clara (2006) and Backus, Foresi, and Telmer's (2001), our paper also complements a growing literature in international economics and finance that study exchange rates in incomplete markets. We do not study how market incompleteness changes the projection of the stochastic discount factor on the space of domestically traded assets itself. Such changes are interesting, and our paper therefore does not suggest that models with incomplete markets are uninteresting or not useful. ${ }^{3}$

The rest of this paper is organized as follows. Section 1 defines exchange rates in the cases of complete and incomplete spanning and presents our main result. Section 2 then studies the exchange rate volatility, the currency risk premium, and the exchange rate cyclicality in details, before gathering all the three puzzles together. Section 3 extends the main result to the nonnormal case and to a large class of log-linear dynamic asset pricing models as examples. Section 4 concludes. All the proofs are presented in the Online Appendix.

\footnotetext{
${ }^{3}$ Notable recent contributions include the work by Alvarez, Atkeson, and Kehoe (2002), Chari, Kehoe, and McGrattan (2002), Bacchetta and van Wincoop (2006), Corsetti, Dedola, and Leduc (2008), Alvarez, Atkeson, and Kehoe (2009), Pavlova and Rigobon (2010, 2012), Bruno and Shin (2014), Maggiori (2014), Gabaix and Maggiori (2015), and Favilukis, Garlappi, and Neamati (2015). Instead of specifying a fully-fledged international economics model as these authors do, we seek results that are valid for any stochastic discount factors. These stochastic discount factors could reflect the impact of market incompleteness on the equilibrium allocations. But the exchange rate puzzles remain: macroeconomic variables like consumption growth, whether the response to an optimal behavior in complete or incomplete markets, exhibit a low correlation across countries and a low correlation to the exchange rate changes in the data.
} 


\section{Exchange Rates in Complete and Incomplete Markets}

In this section, we define exchange rates in complete and incomplete markets and derive key restrictions on incomplete market models.

\subsection{Complete Spanning}

We start by defining some notation. $S_{t}$ denotes the nominal exchange rate in domestic currency (e.g., U.S. dollars) per unit of foreign currency. When $S_{t}$ increases, the foreign currency appreciates and the U.S. dollar depreciates. $R_{t}^{*}$ represents the return on a foreign asset expressed in units of foreign currency, while $R_{t}$ denotes the return on a domestic asset, expressed in units of the domestic currency. More generally, $x^{*}$ denotes a foreign variable expressed in units of foreign currency. $M$ represents the stochastic discount factor. With this notation, the domestic and foreign investor's Euler equations for any foreign return $R_{t}^{*}$ are:

$$
\begin{aligned}
E_{t}\left(M_{t+1} \frac{S_{t+1}}{S_{t}} R_{t+1}^{*}\right) & =1 \\
E_{t}\left(M_{t+1}^{*} R_{t+1}^{*}\right) & =1 .
\end{aligned}
$$

We define variables in nominal terms, but a similar analysis applies to real variables. ${ }^{4}$

Definition of Complete Markets Markets are complete when investors can invest in any contingent claim, either directly or by synthesizing contingent claims using other securities. In other words, markets are complete when securities' payoffs span all the possible states of nature. Suppose that there are $S$ possible states of nature tomorrow. Each contingent claim is a security that pays one dollar in one state $s$ only tomorrow; $p c(s)$ is its price today. Each asset is defined by the set $X$ of its payoffs in each state of nature. Let $x(s)$ denote an asset's payoff in state $s$,

\footnotetext{
${ }^{4}$ Among developed countries, in the absence of high and volatile inflation rates, the three exchange rate puzzles that we study exist on both nominal and real variables: the volatilities of real and nominal exchange rates are similar, and so are their correlations with macroeconomic variables and their risk premia. When dealing with real variables, the same expressions as in Equations (1) and (2) apply, with the following interpretation. In a world with multiple goods, we would choose one good in each country to be the numéraire; $S_{t}$ would then denote the real exchange rate, expressed in units of the domestic numéraire, per unit of the foreign numéraire; and $M_{t}$ would be expressed in the domestic numéraire. Our analysis allows for different consumption baskets at home and abroad.
} 
then the asset price $P(X)$ must satisfy:

$$
P(X)=\sum_{s} p c(s) x(s)=\sum_{s} \pi(s) \frac{p c(s)}{\pi(s)} x(s)=E(M X),
$$

where the last equality is simply a definition of the stochastic discount factor $M$. When markets are complete, the stochastic discount factor is clearly unique. When markets are incomplete, the stochastic discount factor is not unique: under certain conditions, a unique stochastic discount factor exists in the space of traded assets, but many others potentially exist outside that space. ${ }^{5}$

Implications of Complete Markets By comparing the two Euler equations (1) and (2) above, one can guess a candidate foreign pricing kernel:

$$
M_{t+1}^{*}=M_{t+1} \frac{S_{t+1}}{S_{t}}
$$

taking the domestic pricing kernel and the exchange rate process as given. If markets are complete (i.e., complete spanning), then this foreign pricing kernel is the only pricing kernel that is consistent with the absence of arbitrage opportunities. ${ }^{6}$ When goods markets are not frictionless or domestic and foreign agents consume different goods, then real exchange rates vary in equilibrium even if financial markets are themselves frictionless. If markets are not complete (incomplete spanning), then there are lots of other candidate foreign pricing kernels. In the case of complete markets, the log change in exchange rate is thus:

$$
\Delta s_{t+1}=m_{t+1}^{*}-m_{t+1} .
$$

\footnotetext{
${ }^{5}$ If investors can form portfolios freely and the law of one price holds in financial markets, then there exists a unique stochastic discount factor in the space of traded assets (see Cochrane, 2005, Chapter 4). The law of one price in financial markets is defined as follows: the price of a combination of payoffs $X_{1}$ and $X_{2}$ is the combination of their prices, i.e $P\left(a X_{1}+b X_{2}\right)=a P\left(X_{1}\right)+b P\left(X_{2}\right)$ for any real pair $(a, b)$. Any Euler equation implies that the law of one price holds. The spanning condition is different from the law of one price in financial assets.

${ }^{6}$ In models that feature complete spanning, one can thus back out the implied changes in exchange rates from the stochastic discount factors at home and abroad. Equivalently, one can start from the domestic (or foreign) stochastic discount factor and the rate of change in exchange rates, and then derive the implicit foreign (domestic) stochastic discount factor.
} 
Throughout the paper, lower case letters denote natural logarithms. This equation implies that the foreign currency appreciates in bad times for foreign investors, while the home currency depreciates in good times for domestic investors. This implication of complete markets is sometimes viewed as undesirable and counterintuitive (e.g., the Argentine peso depreciated in 2002, clearly not during great times in Argentina), although not always rejected by the data (e.g., the Japanese yen appreciated after the 2014 tsunami in Japan).

In order to break the tight link between the log change in exchange rate and the two log stochastic discount factors, one needs to abandon the assumption of complete spanning. Our paper starts from a simple question: what do we gain by relaxing the complete spanning assumption and introducing a FX wedge between the exchange rate change and the stochastic discount factors? To address this question, we first derive some necessary conditions on the FX wedge implied by incomplete spanning.

\subsection{Incomplete Spanning}

We adopt the approach of an econometrician who commits to a model for the SDF. We start from a pair of pricing kernels $\left(M, M^{*}\right)$ that can be measured by an econometrician with access to sufficiently rich data. For example, if households have access to a rich menu of assets domestically, then we can rely on standard aggregation results to construct a stand-in agent who consume aggregate consumption and price assets off his inter-temporal marginal rate of substitution (IMRS). In the case of the Breeden-Lucas-Rubenstein representative agent model with power utility, then the real $\log$ pricing kernel is $m_{t+1}=\log \delta-\gamma \Delta c_{t+1}$ where $\gamma$ denotes the coefficient of relative risk aversion, $\delta$ denotes the rate of time preference, and $\Delta c_{t+1}$ denotes log aggregate consumption growth. Similarly, the foreign log pricing kernel is $m_{t+1}^{*}=\log \delta^{*}-\gamma^{*} \Delta c_{t+1}^{*}$. The econometrician can test this model by gathering data on aggregate consumption growth at home and abroad. ${ }^{7}$ This is, however, only an example: in this paper, we seek to derive model-free results. Armed with a pair $\left(M, M^{*}\right)$, we explore the effects of incomplete spanning in financial

\footnotetext{
${ }^{7}$ We could also use an unconstrained individual's IMRS, to be measured with individual consumption data, if we do not wish to rely on aggregation results. Alternatively, we could use a cross-sectional average of the individual IMRS to price assets, in the spirit of Mankiw (1986) and Constantinides and Duffie (1996). This would require data on higher-order moments of individual consumption growth.
} 
markets.

To study the impact of incomplete spanning in international financial markets on exchange rates, we fix the foreign and domestic SDFs, and we follow the approach pioneered by Backus, Foresi, and Telmer (2001) who define a new 'perturbed' SDF denoted $\widehat{M}_{t+1}^{*}$ :

$$
\widehat{M}_{t+1}^{*}=M_{t+1}^{*} \exp \left(\eta_{t+1}\right)=M_{t+1} \frac{S_{t+1}}{S_{t}}
$$

There is a stochastic FX wedge between the domestic investor's marginal valuation of one pound, to be delivered in some state tomorrow, given by the right hand side, and the foreign investor's valuation thereof, $M_{t+1}^{*}$. These FX wedges can be interpreted as representing the effects of stochastic taxes on foreign transactions (see, e.g., Chari, Kehoe, and McGrattan (2007)) that mimick the effects of market incompleteness in a complete markets world.

In essence, we compare two different processes for exchange rates. The first one, highlighted in the previous section, is the complete markets one, the second one allows for incomplete spanning:

$$
\Delta s_{t+1}=m_{t+1}^{*}-m_{t+1} \quad \text { vs. } \quad \Delta s_{t+1}=\eta_{t+1}+m_{t+1}^{*}-m_{t+1} .
$$

The Backus, Foresi, and Telmer (2001) approach is very general, as it encompasses many incomplete market models. These models rarely admit a closed-form solution for the exchange rate, but the work of Pavlova and Rigobon (2012) provides a useful exception. In their model, agents trade three assets (domestic and foreign stocks and an international bond), but are subject to four shocks (two endowment shocks and two preference shocks) and markets are thus incomplete. Log preferences lead to the following equilibrium real exchange rate, $Q_{t}^{I M}$ :

$$
Q_{t}^{I M}=\frac{\theta_{H}(t)+\frac{W_{F}(t)}{W_{H}(t)}\left(1-\theta_{F}\right)}{1-\theta_{H}(t)+\frac{W_{F}(t)}{W_{H}(t)} \theta_{F}} \frac{Y_{t}^{*}}{Y_{t}},
$$

where $Y_{t}$ and $Y_{t}^{*}$ are the domestic and foreign endowments, $\theta_{H}(t)$ denotes the domestic intratemporal preference shocks, and $W_{H}(t)$ and $W_{F}(t)$ denote domestic and foreign wealth. In this 
model, the wealth ratio $W_{F}(t) / W_{H}(t)$ is time-varying. In an earlier contribution, Pavlova and Rigobon (2007) consider a similar model, but with only one preference shocks, and thus as many shocks as assets. In Pavlova and Rigobon (2007), where markets are complete, the wealth ratio is constant and the same expression holds for the equilibrium real exchange rate, $Q_{t}^{C M}$. The two models are different: market incompleteness clearly changes the consumption allocation. But the incomplete market model can be thought as introducing an additional source of variation in exchange rates. The ratio of the incomplete to complete market value of exchange rate is:

$$
\frac{Q_{t}^{I M}}{Q_{t}^{C M}}=\frac{\theta_{H}(t)+\frac{W_{F}(t)}{W_{H}(t)}\left(1-\theta_{F}\right)}{1-\theta_{H}(t)+\frac{W_{F}(t)}{W_{H}(t)} \theta_{F}} \times \frac{1-\theta_{H}(t)+\frac{W_{F}}{W_{H}} \theta_{F}}{\theta_{H}(t)+\frac{W_{F}}{W_{H}}\left(1-\theta_{F}\right)},
$$

The FX wedge $\eta_{t+1}$ introduced in Equation (6) captures the percentage change in this ratio $\left(\eta_{t+1}=\Delta q_{t}^{I M}-\Delta q_{t}^{C M}\right)$. Our approach offers a way to study the effects of incomplete market models on exchange rate puzzles without committing to any preferences or frictions.

To derive an upper bound on the effects of incompleteness in international financial markets, we start by only considering investments in the foreign risk-free assets. We assume that there exists a risk-free asset at home and abroad that can be bought and sold by domestic and foreign investors. Domestic investors can trade the foreign risk-free asset, and vice-versa, the foreign investor can invest in the domestic risk-free asset. Naturally, if foreign investors can invest in other domestic assets, this will give rise to additional restrictions. By ignoring these additional restrictions, we are giving incomplete spanning the best shot at producing promising results that cannot be replicated by a simple reduced form model in complete markets. Our results thus provide an upper bound on the effects of incomplete spanning.

Based on the perturbed SDF, the domestic investor's Euler equations for foreign assets, and the foreign investor's Euler equation for the domestic assets are now given by:

$$
\begin{aligned}
& E_{t}\left(M_{t+1} \frac{S_{t+1}}{S_{t}} R_{t+1}^{*}\right)=E_{t}\left(M_{t+1}^{*} \exp \left(\eta_{t+1}\right) R_{t+1}^{*}\right)=1 \\
& E_{t}\left(M_{t+1}^{*} \frac{S_{t}}{S_{t+1}} R_{t+1}\right)=E_{t}\left(M_{t+1} \exp \left(-\eta_{t+1}\right) R_{t+1}\right)=1
\end{aligned}
$$


Again, if international financial markets are complete, then of course $\eta=0$. If international financial markets are incomplete, there are lots of possible $\eta$ 's. ${ }^{8}$

Since the risk-free payoffs are in the space of traded assets for all investors, domestic and foreign, they satisfy the Euler Equations (1) and (2), but the risk-free payoffs also satisfy the two perturbed Euler Equations (7) and (8), in which the incomplete spanning introduces a FX wedge $\eta$ in the spot exchange rates. We start from the Euler Equations (7) and (8) for the risk-free assets:

$$
\begin{aligned}
& E_{t}\left(M_{t+1} \frac{S_{t+1}}{S_{t}}\right)=E_{t}\left(M_{t+1}^{*} \exp \left(\eta_{t+1}\right)\right)=1 / R_{t}^{f, *} \\
& E_{t}\left(M_{t+1}^{*} \frac{S_{t}}{S_{t+1}}\right)=E_{t}\left(M_{t+1} \exp \left(-\eta_{t+1}\right)\right)=1 / R_{t}^{f}
\end{aligned}
$$

We can only consider perturbations $\eta$ that satisfy these Euler equations. If not, we would be violating the assumption of no arbitrage. Below, we explore the restrictions imposed by these conditions on possible $\eta$ 's. To explore these restrictions, we assume conditional joint log normality of the SDFs and the $\eta$ 's. We relax this assumption in Section 3.

Proposition 1. We fix the home log stochastic discount factor $m$ and the foreign log stochastic discount factor $m^{*}$. Incomplete spanning implies that the exchange rate process $S_{t}$ satisifies $\Delta s_{t+1}=\eta_{t+1}+m_{t+1}^{*}-m_{t+1}$. If the log stochastic discount factors and perturbations $\eta$ are jointly conditionally normal, then $\mu_{t, \eta}=E_{t}\left(\eta_{t+1}\right)$ and $\operatorname{var}_{t}\left(\eta_{t+1}\right)$ satisfy:

$$
\begin{aligned}
\operatorname{covar}_{t}\left(m_{t+1}^{*}, \eta_{t+1}\right) & =-\mu_{t, \eta}-\frac{1}{2} \operatorname{var}_{t}\left(\eta_{t+1}\right), \\
\operatorname{covar}_{t}\left(m_{t+1}, \eta_{t+1}\right) & =-\mu_{t, \eta}+\frac{1}{2} \operatorname{var}_{t}\left(\eta_{t+1}\right),
\end{aligned}
$$

\footnotetext{
${ }^{8}$ Note that incomplete spanning could change $M$ and $M^{*}$ themselves in interesting ways by changing equilibrium allocations within a country. We do not take these effects into account. The econometrician is committed to a model for $M$ and $M^{*}$, and our results are valid for any $M$ and $M^{*}$.
} 
where $\mu_{t, \eta}$ satisfies these additional restrictions:

$$
\begin{aligned}
-\mu_{t, \eta} & \leq s t d_{t}\left(\eta_{t+1}\right)\left(s t d_{t}\left(m_{t+1}^{*}\right)+\frac{1}{2} s t d_{t}\left(\eta_{t+1}\right)\right), \text { when } \mu_{t, \eta} \leq-\frac{1}{2} \operatorname{var}_{t}\left(\eta_{t+1}\right), \\
\mu_{t, \eta} & \leq s t d_{t}\left(\eta_{t+1}\right)\left(s t d_{t}\left(m_{t+1}^{*}\right)-\frac{1}{2} s t d_{t}\left(\eta_{t+1}\right)\right), \text { when } \mu_{t, \eta} \geq-\frac{1}{2} \operatorname{var}_{t}\left(\eta_{t+1}\right), \\
\mu_{t, \eta} & \leq s t d_{t}\left(\eta_{t+1}\right)\left(s t d_{t}\left(m_{t+1}\right)+\frac{1}{2} s t d_{t}\left(\eta_{t+1}\right)\right), \text { when } \mu_{t, \eta} \geq \frac{1}{2} \operatorname{var}_{t}\left(\eta_{t+1}\right), \\
-\mu_{t, \eta} & \leq s t d_{t}\left(\eta_{t+1}\right)\left(\operatorname{std} t\left(m_{t+1}\right)-\frac{1}{2} \operatorname{std}\left(\eta_{t+1}\right)\right), \text { when } \mu_{t, \eta} \leq \frac{1}{2} \operatorname{var}_{t}\left(\eta_{t+1}\right), \\
\operatorname{std} t\left(\eta_{t+1}\right) & \leq \operatorname{std}_{t}\left(m_{t+1}^{*}-m_{t+1}\right), \text { everywhere. }
\end{aligned}
$$

Hence, there are limits as to how much incomplete markets noise we can introduce. For example, when the FX wedge has a conditional mean of zero $\left(\mu_{t, \eta}=0\right)$, the amount of noise is bounded above by the following two conditions:

$$
2 m i n\left(s t d_{t}\left(m_{t+1}\right), s t d_{t}\left(m_{t+1}^{*}\right)\right) \geq s t d_{t}\left(\eta_{t+1}\right) \text { and } s t d_{t}\left(m_{t+1}^{*}-m_{t+1}\right) \geq s t d_{t}\left(\eta_{t+1}\right) .
$$

The standard deviation of the log SDF measures the maximal Sharpe ratio among traded assets, defined as the ratio of expected excess returns to their volatilities. This well-known result derives directly from the Euler equation in a lognormal world; $E_{t}\left(M_{t+1} R_{t+1}\right)=1$ implies that:

$$
\frac{E_{t}\left(R_{t+1}-R_{t}^{f}\right)}{s t d_{t}\left(R_{t+1}\right)} \leq s t d_{t}\left(m_{t+1}\right), \text { for any return } R_{t+1} \text {. }
$$

The maximal volatility of the wedge is thus linked to the maximal Sharpe ratio among traded assets.

At this point, we have made no additional assumptions about the process $\eta$ that describes the incomplete spanning. In dynamic asset pricing models, the drift term $\mu_{t, \eta}$ imputed to the exchange rate process is not a free parameter but is instead determined by no arbitrage conditions. We analyze a class of dynamic asset pricing models in Section 3. Additional assets also impose additional restrictions on the wedges. If we allow foreign investors to trade risky 
assets, in addition to the risk-free rate, this will give rise to additional restrictions. For example, if the foreign investor's can trade an additional risky asset, then the wedges cannot covary with these risky returns $\left(r_{t+1}, r_{t+1}^{*}\right)$ :

$$
\operatorname{covar}_{t}\left(r_{t+1}^{*}, \eta_{t+1}\right)=0=\operatorname{covar}_{t}\left(r_{t+1}, \eta_{t+1}\right)
$$

We ignore these additional constraints, which may further limit the explanatory power of incomplete spanning models.

\section{Exchange Rate Puzzles}

In this section, we study the impact of incomplete spanning on each of the key three exchange rate puzzles in a preference-free setting. We start with the volatility puzzle, and then consider the exchange rate cyclicality and exchange rate risk puzzles. We end this section with a simple Lucas (1982) example.

\subsection{Exchange Rate Volatility}

Brandt, Cochrane, and Santa-Clara (2006) note that the exchange rate changes predicted by complete market models are much more volatile than in the data, unless stochastic discount factors are almost perfectly correlated across countries, which seems at odds with the evidence on any macroeconomic variable. Colacito and Croce (2011) offer a compelling resolution to the puzzle by assuming that the long-run risk components of the stochastic discount factors are highly correlated across countries. ${ }^{9}$ In this section, we pursue another route, adding incomplete spanning to the benchmark model.

We show that the volatility of the exchange rate decreases relative to the complete spanning benchmark one-for-one with the volatility of the wedge.

\footnotetext{
${ }^{9}$ In their model, stochastic discount factors are then volatile enough to reproduce the equity premium, but, thanks to their long-run risk components, they are almost perfectly correlated such that exchange rates are as volatile as in the data. The long-run risk components are, however, difficult to measure in the data and most evidence is drawn indirectly from asset prices and not macroeconomic quantities.
} 
Corollary 1. The volatility of exchange rates in incomplete markets is given by:

$$
\operatorname{var}_{t}\left(\Delta s_{t+1}\right)=\operatorname{var}_{t}\left(m_{t+1}\right)+\operatorname{var}_{t}\left(m_{t+1}^{*}\right)-2 \operatorname{cov}_{t}\left(m_{t+1}, m_{t+1}^{*}\right)-\operatorname{var}_{t}\left(\eta_{t+1}\right)
$$

This result follows directly from the covariance restrictions in Equations (9) and (10). Since the wedges are necessarily pro-cyclical, they offset the effect of $m$ and $m^{*}$, and thus reduce the overall volatility of the exchange rate.

To make quantitative progress on the Brandt, Cochrane, and Santa-Clara (2006) puzzle, the wedges need to be volatile. To quantify this statement, we measure the relevant moments in the data. Table 1 reports the annualized volatility of bilateral exchange rates for 15 developed countries (Australia, Belgium, Canada, Denmark, France, Germany, Italy, Japan, Netherlands, New Zealand, Norway, Sweden, Switzerland, U.K., and U.S). All exchange rates are defined with respect to the U.S. dollar. Data are quarterly, over the 1973.IV - 2014.IV period. Across all the countries, the average volatility is $11 \%$ in this sample. It is precisely estimated, with a standard error (obtained by bootstrapping) of $0.4 \%$, and there are only small variations across countries: the cross-sectional standard deviation is $1.6 \%$.

Suppose therefore that we want to match a $11 \%$ per annum volatility of exchange rate changes. Then Corollary 1 implies that:

$$
0.11^{2}=\operatorname{var}_{t}\left(\Delta s_{t+1}\right)=\operatorname{var}_{t}\left(m_{t+1}\right)+\operatorname{var}_{t}\left(m_{t+1}^{*}\right)-2 \operatorname{cov}_{t}\left(m_{t+1}, m_{t+1}^{*}\right)-\operatorname{var}_{t}\left(\eta_{t+1}\right)
$$

As a result, we can simply back out the volatility of the wedge needed to match the volatility of exchange rates in the data:

$$
\operatorname{var}_{t}\left(\eta_{t+1}\right)=\operatorname{var}_{t}\left(m_{t+1}\right)+\operatorname{var}_{t}\left(m_{t+1}^{*}\right)-2 \operatorname{cov}_{t}\left(m_{t+1}, m_{t+1}^{*}\right)-0.11^{2}
$$

This equals the difference between the variance of the complete market exchange rates implied by the stochastic discount factors and the target variance. For example, starting from a maximum Sharpe ratio of 0.50 in both countries $\left(s t d_{t}\left(m_{t+1}\right)=0.50\right.$ and $\left.s t d_{t}\left(m_{t+1}^{*}\right)=0.50\right)$ and a correlation across stochastic discount factors of $0.50\left(\rho_{t}\left(m_{t+1}, m_{t+1}^{*}\right)=0.50\right)$, the wedge must 
Table 1: Exchange Rate Puzzles

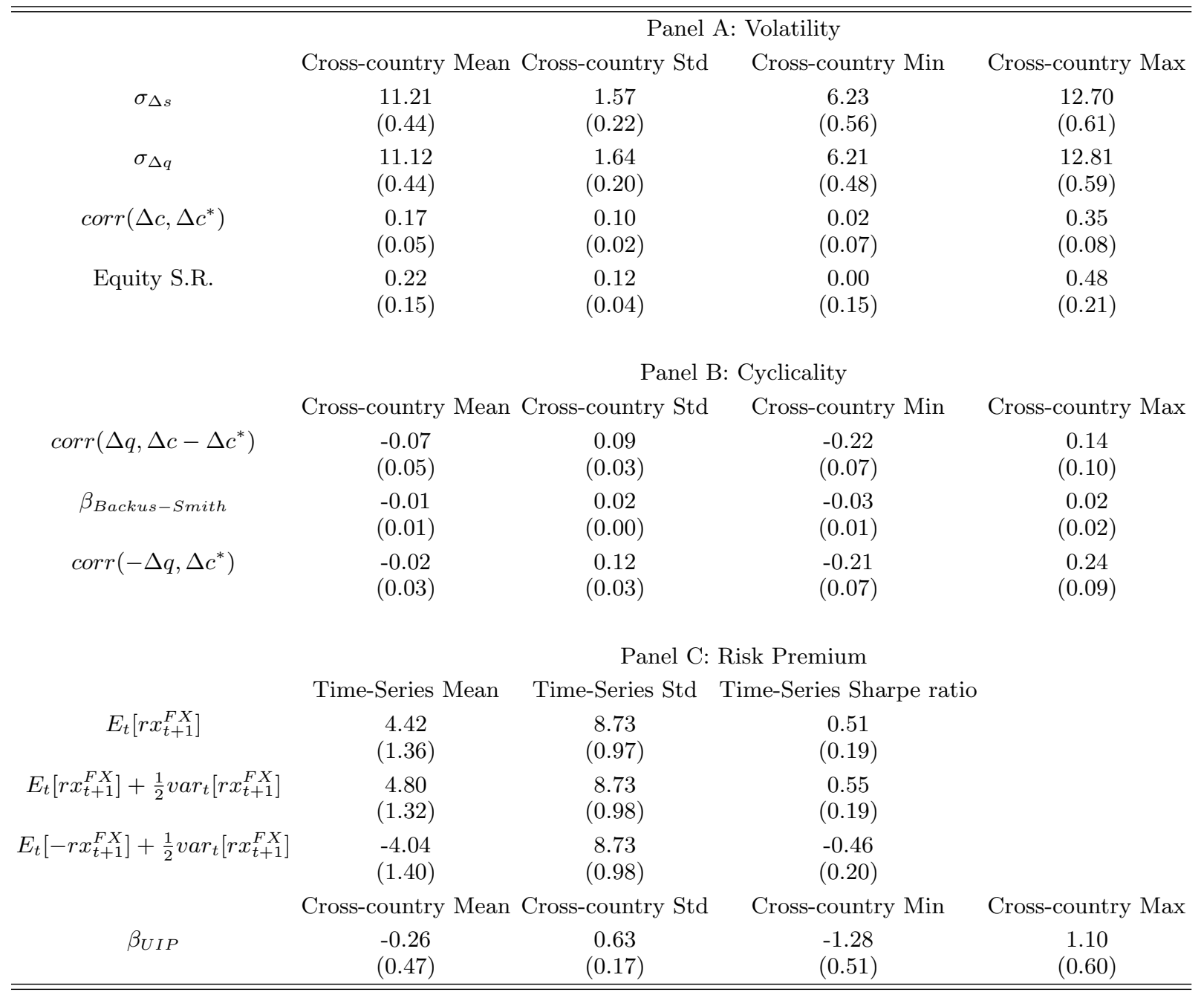

Notes: The table reports summary statistics on three exchange rate puzzles. Panel A focuses on the exchange rate volatility. It reports the cross-country mean of the bilateral nominal and real exchange rate volatilities, along with the cross-country standard deviation of the bilateral exchange rate volatilities and the corresponding minimum and maximum values across countries. Panel A also reports similar moments for the correlation between U.S. and foreign consumption growth rates and equity Sharpe ratios on MSCI country indices. Panel B focuses on the exchange rate cyclicality. It reports similar moments for the correlation between the changes in real exchange rates and the relative consumption growth, the slope coefficient in a regression of relative consumption growth rates on exchange rate changes and a constant, and for the correlation between the changes in real exchange rates and the foreign consumption growth. Panel $\mathrm{C}$ focuses on the exchange rate risk premium. It reports the time-series mean carry trade excess return, its time-series standard deviation and its Sharpe ratio (obtained as the ratio of the mean excess return to its standard deviation). The excess returns are either in logs, or in levels, from the perspective of the U.S. or foreign investor. Finally, Panel C reports the slope coefficient in a regression of exchange rate changes on the foreign minus domestic interest rate difference. Excess returns are annualized (multiplied by 4) and reported in percentages. The standard deviation on the carry trade returns in annualized (multiplied by 2) and reported in percentages. The countries are sorted by the level of their short-term nominal interest rates into four portfolios. The exchange rate risk premium corresponds to the average carry trade excess return obtained by borrowing in low-interest rate currencies (i.e., shorting the first portfolio) and investing in high-interest rate currencies (long the last portfolio). Data are quarterly, over the 1973.IV - 2014.IV period. The panel consists of 15 countries: Australia, Belgium, Canada, Denmark, France, Germany, Italy, Japan, Netherlands, New Zealand, Norway, Sweden, Switzerland, U.K., and U.S. The standard errors (reported between brackets) were generated by block-bootstrapping 10,000 samples, each block containing 2 quarters. 
have a standard deviation of $49 \%$ per annum $\left(s t d_{t}\left(\eta_{t+1}\right)=0.49\right) \cdot{ }^{10}$ Such a correlation across stochastic discount factors is optimistic. In the data, the correlation of consumption growth varies between 0.02 and 0.35 as shown in Panel $\mathrm{A}$ of Table 1. If we decrease the correlation of the SDFs from 0.5 to zero, then we need an even more volatile wedge: $s t d_{t}\left(\eta_{t+1}\right)$ is at least equal to $70 \%$. To stack the deck in favor of the incomplete spanning wedge, we assume throughout the paper a correlation across stochastic discount factors of 0.50 .

Figure 1 plots the implied volatility of the incomplete markets exchange rate against the volatility of the wedge $s t d_{t}\left(\eta_{t+1}\right)$ for various choices of $\mu_{t, \eta}$. We only plot the admissible $\left(\mu_{t, \eta}, s t d_{t}\left(\eta_{t+1}\right)\right)$ pairs that satisfy the inequalities in Proposition 1 . The figure is drawn assuming a maximum (annualized) Sharpe ratio of 0.50. In the figure, we gradually increase $\mu_{t, \eta}$, but it has no bearing on the volatility of the exchange rates. For high values of $s t d_{t}\left(\eta_{t+1}\right)$ close to $50 \%$ the volatility of exchange rates drops within the plausible range. Incomplete spanning helps with the volatility puzzle, but the volatility of the wedges needed is of the same order of magnitude as the maximum Sharpe ratio.

\subsection{Currency Risk Premia}

Next, we turn to the currency risk premium, assuming that investors have access to domestic and foreign risk-free rates. When markets are incomplete, we do not recover the standard expression for the log currency risk premium established in Bekaert (1996), Bansal (1997), Backus, Foresi, and Telmer (2001). But a similar expression emerges, highlighted in the following corollary to Proposition 1.

Corollary 2. The currency risk premium in logs on a long position in foreign currency is:

$$
\begin{aligned}
E_{t}\left[r x_{t+1}^{F X}\right] & =r_{t}^{f, *}-r_{t}^{f}+E_{t}\left(\Delta s_{t+1}\right)=\frac{1}{2}\left[\operatorname{var}_{t}\left(m_{t+1}\right)-\operatorname{var}_{t}\left(m_{t+1}^{*}+\eta_{t+1}\right)\right] \\
& =\frac{1}{2}\left[\operatorname{var}_{t}\left(m_{t+1}\right)-\operatorname{var}_{t}\left(m_{t+1}^{*}\right)\right]+\mu_{t, \eta} .
\end{aligned}
$$

\footnotetext{
${ }^{10} \mathrm{~A}$ maximum Sharpe ratio of 0.50 is a conservative estimate: while MSCI indices that track the unconditional returns on large firms exhibit relatively low Sharpe ratios, many investment strategies (e.g. conditional on firms' characteristics or using different asset classes) deliver Sharpe ratios well beyond 0.5.
} 


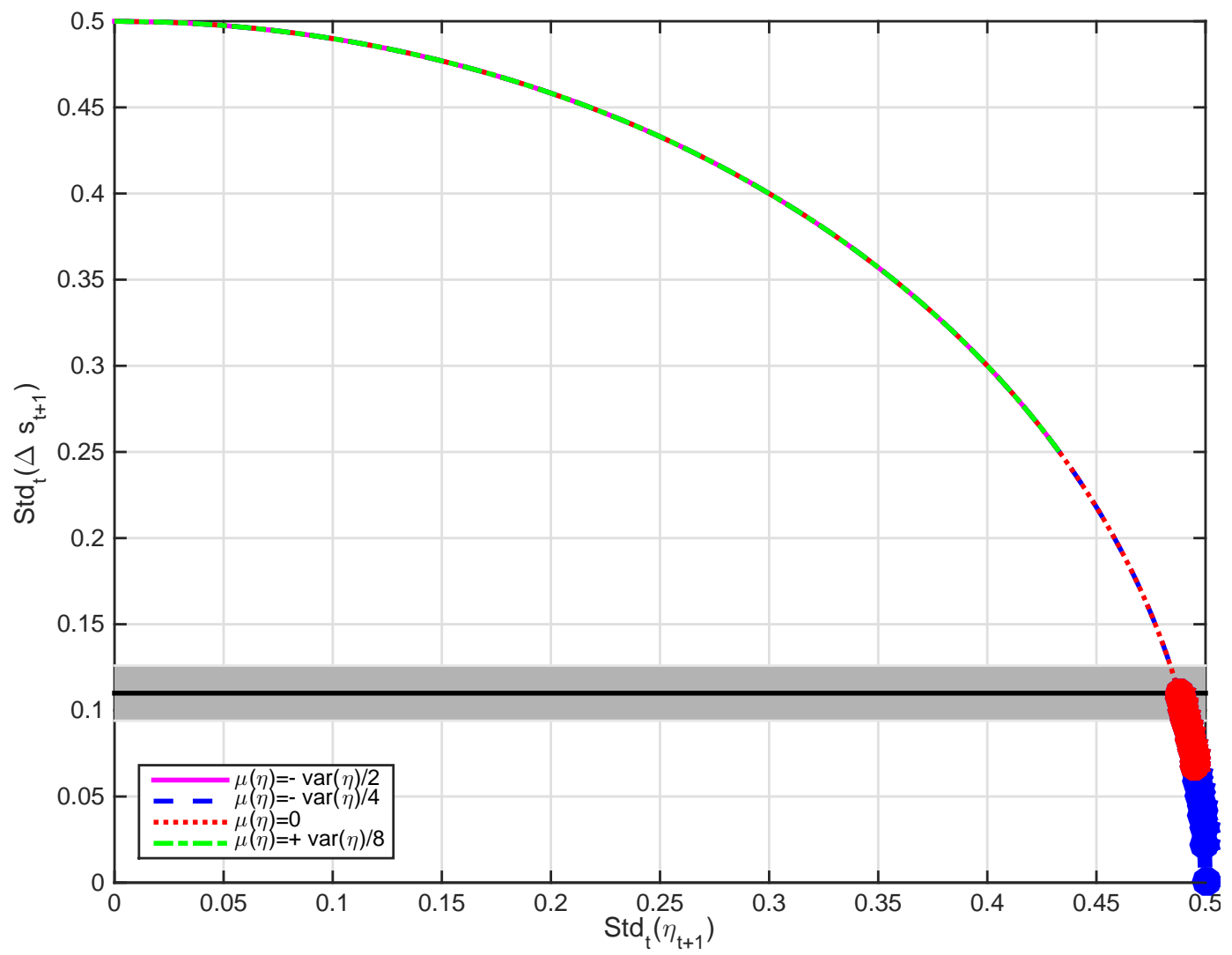

Figure 1: Exchange Rate Volatility: The figure reports the implied volatility of the changes in the log exchange rate, denoted $s t d_{t}\left(\Delta s_{t+1}\right)$, against the volatility of the incomplete market wedge, denoted $s t d_{t}\left(\eta_{t+1}\right)$. The figure is drawn assuming a maximum Sharpe ratio of 0.50 in both countries $\left(s t d_{t}\left(m_{t+1}\right)=0.50\right.$ and $\left.s t d_{t}\left(m_{t+1}^{*}\right)=0.50\right)$ and a correlation across stochastic discount factors of $0.50\left(\rho_{t}\left(m_{t+1}, m_{t+1}^{*}\right)=0.50\right)$. Large dots indicate parameters that imply exchange rate volatilities less than $11 \%$, the average volatility of exchange rates in our sample $\left(\operatorname{std}_{t}\left(\Delta s_{t+1}\right) \leq 0.11\right)$. The gray area indicates the value of the exchange rate volatility in the data: it is centered around the cross-country mean volatility $(11 \%)$; the area represents one cross-country standard deviation (1.6\%) above and below the cross-country mean volatility.

The currency risk premium in levels on a long position in foreign currency is given by:

$$
\begin{aligned}
E_{t}\left[r x_{t+1}^{F X}\right]+\frac{1}{2} \operatorname{var}_{t}\left[r x_{t+1}^{F X}\right] & =-\operatorname{cov}_{t}\left(m_{t+1}, \Delta s_{t+1}\right) \\
& =\operatorname{var}_{t}\left(m_{t+1}\right)-\operatorname{covar}_{t}\left(m_{t+1}^{*}, m_{t+1}\right)-\frac{1}{2} \operatorname{var}_{t}\left(\eta_{t+1}\right)+\mu_{t, \eta}
\end{aligned}
$$


The currency risk premium in levels, from the perspective of the foreign investor, is given by:

$$
\begin{aligned}
E_{t}\left[-r x_{t+1}^{F X}\right]+\frac{1}{2} \operatorname{var}_{t}\left[r x_{t+1}^{F X}\right] & =-\operatorname{cov}_{t}\left(m_{t+1}^{*},-\Delta s_{t+1}\right) \\
& =\operatorname{var}_{t}\left(m_{t+1}^{*}\right)-\operatorname{covar}_{t}\left(m_{t+1}^{*}, m_{t+1}\right)-\frac{1}{2} \operatorname{var}_{t}\left(\eta_{t+1}\right)-\mu_{t, \eta}
\end{aligned}
$$

In the data, as Table 1 reports, the average carry trade excess return is $4.4 \%$, implying a Sharpe ratio of 0.5 . To obtain the estimate of the carry trade excess return, the countries are sorted by the level of their short-term nominal interest rates into four portfolios. The exchange rate risk premium corresponds to the average carry trade excess return obtained by borrowing in low-interest rate currencies (i.e., shorting the first portfolio) and investing in high-interest rate currencies (long the last portfolio). Larger average currency risk premia and Sharpe ratios can be obtained on larger sets of countries (Lustig and Verdelhan, 2007).

Figure 2 plots the theoretical currency risk premium in levels against the volatility of the wedge, $s t d_{t}\left(\eta_{t+1}\right)$, from the perspective of either the home investor (left panel) or foreign investor (right panel). The parameters are identical to those in Figure 1. They imply a large complete markets currency risk premium of $12 \%$ on average per year, above the actual return on currency carry trades in developed countries. The high value of the currency risk premium in complete markets stacks the deck in favor of incomplete markets, allowing for a potential large decrease in risk premia brought by the incomplete market wedge.

For purely expositional purposes, we highlight three useful examples of drifts. First, when the disturbance $\eta$ is mean-zero $\left(\mu_{t, \eta}=0\right)$, incomplete spanning does not introduce any nonstationarity in exchange rates. In this case, the effects of the $\eta$ perturbations are completely identical for the home and foreign countries. This is a natural benchmark case to consider. In this case, the log risk premium is the same as in complete markets, but the risk premium in level decreases for both the home and foreign investor: for values of the wedge volatility that matches the exchange rate volatility in the data, these currency risk premia are zero.

Second, when the foreign investor is wedge-risk-neutral, $E_{t}\left(e^{\eta_{t+1}}\right)=1$, the disturbance $\eta$ is 

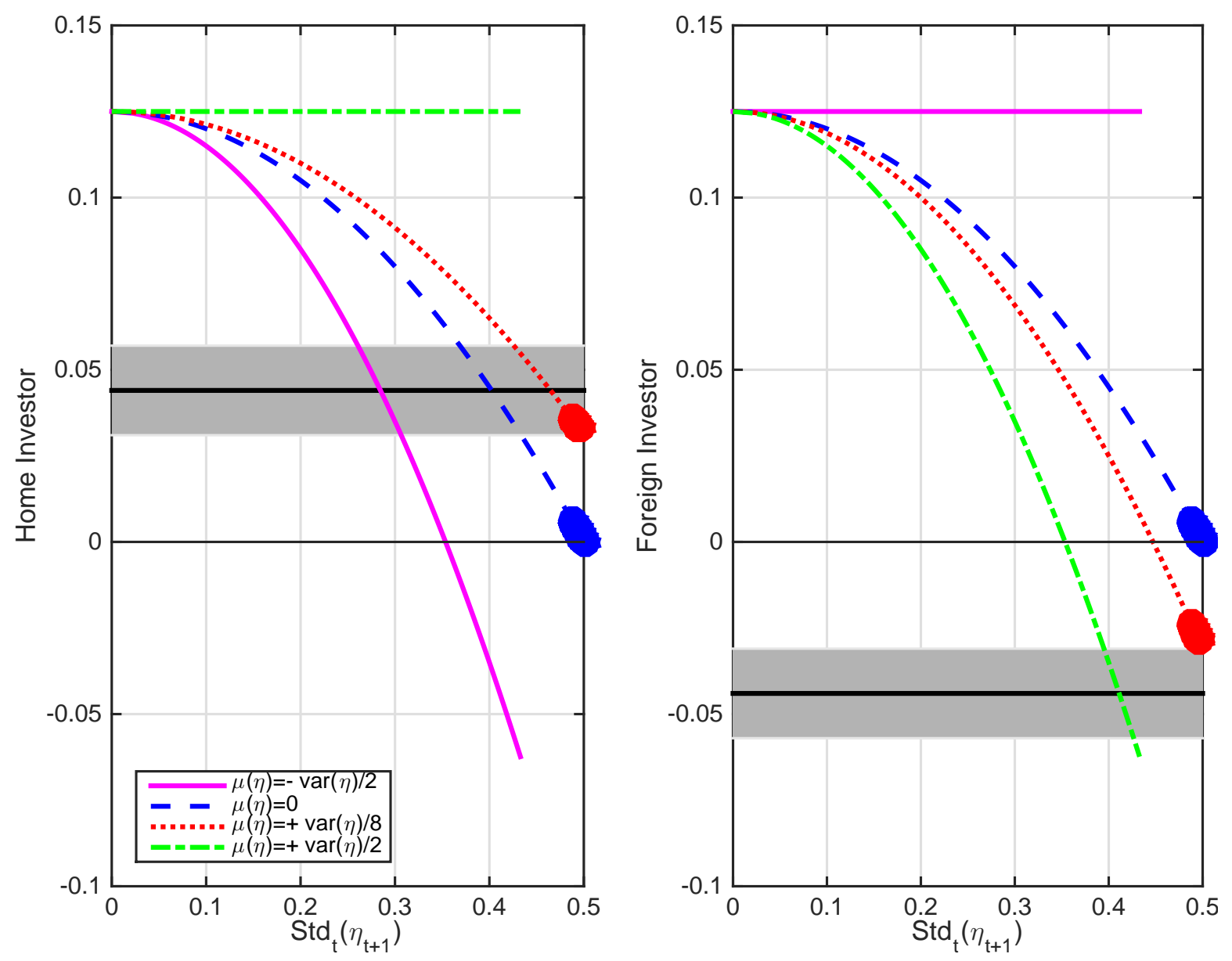

Figure 2: Currency Risk Premia in Level: The figure reports the foreign currency risk premium in level, from the perspective of the home investor (left panel) or foreign investor (right panel), against the volatility of the incomplete market wedge, denoted $s t d_{t}\left(\eta_{t+1}\right)$. For the home investor, the foreign currency risk premium in level is denoted $E_{t}\left[r x_{t+1}^{F X}\right]+\frac{1}{2} \operatorname{var}_{t}\left[r x_{t+1}^{F X}\right]$. The figure is drawn assuming a maximum Sharpe ratio of 0.50 in both countries $\left(\operatorname{std}_{t}\left(m_{t+1}\right)=0.50\right.$ and $\left.s t d_{t}\left(m_{t+1}^{*}\right)=0.50\right)$ and a correlation across stochastic discount factors of $0.50\left(\rho_{t}\left(m_{t+1}, m_{t+1}^{*}\right)=\right.$ $0.50)$. The gray area indicates the value of the average carry trade excess return in the data: it is centered around the mean excess return $(4.4 \%)$; the area represents one standard error $(1.3 \%)$ above and below the mean. Large dots indicate parameters that imply exchange rate volatilities less than $11 \%\left(\operatorname{std}_{t}\left(\Delta s_{t+1}\right) \leq 0.11\right)$.

such that $\mu_{t, \eta}=-\operatorname{var}_{t}\left(\eta_{t+1}\right) / 2$, as shown in Equation (9). The risk premium in level from the perspective of the home investor decreases, but it remains equal to its complete market value from the perspective of the foreign investor.

Third, when the home investor is wedge-risk-neutral, $E_{t}\left(e^{-\eta_{t+1}}\right)=1$, the disturbance $\eta$ is 
such that $\mu_{t, \eta}=+\operatorname{var}_{t}\left(\eta_{t+1}\right) / 2$, as shown in Equation (10). In this case, the risk premium in level from the perspective of the foreign investor decreases, but it remains equal to its complete market value from the perspective of the home investor. Those three corner cases are clearly rejected by the data on currency risk premia. It seems, however, that when the drift term takes on intermediate values (for example, $\mu_{t, \eta}=+\operatorname{var}_{t}\left(\eta_{t+1}\right) / 8$ ), high values of $s t d_{t}\left(\eta_{t+1}\right)$ around $50 \%$ imply currency risk premia in levels that are close to their data counterpart. As we shall see, unfortunately, these parameters imply counterfactual exchange rate cyclicality.

\subsection{Exchange Rate Cyclicality}

Complete market models have strong implications for the sign and the magnitude of the exchange rate cyclicality. Complete markets imply, perhaps counterintuitively, that currencies depreciate in relatively good times for home investors, i.e. when they experience low marginal utility growth compared to the foreign investors. Complete markets in fact imply a perfect correlation between the difference in log stochastic discount factors and the log change in exchange rates: when applied to CRRA preferences, complete markets thus imply a perfect correlation between relative consumption growth rates and exchange rate changes.

In the data, as shown in Panel B of Table 1, the corresponding unconditional correlation is not statistically different from zero. This is the Kollmann (1991) and Backus and Smith (1993) puzzle. Likewise, the unconditional correlation between changes in exchange rates and foreign consumption growth or the slope coefficient in a regression of relative consumption growth rates on exchange rate changes and a constant are also not statistically different from zero. Moving away from complete markets can potentially address the puzzle. Corsetti, Dedola, and Leduc (2008) and Kollmann (1996), for example, offer interesting models in incomplete markets that lower the correlation between exchange rates and consumption growth. Instead of studying one particular model, we consider the potential effect of any wedge introduced by the incomplete spanning on these measures of exchange rate cyclicality.

Corollary 3. The covariance between the difference in log stochastic discount factors $m^{*}-m$ 
and the change in exchange rates in incomplete markets is non-negative:

$$
\begin{aligned}
\operatorname{covar}_{t}\left(m_{t+1}^{*}-m_{t+1}, \Delta s_{t+1}\right) & =\operatorname{covar}_{t}\left(m_{t+1}^{*}-m_{t+1}, \eta_{t+1}\right)+\operatorname{var}_{t}\left(m_{t+1}^{*}-m_{t+1}\right), \\
& =\operatorname{var}_{t}\left(m_{t+1}^{*}-m_{t+1}\right)-\operatorname{var}_{t}\left(\eta_{t+1}\right)=\operatorname{var}_{t}\left(\Delta s_{t+1}\right) \geq 0
\end{aligned}
$$

The slope coefficient in a regression of $m^{*}-m$ on exchange rate changes is equal to 1 , its value when markets are complete:

$$
\beta_{\text {Backus-Smith }}=\frac{\operatorname{covar}_{t}\left(m_{t+1}^{*}-m_{t+1}, \Delta s_{t+1}\right)}{\operatorname{var}_{t}\left(\Delta s_{t+1}\right)}=1
$$

This corollary shows that the impact of incomplete spanning on measures of exchange rate cyclicality is limited for three reasons. First, incomplete spanning does not change the sign of the covariance between exchange rate changes and the difference in log stochastic discount factors spanned by asset markets. Even in incomplete markets, as soon as agents can trade in risk-free bonds, exchange rates will depreciate when the home investor experience better times than the foreign investor; those times, however, are defined by the marginal utility spanned by asset markets, whereas the total marginal utility of the investor may be high or low. Second, incomplete spanning does not change the slope coefficient in a regression of the difference in log stochastic discount factors on exchange rate changes; it is equal to one, as in complete markets. Third, incomplete spanning decreases the correlation between exchange rates and the stochastic discount factor

$\operatorname{corr}_{t}\left(m_{t+1}^{*}-m_{t+1}, \Delta s_{t+1}\right)=\frac{\sqrt{\operatorname{var}_{t}\left(m_{t+1}\right)+\operatorname{var}_{t}\left(m_{t+1}^{*}\right)-2 \operatorname{cov}_{t}\left(m_{t+1}, m_{t+1}^{*}\right)-\operatorname{var}_{t}\left(\eta_{t+1}\right)}}{\sqrt{\operatorname{var}_{t}\left(m_{t+1}\right)+\operatorname{var}_{t}\left(m_{t+1}^{*}\right)-2 \operatorname{cov}_{t}\left(m_{t+1}, m_{t+1}^{*}\right)}} \leq 1$,

only at the cost of a lower Sharpe ratio on the currency risk premium. We now study this tradeoff quantitatively.

Figure 3 plots the correlation between the log home SDF and the change in the exchange rates, $\operatorname{corr}_{t}\left(\Delta s_{t+1}, m_{t+1}\right)$, in the left panel, and the correlation between consumption growth and the change in exchange rates, $\operatorname{corr}_{t}\left(\Delta s_{t+1}, \Delta c_{t+1}\right)$, in the right panel, both against the 
volatility of the incomplete market wedge, denoted $s t d_{t}\left(\eta_{t+1}\right)$. In the right panel, we assume that the coefficient of relative risk aversion is 10 . The correlation between the log home stochastic discount factors $m$ and the change in exchange rates is :

$\operatorname{corr}_{t}\left(m_{t+1}, \Delta s_{t+1}\right)=\frac{\operatorname{covar}_{t}\left(m_{t+1}, \Delta s_{t+1}\right)}{s t d_{t}\left(m_{t+1}\right) s t d_{t}\left(\Delta s_{t+1}\right)}=-\frac{E_{t}\left[r x_{t+1}^{F X}\right]+\frac{1}{2} \operatorname{var}_{t}\left[r x_{t+1}^{F X}\right]}{s t d_{t}\left(m_{t+1}\right) s t d_{t}\left(\Delta s_{t+1}\right)}=\frac{-S R_{t}^{F X}}{s t d_{t}\left(m_{t+1}\right)}$,

where $S R^{F X}$ denotes the Sharpe ratio on the currency risk premium. As we lower the correlation between exchange rates and the home stochastic discount factor, we also lower the currency Sharpe ratios proportionally.

Let us again describe our three simple examples. First, when $\mu_{t, \eta}=-\operatorname{var}_{t}\left(\eta_{t+1}\right) / 2$ (the case of risk-neutral foreign investors), the correlation decreases in absolute value, and can even change sign. Unfortunately, as we saw in the previous section, this parametrization does not reproduce the exchange rate volatility or risk premia. Second, when $\mu_{t, \eta}=0$ (the symmetric case), the correlation tends to zero for very volatile incomplete market wedges. Such parameters can reproduce the exchange rate volatility in the data but still imply zero currency risk premia. Third, when $\mu_{t, \eta}=\operatorname{var}_{t}\left(\eta_{t+1}\right) / 2$ (the case of risk-neutral domestic investor), the correlation actually increases in absolute value. The sweet spot, identified in the previous section, where the drift term takes on intermediate values (for example, $\mu_{t, \eta}=+\operatorname{var}_{t}\left(\eta_{t+1}\right) / 8$ ) and the model implies a reasonable currency risk premium, unfortunately makes the correlation larger in absolute values. In this case, the incomplete market model is even less attractive than its complete market counterpart. In the special case of power utility, the correlation between exchange rate changes and consumption growth rates exceeds 0.7 in the relevant region of the parameter space. While these simple examples illustrate the issue at hand, they rely on specific characteristics of the wedge. We thus now present general results.

\subsection{The Intersection of Three Currency Puzzles}

We bring together the insights gained on exchange rate volatility, cyclicality, and risk premium to show that markets incompleteness cannot improve on the three puzzles at the same time.

We summarize our findings in Figure 4, focusing on the parameter space that reproduces the 

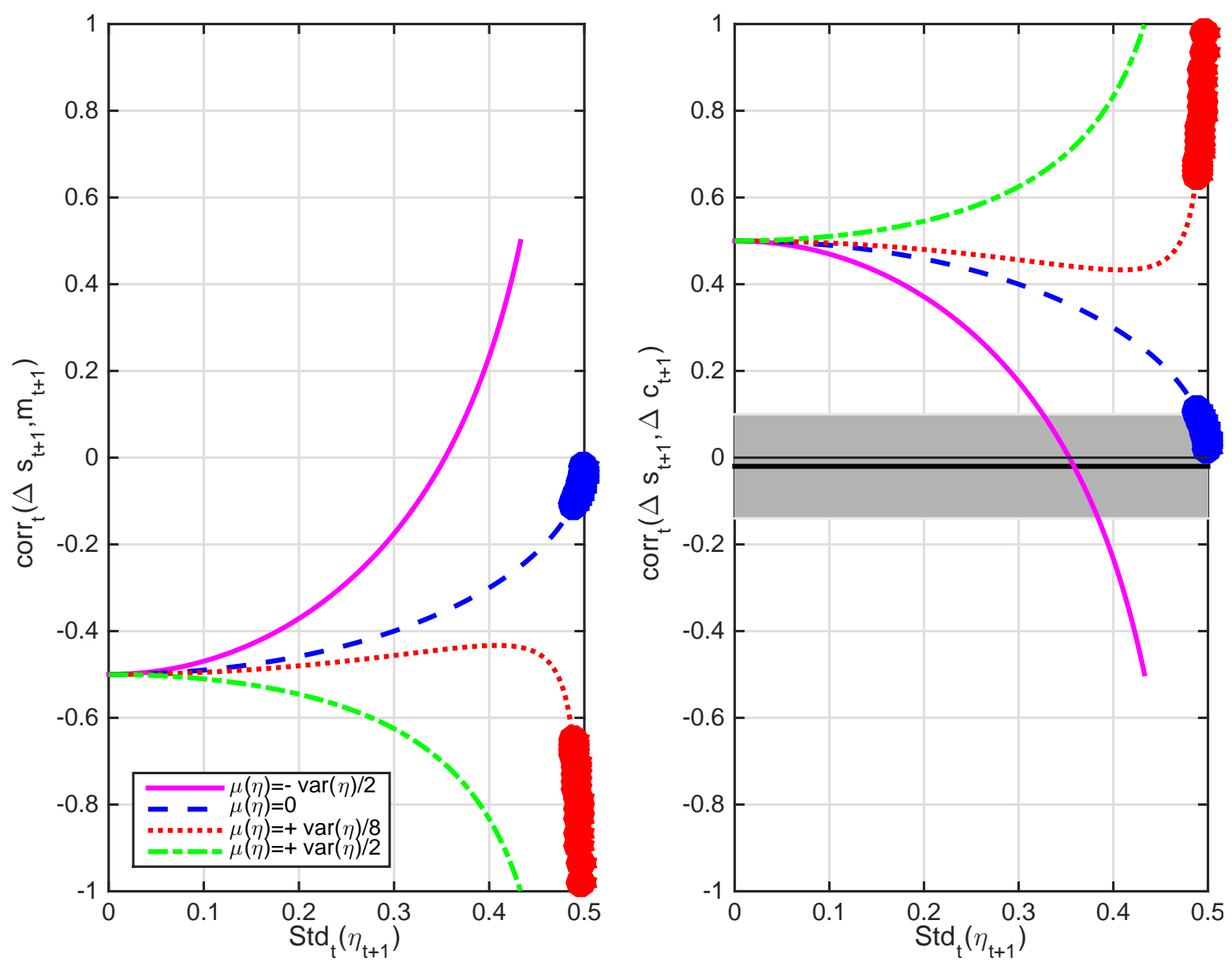

Figure 3: Correlation Between the Changes in Exchange Rates and the SDF or Consumption Growth Rates: The figure reports the correlation between the log home SDF and the change in the exchange rates, $\operatorname{corr}_{t}\left(\Delta s_{t+1}, m_{t+1}\right)$, in the left panel, and the correlation between consumption growth and the change in exchange rates, $\operatorname{corr}_{t}\left(\Delta s_{t+1}, \Delta c_{t+1}\right)$, in the right panel, both against the volatility of the incomplete market wedge, denoted $s t d_{t}\left(\eta_{t+1}\right)$. The figure is drawn assuming a maximum Sharpe ratio of 0.50 in both countries $\left(s t d_{t}\left(m_{t+1}\right)=0.50\right.$ and $\left.s t d_{t}\left(m_{t+1}^{*}\right)=0.50\right)$ and a correlation across stochastic discount factors of $0.50\left(\rho_{t}\left(m_{t+1}, m_{t+1}^{*}\right)=\right.$ 0.50). Large dots indicate parameters that imply exchange rate volatilities less than $11 \%$ $\left(\operatorname{std}_{t}\left(\Delta s_{t+1}\right) \leq 0.11\right)$. In the right panel, the coefficient of constant relative risk aversion is $10(\gamma=10)$.

exchange rate volatility. This volatility is precisely measured and fairly similar across developed markets. We assume that it is equal to $11 \%$, the average value observed in our sample, and derive the implicit relationship between the first and second conditional moments of the wedge $\eta_{t+1}$. As in the rest of the paper, the figure is drawn assuming a maximum Sharpe ratio of 0.50 
in both countries $\left(s t d_{t}\left(m_{t+1}\right)=0.50\right.$ and $\left.s t d_{t}\left(m_{t+1}^{*}\right)=0.50\right)$ and a correlation across stochastic discount factors of $0.50\left(\rho_{t}\left(m_{t+1}, m_{t+1}^{*}\right)=0.50\right)$. For those parameters, the standard deviation of the wedge ranges from around 0.4 to 0.5 .
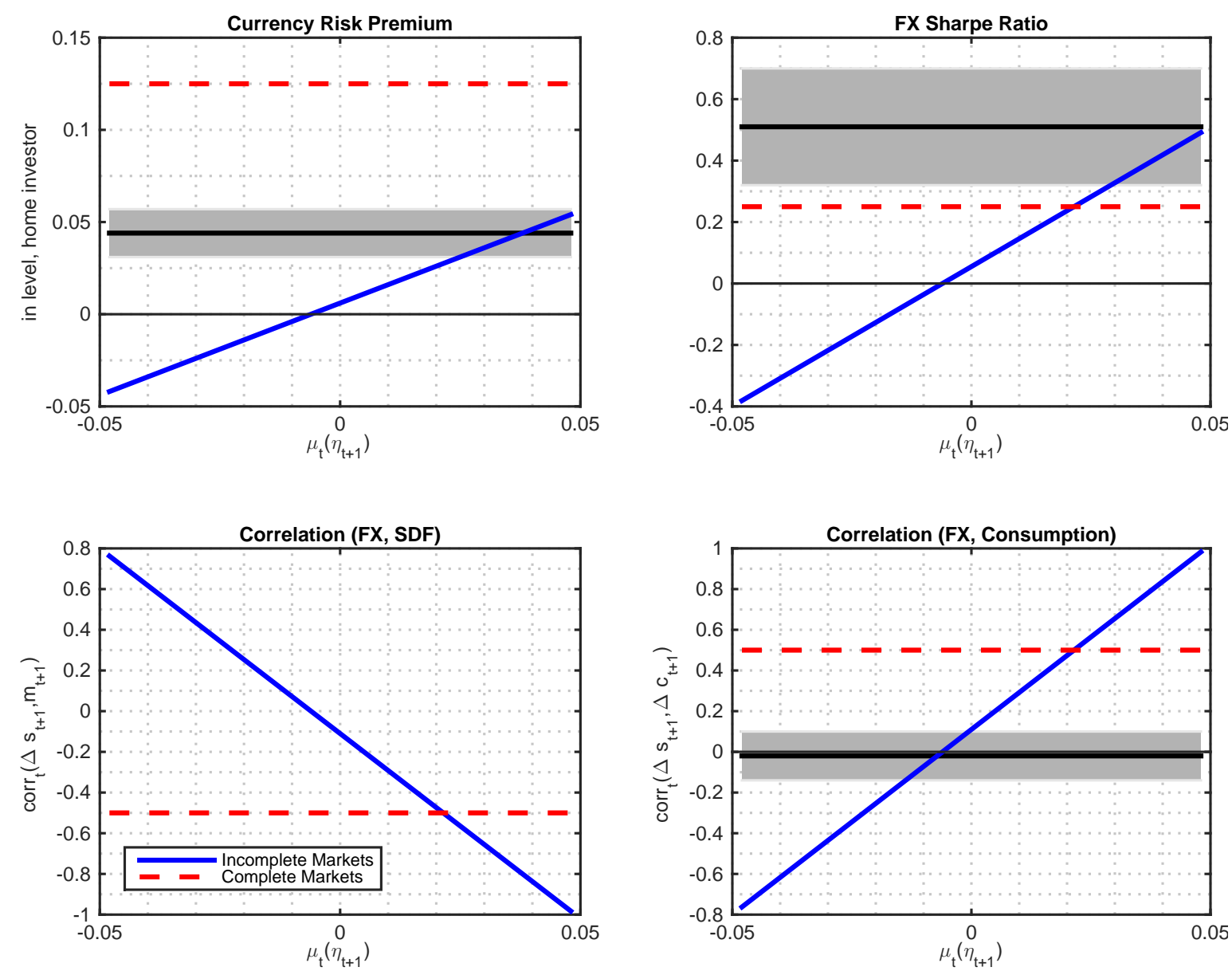

Figure 4: The Intersection of Three Currency Puzzles: The figure reports the results for the admissible combinations of $\mu_{t, \eta}$ and $s t d_{t}\left(\eta_{t+1}\right)$ that produce a $11 \%$ volatility of exchange rate changes. The figure is drawn assuming a maximum Sharpe ratio of 0.50 in both countries $\left(\operatorname{std}_{t}\left(m_{t+1}\right)=0.50\right.$ and $\left.s t d_{t}\left(m_{t+1}^{*}\right)=0.50\right)$ and a correlation across stochastic discount factors of $0.50\left(\rho_{t}\left(m_{t+1}, m_{t+1}^{*}\right)=0.50\right)$. The first panel reports the currency risk premium for each value of $\mu_{t+1}$. The second panel reports the implied Sharpe ratios on currency risk premia. The third panel reports the correlation of changes in the exchange rate with the domestic SDF, $\operatorname{corr}_{t}\left(\Delta s_{t+1}, m_{t+1}\right)$. The fourth panel reports the correlation with the consumption growth difference, $\operatorname{corr}_{t}\left(\Delta s_{t+1}, \Delta c_{t+1}\right)$. The gray area represents the empirical counterpart of each moment.

The upper left subplot of Figure 4 shows the currency risk premium in complete markets 
(dotted line) and in incomplete markets. As already noted, our parameters imply that the complete markets risk premium is around $12 \%$. But the wedge introduced by the markets incompleteness reduces the risk premium to less than $6 \%$. The risk premium is in line with its empirical value only for large drift parameters. For zero or negative drifts, the currency risk premium is essentially zero or turn negative. The upper right subplot of Figure 4 shows the same link between the value of the drift and the currency Sharpe ratio. The lower subplots show that large values of the drifts imply exchange rate correlations with log stochastic discount factors (and consumption growth in the case of CRRA preferences) that are in absolute values even larger than their complete markets counterpart. The wedge exacerbates these features of the complete markets models that incomplete spanning is supposed to address.

\subsection{A Simple Consumption-CAPM Example}

We end this section with a simple consumption-based example, in the tradition of Lucas (1982). Consider a model in which the domestic and foreign representative agents have power utility with risk aversion coefficient $\gamma$. The domestic aggregate consumption growth $\Delta c$ consists of a standard Gaussian component $w \sim N\left(\mu, \sigma^{2}\right)$. The same applies to foreign consumption growth: $w^{*} \sim N\left(\mu^{*}, \sigma^{2, *}\right)$. The domestic and foreign consumption growth rates are thus:

$$
\begin{aligned}
\Delta c_{t+1} & =w_{t+1}, \\
\Delta c_{t+1}^{*} & =w_{t+1}^{*},
\end{aligned}
$$

where the correlation of domestic and foreign shocks is $\rho_{w, w^{*}}$. Assume that the incomplete

market wedge takes the form: $\eta_{t+1}=\gamma d_{t+1}$, where $d \sim N\left(\mu_{d}, \sigma_{d}^{2}\right)$. The correlations between the initial consumption growth shocks and the wedge are denoted $\rho_{w, d}$ and $\rho_{w^{*}, d}$. In this case, Proposition 1 implies that the wedges satisfy:

$$
\begin{aligned}
\mu_{d} & =\gamma^{2} \sigma_{d}^{2} / 2+\rho_{w, d} \gamma^{2} \sigma \sigma_{d} \\
-\mu_{d} & =\gamma^{2} \sigma_{d}^{2} / 2-\rho_{w^{*}, d} \gamma^{2} \sigma^{*} \sigma_{d}
\end{aligned}
$$


With only two consumption growth innovations, the only interesting case is as follows: the domestic investor cannot invest in any foreign risky asset. If the foreign investor could, then the additional covariance restrictions in Equation (12) would apply, and markets would be complete complete. ${ }^{11}$ We thus focus on the case where investors can only invest in risk-free bonds.

Volatility In the absence of wedges, the volatility of the exchange rate changes is $\gamma^{2} \sigma^{* 2}+$ $\gamma^{2} \sigma^{2}-2 \gamma^{2} \rho_{w, w^{*}} \sigma \sigma^{*}$. Adding the wedge, as shown in Corollary 1, reduces the exchange rate variance by $\gamma^{2} \sigma_{d}^{2}$. The unspanned shocks $d_{t+1}$ are counter-cyclical, i.e. negatively correlated with domestic consumption growth, and as a result, always reduces the exchange rate's volatility.

Cyclicality The Backus-Smith correlation coefficient is given by:

$$
1 \geq \operatorname{corr}_{t}\left(\Delta c_{t+1}-\Delta c_{t+1}^{*}, \Delta s_{t+1}\right)=\frac{\sqrt{\gamma^{2} \sigma^{*, 2}+\gamma^{2} \sigma^{2}-2 \gamma^{2} \rho_{w, w^{*}} \sigma \sigma^{*}-\left(\gamma \sigma_{d}\right)^{2}}}{\sqrt{\gamma^{2} \sigma^{*, 2}+\gamma^{2} \sigma^{2}-2 \gamma^{2} \rho_{w, w^{*}} \sigma \sigma^{*}}} \geq 0
$$

The correlation is smaller than one, its complete markets value, but always positive. In the symmetric case where the drift $\mu_{d}$ is zero, the unspanned risk is always negatively correlated with domestic consumption growth, as implied by Equation (15), and positively correlated with foreign consumption growth, as implied by Equation (16).

Risk Premium When markets are complete, the currency risk premium in levels (defined from the perspective of the home investor) is given by $\gamma^{2} \sigma^{2}-\gamma^{2} \rho_{w, w^{*}} \sigma \sigma^{*}$. Likewise, the currency risk premium in levels, this time defined from the perspective of the foreign investor, is equal to $\gamma^{2} \sigma^{* 2}-\gamma^{2} \rho_{w, w^{*}} \sigma \sigma^{*}$. When markets are incomplete, the currency risk premia change. The difference in the currency risk premium (defined from the perspective of the home investor) between the incomplete and complete market cases, $\Delta R P=R P_{t}^{I M}-R P_{t}^{C M}$, is equal to $\Delta R P=$ $\rho_{w, d} \gamma^{2} \sigma \sigma_{d}$. Similarly, the difference in the currency risk premium (defined from the perspective of the foreign investor) is $\Delta R P^{*}=-\rho_{w^{*}, d} \gamma^{2} \sigma \sigma_{d}$. Hence, the total change in the risk premia

\footnotetext{
${ }^{11}$ These conditions imply that $d_{t+1}$ is orthogonal to $w_{t+1}$ and $w_{t+1}^{*}$, because the log return on the domestic (foreign) risky asset is affine in the domestic (foreign) innovation. The additional covariance restrictions in Equation (12), $\rho_{w, d}=0$ and $\rho_{w^{*}, d}=0$, combined with Equations (15) and (16), imply that $\sigma_{d}=0$ and $\mu_{d}=0$. We are back in the case of complete markets: $\eta_{t+1}=0$.
} 
has to be negative; Equations (15) and (16) imply that the sum of the last two expressions is negative. In simple words, a positive drift to mitigate the effect on currency risk premia from the perspective of the domestic investor implies a larger decline for the other investor. The Lucas (1982) model provides a simple example to our preference-free results. We now turn to potential extensions of our benchmark results.

\section{Extensions}

In this section, we consider two key extensions: we first relax the log-normal assumption, and then consider dynamic asset pricing models.

\section{$3.1 \quad$ Non-normality}

When relaxing the log-normality assumption, we first present preference-free results and then develop a consumption-based example with jumps.

\subsubsection{Preference-free Results}

Some of our preference-free results can be extended to an environment with non-Gaussian shocks. To do so, we use a different, entropy-based measure of risk. The conditional entropy of a random variable $X_{t+1}$ is equal to: $L_{t}\left(X_{t+1}\right)=\log E_{t}\left(X_{t+1}\right)-E_{t}\left(\log X_{t+1}\right)$. If the random variable $X_{t+1}$ is $\log$ normally distributed, then its entropy is equal to one half of its variance. In general, entropy measures all higher order cumulants $\kappa_{i}$ of $\log X: L_{t}\left(X_{t+1}\right)=\kappa_{2 t} / 2 !+\kappa_{3 t} / 3 !+\kappa_{4 t} / 4 !+\ldots$ Similarly, the co-entropy is defined as $L_{t}\left(X_{t+1} Y_{t+1}\right)-L_{t}\left(X_{t+1}\right)-L_{t}\left(Y_{t+1}\right)$, which is a natural measure of the covariation. This measure is zero if the variables are conditionally independent. Using these measures of risk, we derive an analog to Proposition 1 in the case of non-Gaussian shocks.

Proposition 2. We fix the home $m$ and foreign $m^{*}$ log stochastic discount factors. Incomplete spanning implies that the exchange rate process $S_{t}$ satisfies $\Delta s_{t+1}=\eta_{t+1}+m_{t+1}^{*}-m_{t+1}$ where 
$\eta$ satisfies the following restrictions:

$$
\begin{aligned}
& \mu_{t, \eta}-L_{t}\left(\exp \left(-\eta_{t+1}\right)\right)=L_{t}\left(M_{t+1} \exp \left(-\eta_{t+1}\right)\right)-L\left(M_{t+1}\right)-L_{t}\left(\exp \left(-\eta_{t+1}\right)\right) \\
& -\mu_{t, \eta}-L_{t}\left(\exp \left(\eta_{t+1}\right)\right)=L_{t}\left(M_{t+1}^{*} \exp \left(\eta_{t+1}\right)\right)-L\left(M_{t+1}^{*}\right)-L_{t}\left(\exp \left(\eta_{t+1}\right)\right)
\end{aligned}
$$

and where the trend $\mu_{t, \eta}$ satisfies:

$$
\begin{aligned}
-\mu_{t \eta} & \leq \log E_{t}\left(M_{t+1} \exp \left(-\eta_{t+1}\right)\right)-E_{t} \log \left(M_{t+1}\right) \\
\mu_{t \eta} & \leq \log E_{t}\left(M_{t+1}^{*} \exp \left(\eta_{t+1}\right)\right)-E_{t} \log \left(M_{t+1}^{*}\right), \\
\mu_{t \eta} & \leq \log E_{t}\left(\frac{M_{t+1}^{*}}{M_{t+1} e^{-\eta_{t+1}}}\right)-E_{t} \log \left(\frac{M_{t+1}^{*}}{M_{t+1}}\right) .
\end{aligned}
$$

These $\eta$ - drift conditions are the exact equivalent of the covariance conditions in the lognormal case. When the stochastic discount factor and the wedge are jointly lognormal, one recovers the same conditions derived in Proposition 1. We can then compare the entropy of the incomplete markets exchange rates to the entropy of the complete markets version, denoted $L_{t}\left(\frac{M_{t+1}^{*}}{M_{t+1}}\right):$

Corollary 4. The entropy of the changes in exchange rates is:

$$
\begin{aligned}
L_{t}\left(\frac{S_{t+1}}{S_{t}}\right) & =L_{t}\left(\frac{M_{t+1}^{*} \exp \left(\eta_{t+1}\right)}{M_{t+1}}\right), \\
& =L_{t}\left(\frac{M_{t+1}^{*}}{M_{t+1}}\right)-\mu_{t, \eta}+\log E_{t}\left(\frac{M_{t+1}^{*}}{M_{t+1} e^{-\eta_{t+1}}}\right)-\log E_{t}\left(\frac{M_{t+1}^{*}}{M_{t+1}}\right) .
\end{aligned}
$$

Hence, the difference between the entropy of the exchange rate change in incomplete versus complete markets is equal to:

$$
\Delta L_{t}=L_{t}^{I M}-L_{t}^{C M}=-\mu_{t, \eta}+\log E_{t}\left(\frac{M_{t+1}^{*}}{M_{t+1} e^{-\eta_{t+1}}}\right)-\log E_{t}\left(\frac{M_{t+1}^{*}}{M_{t+1}}\right)
$$


The change in entropy of exchange rates introduced by incomplete spanning is tightly linked to the change in currency risk premia. To see this point, let us first define the currency risk premium when shocks are non-Gaussian. Backus, Foresi, and Telmer (2001) show that the complete markets' risk premium in logs is simply $L_{t}\left(M_{t+1}\right)-L_{t}\left(M_{t+1}^{*}\right)$. The complete markets' risk premium in levels is thus given by:

$$
E_{t}\left[r x_{t+1}^{F X}\right]+L_{t}\left(S_{t+1} / S_{t}\right)=L_{t}\left(M_{t+1}\right)-L_{t}\left(M_{t+1}^{*}\right)+L_{t}\left(\frac{M_{t+1}^{*}}{M_{t+1}}\right)
$$

The following proposition describes the risk premium with incomplete spanning; it is the counterpart to Corollary 2 in Section 2.2.

Corollary 5. The risk premium in logs on a long position in foreign currency is:

$$
E_{t}\left[r x_{t+1}^{F X}\right]=L_{t}\left(M_{t+1}\right)-L_{t}\left(M_{t+1}^{*}\right)+\mu_{t, \eta}
$$

The risk premium in levels on a long position in foreign currency (from the perspective of the domestic investor) is given by:

$$
E_{t}\left[r x_{t+1}^{F X}\right]+L_{t}\left(S_{t+1} / S_{t}\right)=L_{t}\left(M_{t+1}\right)-L_{t}\left(M_{t+1}^{*}\right)+\mu_{t, \eta}+L_{t}\left(\frac{M_{t+1}^{*} \exp \left(\eta_{t+1}\right)}{M_{t+1}}\right) .
$$

The difference between the currency risk premium in incomplete versus complete markets is thus related to the changes in exchange rate entropy introduced by the incomplete spanning:

$$
\Delta R P_{t}=R P_{t}^{I M}-R P_{t}^{C M}=\Delta L_{t}+\mu_{t, \eta}
$$

In the symmetric case, where the drift of the wedge is zero $\left(\mu_{t, \eta}=0\right)$, a decrease in the entropy of the exchange rate leads to a commensurate decrease in the foreign currency risk premium. When the drift of the wedge is not zero, it may be possible to lower the entropy of exchange rates without lowering their risk premia. 
While Corollaries 4 and 5 offer a clear link between the entropy and risk premia of exchange rates, there is no equivalent result for their cyclicality. In a preference-free setting, we are not able to bound the co-entropy of exchange rates and stochastic discount factors. As a result, the trilemma that we highlight in the lognormal case cannot be formally expressed here. The intuition is simple: as entropy depends on an infinite sum of higher moments, it may be possible to pick some higher moments that affect the co-entropy of exchange rates and stochastic discount factors without affecting much the entropy of the exchange rates or the currency risk premium. We do not know of such a model, but we cannot mathematically rule out its existence.

In the class of non-normal models often used in the option pricing and macro-finance literature, however, we show that the same trilemma applies: introducing incomplete spanning to decrease the volatility of exchange rates also decreases the currency risk premium and implies counterfactual links between stochastic discount factors and exchange rate changes. To illustrate these forces, we turn to a classic jump-based model.

\subsubsection{Merton Jump-based Model}

The domestic and foreign representative agents have power utility with identical risk aversion $\gamma$. Consumption growth in each country consists of a standard Gaussian component and a jump component. The first component is the same as in the previous consumption-based example; it is denoted $w$ and normally distributed as $N\left(\mu, \sigma^{2}\right)$. The second component is a Poisson mixture of normals, denoted $z$. Foreign variables are denoted with a ${ }^{*}$. Log consumption growth is the sum of these two components:

$$
\begin{aligned}
\Delta c_{t+1} & =w_{t+1}+z_{t+1}, \\
\Delta c_{t+1}^{*} & =w_{t+1}^{*}+z_{t+1}^{*}
\end{aligned}
$$

At each date, the number of jumps $j$ takes on non-negative integer values with probabilities $e^{-\varpi} \varpi^{j} / j$ !. The parameter $\varpi$, the jump intensity, is the mean of $j$. Each jump triggers a draw from a normal distribution with mean $\theta$ and variance $\delta^{2}$ for the domestic agent and with mean $\theta^{*}$ and variance $\delta^{* 2}$ for the foreign agent. The jumps are thus common across countries, but 
the jump sizes are not. Conditional on the number of jumps $j$, the domestic jump component is normally distributed as $z_{t} \mid j \sim N\left(j \theta, j \delta^{2}\right)$, while the foreign jump component is normally distributed as $z_{t}^{*} \mid j \sim N\left(j \theta^{*}, j \delta^{2, *}\right)$. If $\varpi$ is small, the jump model is well approximated by a Bernoulli mixture of normals. If $\varpi$ is large, multiple jumps can occur frequently. This functional form is known as the Merton (1976) model. In the macro-finance literature, it has been applied notably by Bates (1988), Naik and Lee (1990), Backus, Chernov, and Zin (2011), and Martin (2013).

Next, we introduce incomplete spanning in this model. We assume that the wedge takes the form $\eta_{t+1}=\gamma d_{t+1}$, where $d_{t+1}$ follows the same Poisson mixture as $z_{t+1}$, but with parameters $\theta_{d}$ and $\delta_{d}$. Conditional on the number of jumps $j$, the jump and wedge components are jointly normal: $z_{t} \mid j \sim N\left(j \theta, j \delta^{2}\right)$ and $d_{t} \mid j \sim N\left(j \theta_{d}, j \delta_{d}^{2}\right)$. We use $\rho_{z, d}$ and $\rho_{z^{*}, d}$ to denote the correlation of jump sizes between the spanned and unspanned components of exchange rates. The jumps are common for the $z_{t+1}$ and $d_{t+1}$ components.

Result 1. Following Proposition 2, the wedges satisfy the following restrictions:

$$
\begin{aligned}
& -\gamma \theta_{d}+\gamma^{2} \delta \delta_{d} \rho_{z, d}+\frac{\gamma^{2} \delta_{d}^{2}}{2}=0 \\
& \gamma \theta_{d}-\gamma^{2} \delta^{*} \delta_{d} \rho_{z^{*}, d}+\frac{\gamma^{2} \delta_{d}^{2}}{2}=0
\end{aligned}
$$

Corollary 4 implies that the change in volatility from complete to incomplete spanning is given by:

$$
\Delta L_{t}=L_{t}^{I M}-L_{t}^{C M}=-\gamma \varpi \theta_{d}+\varpi e^{-\gamma \theta^{*}+\gamma \theta-\gamma^{2} \rho_{z, z^{*}} \delta \delta^{*}+(\gamma \delta)^{2} / 2+\left(\gamma \delta^{*}\right)^{2} / 2}\left(e^{\gamma^{2} \delta \delta_{d} \rho_{z, d}}-1\right) .
$$

When markets are complete, the foreign currency risk premium in levels (from the perspective of the domestic investor) is given by:

$$
\begin{aligned}
E_{t}\left[r x_{t+1}^{F X}\right]+L_{t}\left[r x_{t+1}^{F X}\right] & =\gamma^{2} \sigma^{2}+\varpi\left(e^{-\gamma \theta+(\gamma \delta)^{2} / 2}-1\right)-\varpi\left(e^{-\gamma \theta^{*}+\left(\gamma \delta^{*}\right)^{2} / 2}-1\right) \\
& +\varpi\left(e^{-\gamma \theta^{*}+\gamma \theta-2 \gamma^{2} \rho_{z, z^{*}} \delta \delta^{*}+(\gamma \delta)^{2} / 2+\left(\gamma \delta^{*}\right)^{2} / 2}-1\right) .
\end{aligned}
$$


Introducing incomplete spanning wedges, Corollary 5 implies that the corresponding change in the risk premium is given by:

$$
\Delta R P_{t}=R P_{t}^{I M}-R P_{t}^{C M}=\varpi e^{-\gamma \theta^{*}+\gamma \theta-\gamma^{2} \rho_{z, z^{*}} \delta \delta^{*}+(\gamma \delta)^{2} / 2+\left(\gamma \delta^{*}\right)^{2} / 2}\left(e^{\gamma^{2} \delta \delta_{d} \rho_{z, d}}-1\right) .
$$

When the wedge does not have a drift $\left(\theta_{d}=0\right)$, Equations (23) and (24) imply that, again, the market incompleteness change the exchange rate volatility and the exchange rate risk premium by the same amount. More precisely, in the absence of a drift, the market incompleteness always reduces the exchange rate volatility and the exchange rate risk premium. Equations (21) and (22) imply that the correlation is given by $\rho_{z, d}=-\rho_{z^{*}, d}=-0.5 \delta_{d} / \delta$. The change in volatility and risk premium is thus negative:

$$
\Delta R P_{t}=R P_{t}^{I M}-R P_{t}^{C M}=\varpi e^{-\gamma \theta^{*}+\gamma \theta-\gamma^{2} \rho_{z, z^{*}} \delta \delta^{*}+(\gamma \delta)^{2} / 2+\left(\gamma \delta^{*}\right)^{2} / 2}\left(e^{-\frac{\gamma^{2} \delta_{d}^{2}}{2}}-1\right)=\Delta L_{t}<0 .
$$

We turn to a simple calibration, where the wedge does not have a drift $\left(\theta_{d}=0\right)$ and countries are symmetric $\left(\theta=\theta^{*}, \delta=\delta^{*}\right)$ in order to study the magnitudes of volatilities and risk premia.

Calibration We follow Backus, Chernov, and Martin (2011) and set the risk-aversion parameter $(\gamma)$ to 5.19 , the mean $(\mu)$ and standard deviation $(\sigma)$ of the normal consumption growth shocks to $2.3 \%$ and $1 \%$, the jump intensity $\varpi$ to $1.7 \%$, the mean jump size $\theta$ to $-38 \%$, and the jump size volatility $\delta$ to $25 \%$. These parameters were chosen to match the international evidence reported in Nakamura, Steinsson, Barro, and Ursua (2013). We assume that the jump sizes are uncorrelated across countries, but the jumps are common. The absence of idiosyncratic jumps helps the model to generate low exchange rate volatility.

Figure 5 plots the exchange rate volatility $\sqrt{2 L}$ and the currency risk premium on a long position in foreign currency from the perspective of the home investor. In this calibration, there is no wedge that can simultaneously deliver a reasonable exchange rate volatility and a significant risk premium. When the variance of the jumps in the wedge reaches its maximum, 
the exchange rate volatility is still close to $20 \%$ and the currency risk premium is less than $2 \%$. When we use the more conservative calibration in Backus, Chernov, and Martin (2011) with smaller diasters, with the jump intensity $\varpi$ set to $1.7 \%$, the mean jump size $\theta$ to $-38 \%$, and the jump size volatility $\delta$ to $25 \%$, we can match the exchange rate volatility, but all the currency risk premia are too small. In addition, varying the coefficient of risk aversion does not resolve this tension.

Finally, we also explored a third calibration due to Backus, Chernov, and Martin (2011) that is based on equity index options rather than aggregate consumption growth data with more frequent but much smaller jumps. In this 'Merton' model, we choose $\gamma=8.70, \sigma=2.53 \%$, $\omega=139 \%, \theta=-0.74 \%$ and $\delta=1.91 \%$. These results are displayed in Figure 6 , which, again, plots the exchange rate volatility $\sqrt{2 L}$ and the currency risk premium on a long position in foreign currency. Again, we cannot match both moments simultaneously. Since we cannot even match these two exchange rate moments in a rare disaster model, we ignore the exchange rate cyclicality puzzle. 

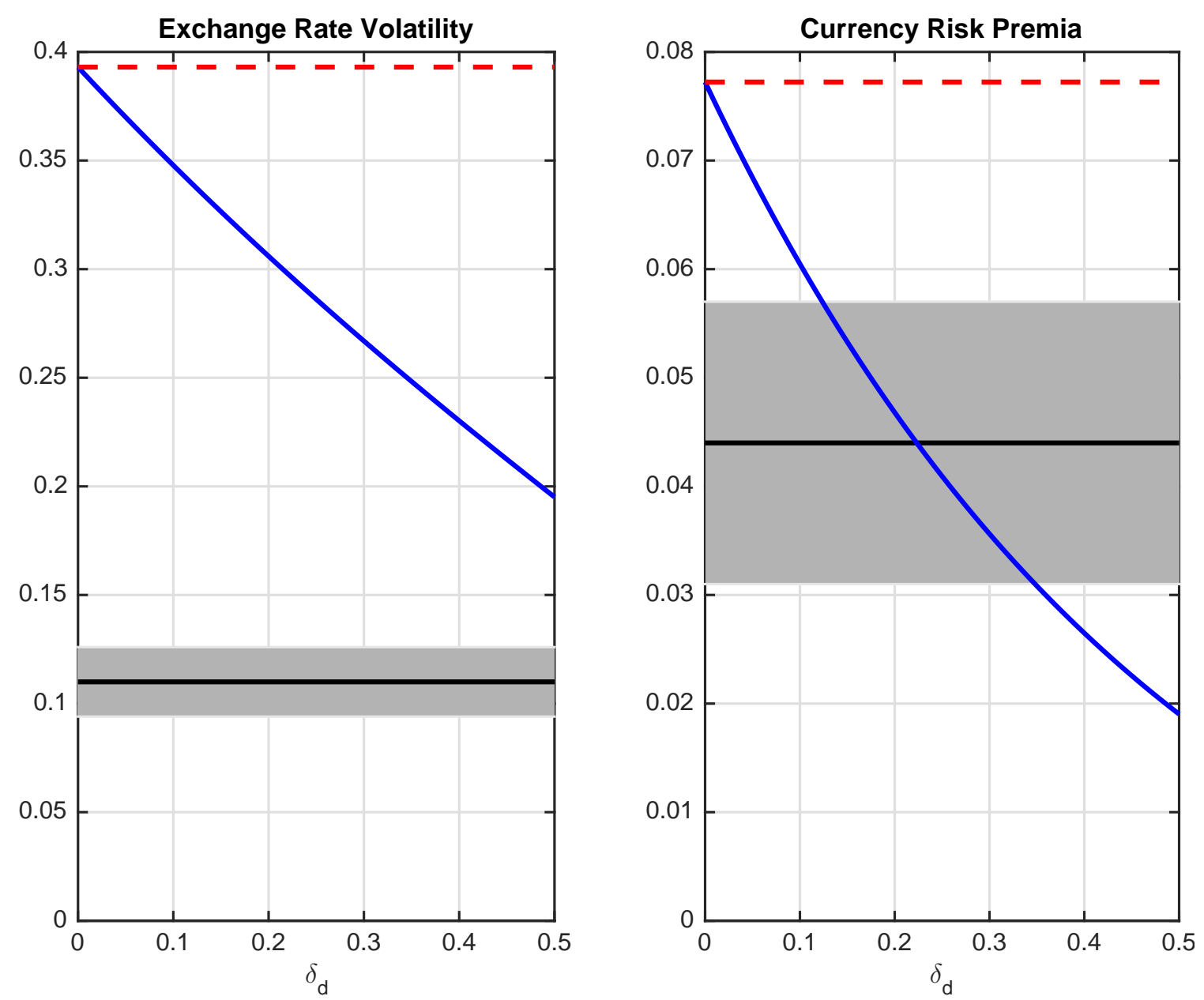

Figure 5: Exchange Rate Volatility and Risk Premia in a Barro-Rietz disaster version of the Merton (1976) Model: In the model, the incomplete spanning wedge follows the same Poisson mixture as the jump components of consumption growth. Each jump triggers a draw from a normal distribution with mean $\theta$ and variance $\delta^{2}$ for the domestic agent, with mean $\theta^{*}$ and variance $\delta^{* 2}$ for the foreign agent, and with mean $\theta_{d}$ and variance $\delta_{d}^{2}$ for the wedge. We assume that the wedge does not introduce non-stationarity in exchange rates $\left(\theta_{d}=0\right)$, that the two countries' consumption growth processes are symmetric $\left(\theta=\theta^{*}, \delta=\delta^{*}\right)$ and that the jump components are not correlated across countries. We follow Backus, Chernov, and Martin (2011) and set the risk aversion parameter $(\gamma)$ to 5.19 , the mean $(\mu)$ and standard deviation $(\sigma)$ of the normal consumption growth shocks to $2.3 \%$ and $1 \%$, the jump intensity $(\varpi)$ to $1.7 \%$, the mean jump size $(\theta)$ to $-38 \%$, and the jump size volatility $(\delta)$ to $25 \%$. The figure reports the exchange rate volatility (defined as $\sqrt{2 L}$, where $L$ denotes the average entropy) and the currency risk premium in levels from the perspective of the home investor, $E_{t}\left[r x_{t+1}^{F X}\right]+L_{t}\left[r x_{t+1}^{F X}\right]$, for the admissible combinations of the jump parameters $\delta_{d} \leq 2 \delta$. The gray area represents the empirical counterpart of each moment. 

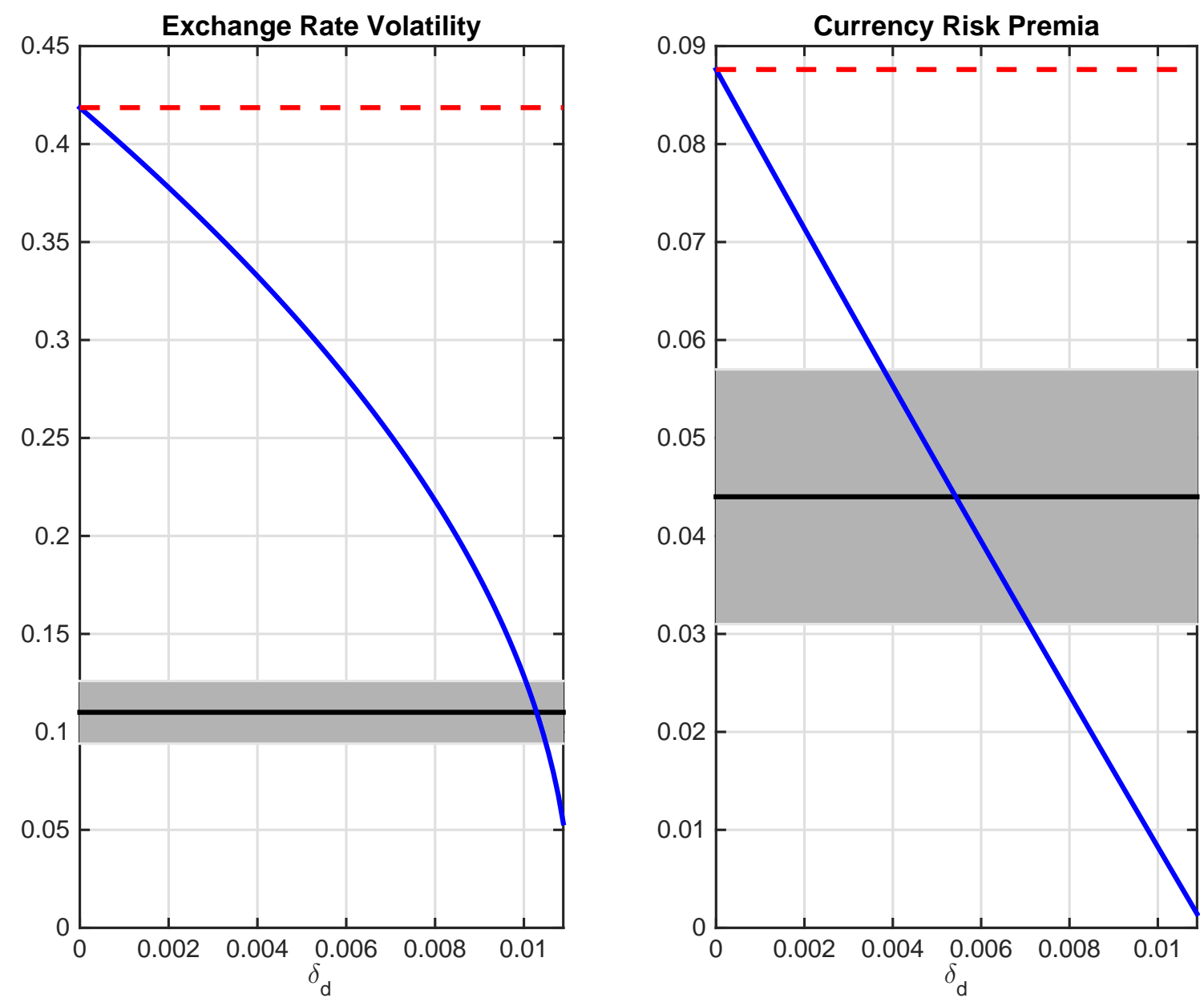

Figure 6: Exchange Rate Volatility and Risk Premia in an option-based Merton (1976) Model: In the model, the incomplete spanning wedge follows the same Poisson mixture as the jump components of consumption growth. Each jump triggers a draw from a normal distribution with mean $\theta$ and variance $\delta^{2}$ for the domestic agent, with mean $\theta^{*}$ and variance $\delta^{* 2}$ for the foreign agent, and with mean $\theta_{d}$ and variance $\delta_{d}^{2}$ for the wedge. We assume that the wedge does not introduce non-stationarity in exchange rates $\left(\theta_{d}=0\right)$, that the two countries' consumption growth processes are symmetric $\left(\theta=\theta^{*}, \delta=\delta^{*}\right)$ and that the jump components are not correlated across countries. We follow Backus, Chernov, and Martin (2011) and set the risk aversion parameter $(\gamma)$ to 8.70 , the mean $(\mu)$ and standard deviation $(\sigma)$ of the normal consumption growth shocks to $3.03 \%$ and $2.53 \%$, the jump intensity $(\varpi)$ to $139 \%$, the mean jump size $(\theta)$ to $-0.74 \%$, and the jump size volatility $(\delta)$ to $1.91 \%$. The figure reports the exchange rate volatility (defined as $\sqrt{2 L}$, where $L$ denotes the average entropy) and the currency risk premium in levels from the perspective of the home investor, $E_{t}\left[r x_{t+1}^{F X}\right]+L_{t}\left[r x_{t+1}^{F X}\right]$, for the admissible combinations of the jump parameters $\delta_{d} \leq 2 \delta$. The gray area represents the empirical counterpart of each moment. 


\subsection{Dynamic Asset Pricing Models}

In this section, we extend our benchmark results to a large class of dynamic asset pricing models. Specifying a law of motion for the stochastic discount factor further restrains the ability of the incomplete spanning wedge to address the main currency puzzles because it completely pins down the first moment of the wedge. We use the Cox, Ingersoll, and Ross (1985) model (denoted CIR) model to illustrate this finding. Similar results appear naturally in the case of CRRA preferences with heteroskedastic consumption, since that model is isomorphic to the CIR model. For the sake of clarity and space, we focus on a simple CIR model with country-specific factors. The Appendix presents a CIR model with common factors and a consumption-based model.

In discrete time, the simplest version of the CIR model is defined by the following two equations:

$$
\begin{aligned}
-\log M_{t+1} & =\alpha+\chi z_{t}+\sqrt{\gamma z_{t}} u_{t+1} \\
z_{t+1} & =(1-\phi) \theta+\phi z_{t}-\sigma \sqrt{z_{t}} u_{t+1}
\end{aligned}
$$

where $M$ denotes the home stochastic discount factor. The disturbances $u_{t+1} \sim \mathbb{N}(0,1)$ are i.i.d. over time. ${ }^{12}$ The foreign stochastic discount factor follows a similar law of motion but with its own factor $z_{t}^{*}$ and shocks $u_{t+1}^{*}$.

$$
\begin{aligned}
-\log M_{t+1}^{*} & =\alpha+\chi z_{t}^{*}+\sqrt{\gamma^{*} z_{t}^{*}} u_{t+1}^{*}, \\
z_{t+1}^{*} & =(1-\phi) \theta+\phi z_{t}^{*}-\sigma \sqrt{z} u_{t+1}^{*},
\end{aligned}
$$

As noted in Equation (11), since the SDF is lognormal, the maximum Sharpe ratios at home and

\footnotetext{
${ }^{12}$ In this model, $\log$ bond prices are affine in the state variable $z_{t}: p_{t}^{(n)}=-B_{0}^{n}-B_{1}^{n} z_{t}$. The price of a one period-bond is: $P^{(1)}=E_{t}\left(M_{t+1}\right)=e^{-\alpha-\left(\chi-\frac{1}{2} \gamma\right) z_{t}}$. Bond prices are defined recursively by the Euler equation: $P_{t}^{(n)}=E_{t}\left(M_{t+1} P_{t+1}^{(n-1)}\right)$. Thus the bond price coefficients evolve according to the following second-order difference equations:

$$
\begin{aligned}
& B_{0}^{n}=\alpha+B_{0}^{n-1}+B_{1}^{n-1}(1-\phi) \theta \\
& B_{1}^{n}=\chi-\frac{1}{2} \gamma+B_{1}^{n-1} \phi-\frac{1}{2}\left(B_{1}^{n-1}\right)^{2} \sigma^{2}+\sigma \sqrt{\gamma} B_{1}^{n-1} .
\end{aligned}
$$
}


abroad are $s t d_{t}\left(m_{t+1}\right)=\sqrt{\gamma z_{t}}$, and $s t d_{t}\left(m_{t+1}^{*}\right)=\sqrt{\gamma^{*} z_{t}^{*}}$, respectively. The real version of this CIR model with $\chi=0$ is isomorphic to a model in which the domestic (foreign) representative agent has power utility preferences over consumption with CRRA coefficient $\sqrt{\gamma}\left(\sqrt{\gamma^{*}}\right)$ and aggregate consumption growth is heteroskedastic.

We assume that domestic investors can trade at least one risky domestic asset (e.g., a longer maturity bond) and the one-period risk-free bond, but they can only trade the foreign risk-free bond. They cannot trade any foreign risky assets. All domestic shocks are spanned, but not the foreign shocks.

When markets are complete, the volatility of exchange rate changes is simply equal to $\operatorname{var}_{t}\left(\Delta s_{t+1}\right)=\gamma z_{t}+\gamma^{*} z_{t}^{*}$. In order to describe the class of potential wedges, we define the target volatility of the incomplete spanning exchange rate as $\operatorname{var}_{t}\left(\Delta s_{t+1}\right)=\kappa z_{t}+\kappa^{*} z_{t}^{*}$. As noted in Corollary 1, the implied volatility of the incomplete spanning exchange rate process is then equal to $\operatorname{var}_{t}\left(\Delta s_{t+1}\right)=\gamma z_{t}+\gamma^{*} z_{t}^{*}-\operatorname{var}_{t}\left(\eta_{t+1}\right)$, which implies that the volatility of the wedge is $\operatorname{var}_{t}\left(\eta_{t+1}\right)=(\gamma-\kappa) z_{t}+\left(\gamma^{*}-\kappa^{*}\right) z_{t}^{*}$. The following result defines the incomplete markets wedge that matches the desired volatility of the exchange rates while satisfying all the restrictions of Proposition 1.

Result 2. In the CIR model with country-specific factors that define the domestic $m_{t+1}$ and foreign $m_{t+1}^{*} \log$ stochastic discount factors, incomplete spanning leads to a wedge $\eta_{t+1}$ and an exchange rate process $S_{t}$ that satisfies $\Delta s_{t+1}=\eta_{t+1}+m_{t+1}^{*}-m_{t+1}$ with variance $\operatorname{var}_{t}\left(\Delta s_{t+1}\right)=$ $\kappa z_{t}+\kappa^{*} z_{t}^{*}$, where $\eta_{t}$ follows:

$$
\begin{aligned}
\eta_{t+1}=\psi z_{t}+\psi^{*} z_{t}^{*} & -\sqrt{(\gamma-\lambda) z_{t}} u_{t+1}+\sqrt{\left(\gamma^{*}-\lambda^{*}\right) z_{t}^{*}} u_{t+1}^{*} \\
& +\sqrt{(\lambda-\kappa) z_{t}} \epsilon_{t+1}+\sqrt{\left(\lambda^{*}-\kappa^{*}\right) z_{t}^{*}} \epsilon_{t+1}^{*}
\end{aligned}
$$

where $\epsilon_{t+1} \sim \mathbb{N}(0,1)$ and $\epsilon_{t+1}^{*} \sim \mathbb{N}(0,1)$ are i.i.d., and where the parameters $\lambda, \lambda^{*}, \psi$, and $\psi^{*}$ 
satisfy $\kappa \leq \lambda \leq \gamma, \kappa^{*} \leq \lambda^{*} \leq \gamma^{*}$, as well as:

$$
\begin{aligned}
\kappa & =\gamma-\sqrt{\gamma} \sqrt{\gamma-\lambda}, \\
\kappa^{*} & =\gamma^{*}-\sqrt{\gamma^{*}} \sqrt{\gamma^{*}-\lambda^{*}} \\
\psi & =-\frac{1}{2}(\gamma-\kappa), \\
\psi^{*} & =\frac{1}{2}\left(\gamma^{*}-\kappa^{*}\right) .
\end{aligned}
$$

The class of incomplete spanning models built on the CIR framework has only two degrees of freedom, described by the two parameters $\kappa$ and $\kappa^{*}$. Again, these two parameters determine the exchange rate volatility. Once they are chosen, the law of motion of the incomplete spanning wedge is entirely determined. Equations (26) and (27) implicitly pin down the parameters $\lambda$ and $\lambda^{*}$. As Equations (28) and (29) show, the drift term in the $\eta$ process is not a free parameter either, it is determined by the other parameters of the model. ${ }^{13}$

The incomplete markets wedges leave the domestic and foreign term structure unchanged. The term $(\gamma-\lambda)$ measures the exchange rate's exposure to spanned shocks, while $(\lambda-\kappa)$ measures the exposure to unspanned shocks. If we allow the domestic investor to trade any foreign risky bond, then the wedges are zero again: $\kappa=\gamma=\lambda$ and $\kappa^{*}=\gamma^{*}=\lambda^{*}$, because we need to impose two additional orthogonality conditions given by Equation (12) between log returns and $\eta$. This result is intuitive: if there are as many assets as exogenous shocks, markets are complete.

The key result is that the drift of the wedge is determined by the rest of the model; it is no longer a free parameter. Once we impose these dynamic no-arbitrage restrictions on the drift term, the effect on currency risk premia is unambiguous. When markets are complete, the log currency risk premium is given by $E_{t}\left[r x_{t+1}^{F X}\right]=\frac{1}{2}\left(\gamma z_{t}-\gamma^{*} z_{t}^{*}\right)$, while the currency risk premium in levels is given by $\gamma z_{t}$. When markets are incomplete, the risk premium in levels is always

\footnotetext{
${ }^{13}$ In the symmetric case, where $\gamma=\gamma^{*}$ (the two SDFs react in the same proportion to exogenous shocks) and $\kappa=\kappa^{*}$ (the exchange rate volatility exhibit the same sensitivity to the two state variables), then Equations (28) and (29) imply that $\psi=-\psi^{\star}$, and the drift term is zero on average $\left(E\left[\mu_{t, \eta}\right]=0\right)$. In the symmetric case, on average, the wedge has no impact on exchange rates.
} 
smaller than in complete markets because $\kappa \leq \gamma$.

Result 3. In the incomplete market model described in Result 2, the risk premium in logs on a long position in foreign currency is:

$$
E_{t}\left[r x_{t+1}^{F X}\right]=\frac{1}{2}\left[\kappa z_{t}-\kappa^{*} z_{t}^{*}\right]
$$

The risk premium in levels on a long position in foreign currency is always smaller in incomplete markets than in complete markets:

$$
E_{t}\left[r x_{t+1}^{F X}\right]+\frac{1}{2} \operatorname{var}_{t}\left[r x_{t+1}^{F X}\right]=\kappa z_{t} \leq \gamma z_{t}
$$

In the incomplete market model, the Fama slope coefficient in a regression of exchange rates $\left(-\Delta s_{t+1}\right)$ on the interest rate difference $r_{t}^{*}-r_{t}$ is:

$$
\frac{\operatorname{cov}\left(-\Delta s_{t+1}, r_{t}^{*}-r_{t}\right)}{\operatorname{var}\left(r_{t}^{*}-r_{t}\right)}=1+\frac{1}{2} \frac{\kappa\left(\chi-\frac{1}{2} \gamma\right)+\kappa^{*}\left(\chi-\frac{1}{2} \gamma^{*}\right)}{\left(\chi-\frac{1}{2} \gamma\right)^{2}+\left(\chi-\frac{1}{2} \gamma^{*}\right)^{2}}
$$

If incomplete spanning reduces the standard deviation of exchange rates by $50 \%(\sqrt{\kappa / \gamma}=$ $0.5)$, then the currency risk premium is reduced by a factor of $0.25(\kappa / \gamma=0.25$, implying a reduction by $75 \%) .{ }^{14}$ Since a real version of the CIR model is isomorphic to the ConsumptionCAPM with heteroscedastic consumption growth, this result implies that incomplete spanning effectively reduces the representative agent's risk aversion coefficient when pricing currency risk, but not for other risk sources.

To quantitatively illustrate the trade-off between exchange rate volatility and risk premia, we adopt the following parameters for the two countries: $\lambda_{d}=-1.07, \gamma=\lambda_{d}^{2}, \theta=0.004428$, $\phi=0.976, \alpha=0, \chi=-1+\lambda_{d}^{2} / 2, \sigma=0.008356$. These parameters match the mean short-term

\footnotetext{
${ }^{14}$ Currency Sharpe ratios decrease as well, since for all $z_{t}, z_{t}^{*}$ :

$$
\frac{E_{t}\left[r x_{t+1}^{F X}\right]+\frac{1}{2} \operatorname{var}_{t}\left[r x_{t+1}^{F X}\right]}{s t d_{t}\left(\Delta s_{t+1}\right)}=\frac{\kappa z_{t}}{\sqrt{\kappa z_{t}+\kappa z_{t}^{*}}}=\sqrt{\kappa} \frac{z_{t}}{\sqrt{z_{t}+z_{t}^{*}}} \leq \sqrt{\gamma} \frac{z_{t}}{\sqrt{z_{t}+z_{t}^{*}}}
$$
}


interest rate rate, its volatility, and its autocorrelation. They are close to those used in Backus, Foresi, and Telmer (1998): the only difference is that we defined $\chi=-1+\lambda_{d}^{2} / 2$ (instead of $\left.\chi=1+\lambda_{d}^{2} / 2\right)$ in order to obtain counter-cyclical short-term interest rates, a necessary feature to replicate the uncovered interest rate (UIP) puzzle in this class of models.

Figure 7 reports the annualized volatility of the exchange rate and the UIP slope coefficients for all admissible combinations of the parameters $\kappa$. The first panel plots the parameters $\kappa$ and $\lambda$ against the annualized volatility of the wedge, $s t d_{t}\left(\eta_{t+1}\right)$. The second panel plots the annualized volatility of the exchange rate. The third panel plots the UIP slope coefficient in a regression of exchange rates $\left(-\Delta s_{t+1}\right)$ on the interest rate difference $r_{t}^{*}-r_{t}$. UIP implies that this slope coefficient is one; in the data, it is statistically different from one and often negative. As the volatility of the wedge increases, the exchange rate volatility decreases. It can reach its empirical value, but only at the cost of driving the UIP slope coefficients to one. The fourth panel reports the currency risk premium. In the model, as shown in Corollary 3 , it varies with the state variable $z$. In order to focus on potentially large values, it is here evaluated at the mean plus two standard deviations of the state variable $z$. Even in this very favorable case, when the exchange rate volatility reaches its empirical value, the currency risk premium is zero.

These conclusions do not depend on the country-specific nature of the factors. When we include common factors, we find that incomplete spanning still lowers the currency risk premium in levels and also forces the UIP regression coefficient to one. We analyze this general case with common factors in the Appendix, along with a version of the Lucas (1982) model with hetereroscedastic consumption growth. 

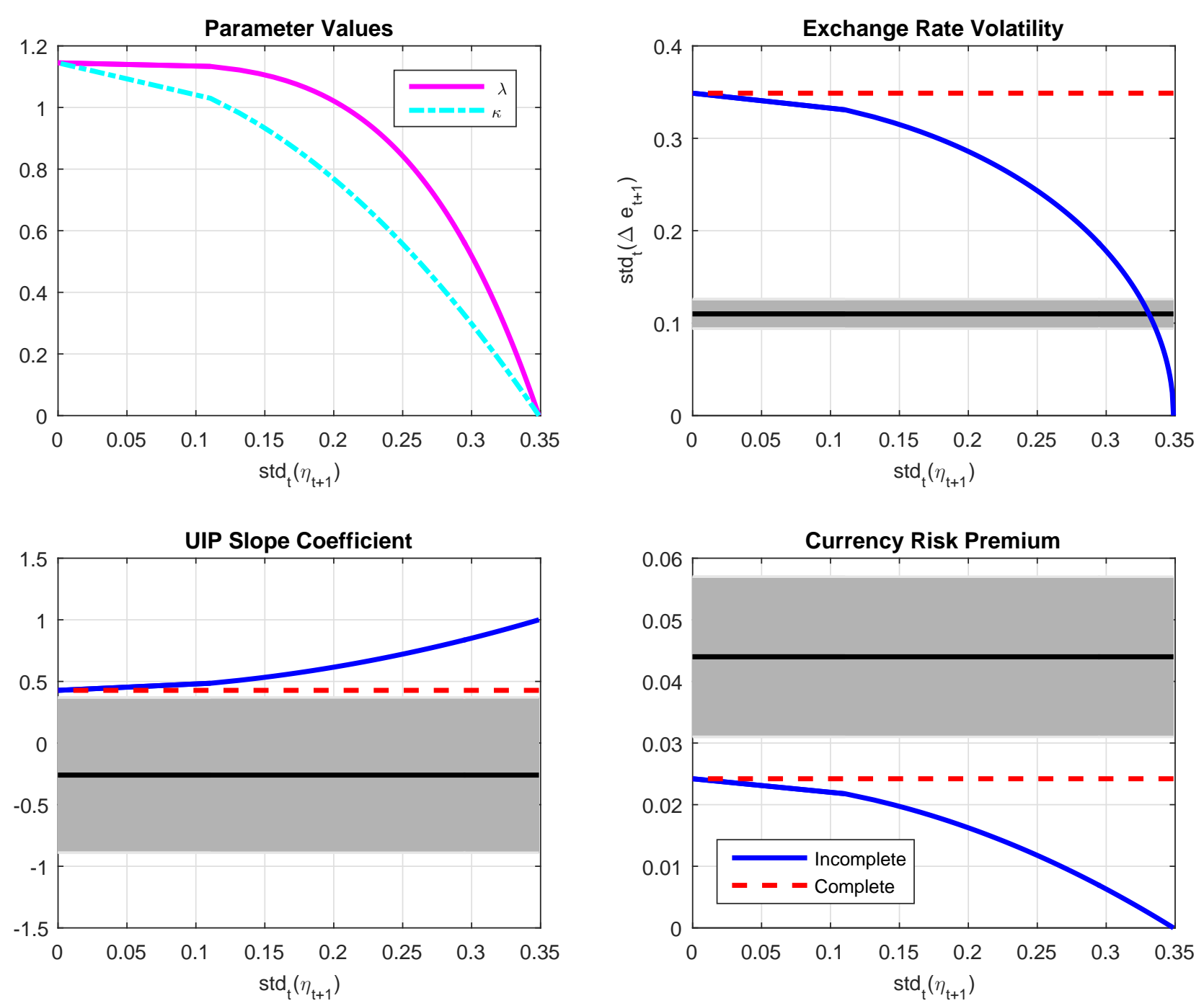

Figure 7: Cox, Ingersoll, and Ross (1985) Example: The figure reports the wedge parameters, the annualized volatility of the exchange rate, the UIP slope coefficient, and the currency risk premium for different volatilities of the incomplete spanning wedge. The first panel plots the parameters $\kappa$ and $\lambda$ that characterize the wedge against its annualized volatility, $s t d_{t}\left(\eta_{t+1}\right)$. The second panel plots the annualized volatility of the exchange rate. The third panel plots the UIP slope coefficient in a regression of exchange rates on the foreign minus domestic interest rates. If the uncovered interest rate parity were to hold, the UIP slope coefficient would be one. The fourth panel reports the currency risk premium evaluated at the mean plus two standard deviations of the state variable. We adopt the following parameters for the two countries: $\lambda_{d}=-1.07, \gamma=\lambda_{d}^{2}, \theta=0.004428, \phi=0.976, \alpha=0, \chi=-1+\lambda_{d}^{2} / 2, \sigma=0.008356$. 


\section{Conclusion}

Our paper investigates whether incomplete spanning in international financial markets can account for the behavior of exchange rates. To answer this question, we allow for a great deal of incompleteness by only enforcing the Euler equations in forwards and futures currency markets. To help resolve the currency volatility and correlation puzzles, the quantity of unspanned risk needed in currency markets is of the same size as the maximum Sharpe ratio. Adding this amount of noise to exchange rates shrinks all currency risk premia to zero in violation of a large body of empirical evidence from currency markets.

The limits of incomplete spanning underlines the robustness of the key exchange rate puzzles. In the future, the solutions to these puzzles may involve two ingredients. As suggested by complete market models, stochastic discount factors may be very highly correlated, even if macroeconomic series are not. To support this view further, researchers need to find direct evidence of such high correlations. In the realm of segmented markets, models that segment international currency markets by only allowing financial intermediaries (e.g., Gabaix and Maggiori, 2015) or a subset of investors (see, e.g., Chien, Lustig, and Naknoi, 2015 and Dou and Verdelhan, 2015) to trade a complete (or incomplete) menu of international securities are promising. These models sever the link between aggregate quantities and real exchange rates by concentrating aggregate risk among a small pool of investors. But these segmented markets models face a challenging measurement test: researchers need to show that changes in exchange rates are highly correlated with the marginal utility growth of these market participants. 


\section{References}

Alvarez, F., A. Atkeson, And P. J. Kehoe (2002): "Money, Interest Rates and Exchange Rates with Endogenously Segmented Markets," Journal of Political Economy, 110(1), 73-112.

- (2009): "Time-Varying Risk, Interest Rates and Exchange Rates in General Equilibrium," Review of Economic Studies, 76, 851 - 878.

Bacchetta, P., And E. VAn Wincoop (2006): "Can Information Heterogeneity Explain the Exchange Rate Determination Puzzle?," American Economic Review, 96(3), 552-576.

Backus, D., S. Foresi, and C. Telmer (1998): "Discrete-Time Models of Bond Pricing," Discussion paper, National Bureau of Economic Research.

- (2001): "Affine Term Structure Models and the Forward Premium Anomaly," Journal of Finance, 56(1), 279-304.

Backus, D., And G. Smith (1993): "Consumption and Real Exchange Rates in Dynamic Economies with Non-Traded Goods," Journal of International Economics, 35, 297-316.

Backus, D. K., M. Chernov, and I. Martin (2011): "Disasters Implied by Equity Index Options," Journal of Finance, 66, 1967-2009.

Bansal, R. (1997): "An Exploration of the Forward Premium Puzzle in Currency Markets," Review of Financial Studies, 10, 369-403.

Bansal, R., and I. Shaliastovich (2012): "A Long-Run Risks Explanation of Predictability Puzzles in Bond and Currency Markets," Review of Financial Studies.

Bates, D. S., ET AL. (1988): Pricing options under jump-diffusion processes. Citeseer.

Bekaert, G. (1996): "The Time Variation of Risk and Return in Foreign Exchange Markets: A General Equilibrium Perspective," The Review of Financial Studies, 9(2), 427-470. 
Brandt, M. W., J. Cochrane, and P. Santa-Clara (2006): "International Risk-Sharing is Better Than You Think, or Exchange Rates are Too Smooth," Journal of Monetary Economics, 53(4), 671-698.

Brennan, M. J., And Y. Xia (2006): "International Capital Markets and Foreign Exchange Risk," Review of Financial Studies, 19(3), 753-795.

Bruno, V., And H. S. Shin (2014): "Cross-Border Banking and Global Liquidity," The Review of Economic Studies, p. rdu042.

Chari, V. V., P. J. Kehoe, and E. R. McGrattan (2002): "Can Sticky Price Models Generate Volatile and Persistent Real Exchange Rates?," The Review of Economic Studies, 69(240), 533-564.

Chari, V. V., P. J. Kehoe, and E. R. McGrattan (2007): "Business cycle accounting," Econometrica, 75(3), 781-836.

Chien, Y., H. Lustig, And K. Naknoi (2015): "Why Are Exchange Rates So Smooth? A Segmented Asset Markets Explanation," Working Paper UCLA Anderson School of Management.

Cochrane, J. H. (2005): Asset Pricing. Princeton University Press, Princeton, N.J.

Colacito, R., and M. M. Croce (2011): "Risks For The Long Run And The Real Exchange Rate," Journal of Political Economy, 119(1), 153-182.

Constantinides, G. M., and D. Duffie (1996): “Asset Pricing with Heterogeneous Consumers," The Journal of Political Economy, 104, 219-240.

Corsetti, G., L. Dedola, and S. Leduc (2008): "International Risk Sharing and the Transmission of Productivity Shocks," Review of Economic Studies, 75(2), 443 - 473.

Cox, J., J. Ingersoll, and S. Ross (1985): “An Intertemporal General Equilibrium Model of Asset Pricing," Econometrica, 53, 363-384. 
Dou, W. W., And A. Verdelhan (2015): "The Volatility of International Capital Flows and Foreign Assets," Working Paper MIT Sloan.

FAma, E. F. (1984): "Forward and Spot Exchange Rates," Journal of Monetary Economics, $14,319-338$.

FArhi, E., And X. Gabaix (2015): "Rare Disasters and Exchange Rates," The Quarterly Journal of Economics, forthcoming.

Favilukis, J., L. Garlappi, and S. Neamati (2015): "The Carry Trade and Uncovered Interest Parity when Markets are Incomplete," Working Paper UBC.

Frachot, A. (1996): "A Reexamination of the Uncovered Interest Rate Parity Hypothesis," Journal of International Money and Finance, 15(3), 419-437.

Gabaix, X., And M. Maggiori (2015): "International Liquidity and Exchange Rate Dynamics," The Quarterly Journal of Economics, 130(3), 1369-1420.

Graveline, J. J., And S. Joslin (2011): “G10 Swap and Exchange Rates," Working Paper University of Southern California.

Hansen, L. P., And R. J. Hodrick (1980): "Forward Exchange Rates as Optimal Predictors of Future Spot Rates: An Econometric Analysis," Journal of Political Economy, 88(5), 829-853.

Hansen, L. P., and R. Jagannathan (1991): "Implications of Security Market Data for Models of Dynamic Economies," Journal of Political Economy, 99(2), 225-262.

Hodrick, R., and M. Vassalou (2002): "Do We Need Multi-Country Models to Explain Exchange Rate and Interest Rate and Bond Return Dynamics?," Journal of Economic Dynamics and Control, 26(7), 1275-1299.

Kollmann, R. (1996): "Incomplete asset markets and the cross-country consumption correlation puzzle," Journal of Economic Dynamics and Control, 20(5), 945 - 961.

Kollmann, R. M. (1991): "Essays on International Business Cycles," Ph.D. thesis, University of Chicago, Department of Economics. 
LEWIS, K. K. (1995): "Puzzles in International Financial Markets," in Handbook of International Economics, ed. by G. Grossman, and K. Rogoff, pp. 1913-1971. Elsevier Science B.V., Amsterdam.

LuCAS, R. E. J. (1982): "Interest rates and currency prices in a two country world," Journal of Monetary Economics, 10, 335-360.

Lustig, H., N. Roussanov, and A. Verdelhan (2011): "Common Risk Factors in Currency Markets," Review of Financial Studies, 24 (11), 3731-3777.

(2014): "Countercyclical Currency Risk Premia," Journal of Financial Economics, 111 (3), 527-553.

Lustig, H., And A. Verdelhan (2007): "The Cross-Section of Foreign Currency Risk Premia and Consumption Growth Risk," American Economic Review, 97(1), 89-117.

MagGioRI, M. (2014): "Financial Intermediation, International Risk Sharing, and Reserve Currencies," Working Paper Harvard University.

Mankiw, G. N. (1986): "The Equity Premium and the Concentration of Aggregate Shocks," Journal of Financial Economics, 17, 211-219.

Martin, I. W. (2013): "Consumption-based asset pricing with higher cumulants," The Review of Economic Studies, 80(2), 745-773.

Merton, R. C. (1976): "Option pricing when underlying stock returns are discontinuous," Journal of financial economics, 3(1), 125-144.

NAIK, V., AND M. LEE (1990): "General equilibrium pricing of options on the market portfolio with discontinuous returns," Review of Financial Studies, 3(4), 493-521.

Nakamura, E., J. Steinsson, R. J. Barro, and J. F. Ursua (2013): "Crises and Recoveries in an Empirical Model of Consumption Disasters," American Economic Journal: Macroeconomics, 5(3), 35-74. 
Pavlova, A., And R. Rigobon (2007): "Asset Prices and Exchange Rates," Review of Financial Studies, 20 (4), 1139-1180.

(2010): "An Asset-Pricing View of External Adjustment," Journal of International Economics, 80(1), 144-156.

(2012): "Equilibrium Portfolios and External Adjustment Under Incomplete Markets," AFA 2009 San Francisco Meetings Paper.

Ross, S. A. (1978): "A Simple Approach to the Valuation of Risky Streams," Journal of Business, pp. 453-475.

Sarno, L., P. Schneider, and C. Wagner (2012): "Properties of Foreign Exchange Risk Premiums," Journal of Financial Economics, 105(2), 279 - 310.

TRYON, R. (1979): "Testing for Rational Expectations in Foreign Exchange Markets," International Finance Discussion Papers. 


\section{Appendix}

\section{For Online Publication}

Section A presents the proof of our main general results. Section B studies three examples: a simple consumption-based example; a Cox, Ingersoll, and Ross (1985) model with common factors; a consumption-based example with heteroscedasticity. Section C reports summary statistics on the exchange rate entropy.

\section{A Proofs of Main Results}

In this section, we gather all the proofs of the main results in the text, in the order they appear there. We distinguish between the propositions and their corollaries, which are model-free findings, and the results, which are model-specific.

\section{Proof of Proposition 1:}

Proof. We start from the domestic investor's Euler equation for the foreign risk-free asset, and the foreign investor's Euler equation for the domestic risk-free asset respectively:

$$
\begin{aligned}
E_{t}\left(\widehat{M}_{t+1}^{*}\right) & =E_{t}\left(M_{t+1} \frac{S_{t+1}}{S_{t}}\right)=E_{t}\left(M_{t+1}^{*} \exp \left(\eta_{t+1}\right)\right)=1 / R_{t}^{f, *} \\
E_{t}\left(M_{t+1}\right) & =E_{t}\left(M_{t+1}^{*} \frac{S_{t}}{S_{t+1}}\right)=E_{t}\left(M_{t+1} \exp \left(-\eta_{t+1}\right)\right)=1 / R_{t}^{f,} .
\end{aligned}
$$

By using conditional joint log normality of the foreign SDF and exp $(\eta)$, the first Euler equation implies that:

$$
\begin{aligned}
E_{t}\left(\log M_{t+1}^{*}\right)+\frac{1}{2} \operatorname{Var}_{t}\left(\log M_{t+1}^{*}\right) & =E_{t}\left(\log M_{t+1}^{*}\right)+\mu_{t, \eta}+\frac{1}{2} \operatorname{Var}_{t}\left(\log M_{t+1}^{*}\right) \\
& +\frac{1}{2} \operatorname{Var}_{t}\left(\eta_{t+1}\right)+\operatorname{covar}_{t}\left(\eta_{t+1}, \log M_{t+1}^{*}\right),
\end{aligned}
$$

where $\mu_{t, \eta}=E_{t}\left(\eta_{t+1}\right)$. This implies that $\operatorname{covar}_{t}\left(m_{t+1}^{*}, \eta_{t+1}\right)=-\mu_{t, \eta}-0.5 \operatorname{var}_{t}\left(\eta_{t+1}\right)$. We move on to the second equation. The second Euler equation for the domestic risk-free asset implies that:

$$
\begin{aligned}
E_{t}\left(\log M_{t+1}\right)+\frac{1}{2} \operatorname{Var}_{t}\left(\log M_{t+1}\right) & =E_{t}\left(\log M_{t+1}\right)-\mu_{t, \eta}+\frac{1}{2} \operatorname{Var}_{t}\left(\log M_{t+1}\right) \\
& +(1 / 2) \operatorname{Var}_{t}\left(\eta_{t+1}\right)-\operatorname{covar}_{t}\left(\eta_{t+1}, \log M_{t+1}\right)
\end{aligned}
$$

This implies that $\operatorname{covar}_{t}\left(m_{t+1}, \eta_{t+1}\right)=-\mu_{t, \eta}+0.5 \operatorname{var}_{t}\left(\eta_{t+1}\right)$.

The inequality restrictions on $\mu_{t, \eta}$ follow directly from the Cauchy-Schwarz inequality for (1) $\left|\operatorname{covar}_{t}\left(m_{t+1}^{*}, \eta_{t+1}\right)\right| \leq$ $s t d_{t}\left(m_{t+1}^{*}\right) s t d_{t}\left(\eta_{t+1}\right)$ and (2) $\left|\operatorname{covar}_{t}\left(m_{t+1}, \eta_{t+1}\right)\right| \leq s t d_{t}\left(m_{t+1}\right) s t d_{t}\left(\eta_{t+1}\right)$. Finally, we also impose that (3):

$$
\left|\operatorname{covar}_{t}\left(m_{t+1}^{*}-m_{t+1}, \eta_{t+1}\right)\right| \leq s t d_{t}\left(m_{t+1}^{*}-m_{t+1}\right) s t d_{t}\left(\eta_{t+1}\right) .
$$

When $\mu_{t, \eta} \leq-(1 / 2) \operatorname{var}_{t}\left(\eta_{t+1}\right)$, the first inequality implies that:

$$
-\left(\mu_{t, \eta}+\frac{1}{2} \operatorname{var}_{t}\left(\eta_{t+1}\right)\right) \leq s t d_{t}\left(m_{t+1}^{*}\right) s t d_{t}\left(\eta_{t+1}\right) .
$$

This in turn implies that:

$$
\left.-\left(\mu_{t, \eta}\right) \leq s t d_{t}\left(m_{t+1}^{*}\right) s t d_{t}\left(\eta_{t+1}\right)+\frac{1}{2} \operatorname{var}_{t}\left(\eta_{t+1}\right)\right) .
$$

When $\mu_{t, \eta} \geq-(1 / 2) \operatorname{var}_{t}\left(\eta_{t+1}\right)$, the first inequality implies that:

$$
\mu_{t, \eta}+\frac{1}{2} \operatorname{var}_{t}\left(\eta_{t+1}\right) \leq s t d_{t}\left(m_{t+1}^{*}\right) s t d_{t}\left(\eta_{t+1}\right)
$$

This in turn implies that:

$$
\mu_{t, \eta} \leq s t d_{t}\left(m_{t+1}^{*}\right) s t d_{t}\left(\eta_{t+1}\right)-\frac{1}{2} \operatorname{var}_{t}\left(\eta_{t+1}\right)
$$


Next, we turn to the second inequality. When $\mu_{t, \eta} \geq(1 / 2) \operatorname{var}_{t}\left(\eta_{t+1}\right)$, the second inequality implies that:

$$
\mu_{t, \eta}-\frac{1}{2} \operatorname{var}_{t}\left(\eta_{t+1}\right) \leq s t d_{t}\left(m_{t+1}\right) s t d_{t}\left(\eta_{t+1}\right)
$$

This in turn implies that:

$$
\mu_{t, \eta} \leq s t d_{t}\left(m_{t+1}\right) s t d_{t}\left(\eta_{t+1}\right)+\frac{1}{2} \operatorname{var}_{t}\left(\eta_{t+1}\right)
$$

When $\mu_{t, \eta} \leq(1 / 2) \operatorname{var}_{t}\left(\eta_{t+1}\right)$, the second inequality implies that:

$$
-\left(\mu_{t, \eta}-\frac{1}{2} \operatorname{var}_{t}\left(\eta_{t+1}\right)\right) \leq s t d_{t}\left(m_{t+1}\right) s t d_{t}\left(\eta_{t+1}\right) .
$$

This in turn implies that:

$$
-\mu_{t, \eta} \leq s t d_{t}\left(m_{t+1}\right) s t d_{t}\left(\eta_{t+1}\right)-\frac{1}{2} \operatorname{var}_{t}\left(\eta_{t+1}\right) .
$$

Finally, the third inequality implies that:

$$
s t d_{t}\left(\eta_{t+1}\right) \leq s t d_{t}\left(m_{t+1}^{*}-m_{t+1}\right) .
$$

\section{Proof of Corollary 1:}

Proof. We start from the definition of log changes in exchange rates: $\operatorname{var}_{t}\left(\Delta s_{t+1}\right)=\operatorname{var}_{t}\left(\eta_{t+1}+m_{t+1}^{*}-m_{t+1}\right)$. This can be simplified to:

$$
\begin{aligned}
\operatorname{var}_{t}\left(\Delta s_{t+1}\right) & =\operatorname{var}_{t}\left(m_{t+1}\right)+\operatorname{var}_{t}\left(m_{t+1}^{*}\right)+\operatorname{var}_{t}\left(\eta_{t+1}\right)-2 \operatorname{cov}_{t}\left(m_{t+1}, m_{t+1}^{*}\right) \\
& -2 \operatorname{cov}_{t}\left(m_{t+1}, \eta_{t+1}\right)+2 \operatorname{cov}_{t}\left(\eta_{t+1}, m_{t+1}^{*}\right) .
\end{aligned}
$$

Proposition 1 implies that:

$$
\begin{aligned}
\operatorname{var}_{t}\left(\Delta s_{t+1}\right) & =\operatorname{var}_{t}\left(m_{t+1}\right)+\operatorname{var}_{t}\left(m_{t+1}^{*}\right)-2 \operatorname{cov}_{t}\left(m_{t+1}, m_{t+1}^{*}\right) \\
& -\operatorname{var}_{t}\left(\eta_{t+1}\right)-\operatorname{var}_{t}\left(\eta_{t+1}\right)+\operatorname{var}_{t}\left(\eta_{t+1}\right),
\end{aligned}
$$

which establishes the result. Finally, we prove the volatility results. The volatility of the log pricing kernel in the foreign country is given by

$$
\operatorname{var}_{t}\left(m_{t+1}^{*}+\eta_{t+1}\right)=\operatorname{var}_{t}\left(m_{t+1}^{*}\right)+\operatorname{var}_{t}\left(\eta_{t+1}\right)+2 \operatorname{covar}_{t}\left(m_{t+1}^{*}, \eta_{t+1}\right) .
$$

The result follows directly from the covariance condition. Note that $\operatorname{covar}_{t}\left(m_{t+1}^{*}, \eta_{t+1}\right)=-\mu_{t, \eta}-\frac{1}{2} \operatorname{var}_{t}\left(\eta_{t+1}\right)$.

$$
\operatorname{var}_{t}\left(m_{t+1}^{*}+\eta_{t+1}\right)=\operatorname{var}_{t}\left(m_{t+1}^{*}\right)+\operatorname{var}_{t}\left(\eta_{t+1}\right)+2\left(-\mu_{t, \eta}-\frac{1}{2} \operatorname{var}_{t}\left(\eta_{t+1}\right)\right)
$$

\section{Proof of Corollary 2}

Proof. The expression for the log risk premium follows because $\operatorname{covar}_{t}\left(m_{t+1}^{*}, \eta_{t+1}\right)=-\mu_{t, \eta}-\operatorname{var}_{t}\left(\eta_{t+1}\right) / 2$. The expression for the risk premium in level follows because $\operatorname{var}_{t}\left[\operatorname{rx}_{t+1}^{F X}\right] / 2=\operatorname{var}_{t}\left(\Delta s_{t+1}\right) / 2$ which is given by:

$$
\frac{1}{2} \operatorname{var}_{t}\left(m_{t+1}\right)+\frac{1}{2} \operatorname{var}_{t}\left(m_{t+1}^{*}\right)-\operatorname{cov}_{t}\left(m_{t+1}, m_{t+1}^{*}\right)-\frac{1}{2} \operatorname{var}_{t}\left(\eta_{t+1}\right)
$$

The log risk premium is increased by $\mu_{t, \eta}$ relative to the complete markets case. The foreign investor's log risk premium on domestic currency is naturally the opposite of the one above. The symmetry does not hold in levels because of the usual Jensen term. The foreign investor's risk premium in levels on a long position in domestic currency is given by:

$$
E_{t}\left[r x_{t+1}^{F X}\right]+\frac{1}{2} \operatorname{var}_{t}\left[r x_{t+1}^{F X}\right]=\operatorname{cov}_{t}\left(m_{t+1}^{*}, \Delta s_{t+1}\right)=\operatorname{var}_{t}\left(m_{t+1}^{*}\right)-\operatorname{covar}_{t}\left(m_{t+1}^{*}, m_{t+1}\right)-\frac{1}{2} \operatorname{var}_{t}\left(\eta_{t+1}\right)-\mu_{t, \eta} .
$$




\section{Proof of Corollary 3}

Proof. This result follows immediately from Proposition 1. We subtract the second $\operatorname{covar}_{t}\left(m_{t+1}, \eta_{t+1}\right)=-\mu_{t, \eta}+$ $0.5 \operatorname{var}_{t}\left(\eta_{t+1}\right)$ from the first covariance condition $\operatorname{covar}_{t}\left(m_{t+1}, \eta_{t+1}\right)=-\mu_{t, \eta}+0.5 \operatorname{var}_{t}\left(\eta_{t+1}\right)$. That delivers the results.

\section{Proof of Proposition 2:}

Proof. By definition, the conditional entropy of a random variable $X_{t+1}$ is equal to:

$$
L_{t}\left(X_{t+1}\right)=\log E_{t}\left(X_{t+1}\right)-E_{t}\left(\log X_{t+1}\right)
$$

We assume here that both investors have access to risk-free rates. Let us start again from the Euler equation of the foreign investor:

$$
\frac{1}{R_{t}^{f, *}}=E_{t}\left(M_{t+1}^{*} \exp \left(\eta_{t+1}\right)\right)
$$

Taking logs leads to:

$$
-r_{t}^{f, *}=\log E\left(M_{t+1}^{*} \exp \left(\eta_{t+1}\right)\right)=L_{t}\left(M_{t+1}^{*} \exp \left(\eta_{t+1}\right)\right)+E_{t}\left(\log M_{t+1}^{*}\right)+E_{t}\left(\eta_{t+1}\right)
$$

But the risk-free rate also satisfies the Euler equation $E\left(M_{t+1}^{*} R_{t}^{f, *}\right)=1$. Taking logs again leads to:

$$
\log E\left(M_{t+1}^{*} R_{t}^{f, *}\right)=L\left(M_{t+1}^{*} R_{t}^{f, *}\right)+E_{t}\left(\log M_{t+1}^{*}\right)+r_{t}^{f, *}=0
$$

Plugging the implied value of the log risk-free rate in the first equation above delivers the result, noting that $L_{t}\left(a_{t} X_{t+1}\right)=L_{t}\left(X_{t+1}\right)$ for any variable $a_{t}$ known at date $t$ :

$$
L\left(M_{t+1}^{*}\right)+E_{t}\left(\log M_{t+1}^{*}\right)=L_{t}\left(M_{t+1}^{*} \exp \left(\eta_{t+1}\right)\right)+E_{t}\left(\log M_{t+1}^{*}\right)+E_{t}\left(\eta_{t+1}\right),
$$

which simplifies to:

$$
L_{t}\left(M_{t+1}^{*} \exp \left(\eta_{t+1}\right)\right)=L\left(M_{t+1}^{*}\right)-E_{t}\left(\eta_{t+1}\right) .
$$

Likewise, one can show that:

$$
L_{t}\left(M_{t+1} \exp \left(-\eta_{t+1}\right)\right)=L\left(M_{t+1}\right)+E_{t}\left(\eta_{t+1}\right) .
$$

Finally, we derive restrictions the set of feasible $\mu_{t, \eta}$ from non-negativity of $L_{t}\left(M_{t+1} \exp \left(-\eta_{t+1}\right)\right), L_{t}\left(M_{t+1}^{*} \exp \left(\eta_{t+1}\right)\right)$ and $L_{t}\left(\frac{S_{t+1}}{S_{t}}\right)$. To start, note that:

$$
\begin{gathered}
L_{t}\left(M_{t+1} \exp \left(-\eta_{t+1}\right)\right)=\log E_{t}\left(M_{t+1} \exp \left(\eta_{t+1}\right)\right)-E_{t} \log \left(M_{t+1}\right)+E_{t}\left(\eta_{t+1}\right) \geq 0 \\
L_{t}\left(M_{t+1}^{*} \exp \left(\eta_{t+1}\right)\right)=\log E_{t}\left(M_{t+1}^{*} \exp \left(\eta_{t+1}\right)\right)-E_{t} \log \left(M_{t+1}^{*}\right)-E_{t}\left(\eta_{t+1}\right) \geq 0
\end{gathered}
$$

This implies that the following restrictions need to be satisfied:

which in turn implies that:

$$
\begin{aligned}
-\mu_{t \eta} & \leq \log E_{t}\left(M_{t+1} \exp \left(-\eta_{t+1}\right)\right)-E_{t} \log \left(M_{t+1}\right) . \\
\mu_{t \eta} & \leq \log E_{t}\left(M_{t+1}^{*} \exp \left(\eta_{t+1}\right)\right)-E_{t} \log \left(M_{t+1}^{*}\right),
\end{aligned}
$$

$$
-\left(\log E_{t}\left(M_{t+1} \exp \left(-\eta_{t+1}\right)\right)-E_{t} \log \left(M_{t+1}\right)\right) \leq \mu_{t \eta} \leq \log E_{t}\left(M_{t+1}^{*} \exp \left(\eta_{t+1}\right)\right)-E_{t} \log \left(M_{t+1}^{*}\right)
$$

Finally, we also know that

$$
L_{t}\left(\frac{S_{t+1}}{S_{t}}\right)=-E_{t}\left(\eta_{t+1}\right)+\log E_{t}\left(\frac{M_{t+1}^{*}}{M_{t+1} e^{-\eta_{t+1}}}\right)-E_{t} \log \left(\frac{M_{t+1}^{*}}{M_{t+1}}\right) \geq 0
$$


This, in turn, implies that:

$$
\log E_{t}\left(\frac{M_{t+1}^{*}}{M_{t+1} e^{-\eta_{t+1}}}\right)-E_{t} \log \left(\frac{M_{t+1}^{*}}{M_{t+1}}\right) \geq \mu_{t \eta}
$$

\section{Proof of Corollary 4:}

Proof. Note that the entropy of the ratio of two random variables is:

$$
\begin{aligned}
L_{t}\left(\frac{X_{t+1}}{Y_{t+1}}\right) & =\log E_{t}\left(\frac{X_{t+1}}{Y_{t+1}}\right)-E_{t}\left(\log X_{t+1}\right)+E_{t}\left(\log Y_{t+1}\right) \\
& =\log E_{t}\left(\frac{X_{t+1}}{Y_{t+1}}\right)+L_{t}\left(X_{t+1}\right)-\log E_{t}\left(X_{t+1}\right)-L\left(Y_{t+1}\right)+\log E_{t}\left(Y_{t+1}\right) .
\end{aligned}
$$

By applying this fomula to the following expression with $X_{t+1}=M_{t+1}^{*} / M_{t+1}$ and $Y_{t+1}=M_{t+1}^{*} /\left[M_{t+1} e^{-\eta_{t+1}}\right]$, we obtain

$$
\begin{aligned}
L_{t}\left(e^{-\eta_{t+1}}\right) & =L_{t}\left(\frac{M_{t+1}^{*} / M_{t+1}}{M_{t+1}^{*} /\left[M_{t+1} e^{\left.-\eta_{t+1}\right]}\right.}\right) \\
& =L_{t}\left(\frac{M_{t+1}^{*}}{M_{t+1}}\right)-L_{t}\left(\frac{M_{t+1}^{*}}{M_{t+1} e^{-\eta_{t+1}}}\right)+\log E_{t}\left(e^{-\eta_{t+1}}\right)-\log E_{t}\left(\frac{M_{t+1}^{*}}{M_{t+1}}\right)+\log E_{t}\left(\frac{M_{t+1}^{*}}{M_{t+1} e^{-\eta_{t+1}}}\right)
\end{aligned}
$$

This last step leads to the result in the text as the second term is the entropy of the change in exchange rates.

\section{Proof of Corollary 5:}

Proof. The first result just follows from the definition of the log change in the exchange rate and the definition of the risk-free rate at home and abroad. The second result follows immediately because $E_{t}\left[r x_{t+1}^{F X}\right]+L_{t}\left(r x_{t+1}^{F X}\right)=$ $E_{t}\left[r x_{t+1}^{F X}\right]+L_{t}\left(S_{t+1} / S_{t}\right)$; only $S_{t+1} / S_{t}$ is random.

$$
\begin{aligned}
\Delta R P & =R P^{I M}-R P^{C M}=-L_{t}\left(\frac{M_{t+1}^{*}}{M_{t+1}}\right)+\mu_{t, \eta}+L_{t}\left(\frac{M_{t+1}^{*} e^{\eta_{t+1}}}{M_{t+1}}\right) \\
& =-L_{t}\left(e^{-\eta_{t+1}}\right)+\log E_{t}\left(e^{-\eta_{t+1}}\right)-\log E_{t}\left(\frac{M_{t+1}^{*}}{M_{t+1}}\right)+\log E_{t}\left(\frac{M_{t+1}^{*} e^{\eta_{t+1}}}{M_{t+1}}\right)+\mu_{t, \eta} \\
& =-\log E_{t}\left(\frac{M_{t+1}^{*}}{M_{t+1}}\right)+\log E_{t}\left(\frac{M_{t+1}^{*} e^{\eta_{t+1}}}{M_{t+1}}\right)=\Delta L+\mu_{t, \eta}
\end{aligned}
$$

The second line uses the entropy of a ratio of two random variables.

\section{Proof of Result 1:}

Proof. We start from the complete market benchmark. The conditional entropy of the pricing kernel $M_{t+1}$ is equal to:

$$
\begin{aligned}
L_{t}\left(M_{t+1}\right) & =L_{t}\left(e^{-\gamma \Delta c_{t+1}}\right)=L_{t}\left(e^{-\gamma w_{t+1}}\right)+L_{t}\left(e^{-\gamma z_{t+1}}\right) \\
& =\frac{\gamma^{2} \sigma^{2}}{2}+\varpi\left(e^{-\gamma \theta+(\gamma \delta)^{2} / 2}-1\right)+\gamma \varpi \theta .
\end{aligned}
$$

The entropy of the jump component is presented in Equation (24), page 1981 of Backus, Chernov, and Zin (2011) and derived in their Appendix A. The entropy of the 'complete spanning' exchange rate is given by:

$$
\begin{aligned}
L_{t}\left(\frac{M_{t+1}^{*}}{M_{t+1}}\right) & =L_{t}\left(e^{-\gamma\left(\Delta c_{t+1}^{*}-\Delta c_{t+1}\right)}\right)=L_{t}\left(e^{-\gamma w_{t+1}^{*}}\right)+L_{t}\left(e^{-\gamma z_{t+1}^{*}+\gamma z_{t+1}}\right)+L_{t}\left(e^{\gamma w_{t+1}}\right), \\
& =\frac{\gamma^{2, *} \sigma^{*, 2}}{2}+\frac{\gamma^{2} \sigma^{2}}{2}+\varpi\left(e^{-\gamma \theta^{*}+\gamma \theta-\gamma \gamma^{*} \rho_{z, z^{*}} \delta \delta^{*}+(\gamma \delta)^{2} / 2+\left(\gamma \delta^{*}\right)^{2} / 2}-1\right)+\gamma^{*} \varpi \theta^{*}-\gamma \varpi \theta .
\end{aligned}
$$


The log currency risk premium is given by the difference in the entropy of the domestic and the foreign pricing kernels:

$$
\begin{aligned}
E_{t}\left[r x_{t+1}^{F X}\right] & =-L_{t}\left(M_{t+1}^{*}\right)+L_{t}\left(M_{t+1}\right)=-L_{t}\left(e^{-\gamma \Delta c_{t+1}^{*}}\right)+L_{t}\left(e^{-\gamma \Delta c_{t+1}}\right), \\
& =-L_{t}\left(e^{-\gamma w_{t+1}^{*}}\right)-L_{t}\left(e^{-\gamma z_{t+1}^{*}}\right)+L_{t}\left(e^{-\gamma w_{t+1}}\right)+L_{t}\left(e^{-\gamma z_{t+1}}\right), \\
& =-\frac{\gamma^{2, *} \sigma^{*, 2}}{2}-\varpi\left(e^{-\gamma \theta^{*}+\left(\gamma \delta^{*}\right)^{2} / 2}-1\right) \\
& +\frac{\gamma^{2} \sigma^{2}}{2}+\varpi\left(e^{-\gamma \theta+(\gamma \delta)^{2} / 2}-1\right)-\left(\gamma^{*} \varpi \theta^{*}-\gamma \varpi \theta\right) .
\end{aligned}
$$

Hence, the foreign currency risk premium in levels is given by:

$$
\begin{aligned}
E_{t}\left[r x_{t+1}^{F X}\right]+L_{t}\left[r x_{t+1}^{F X}\right] & =\gamma^{2} \sigma^{2}+\varpi\left(e^{-\gamma \theta+(\gamma \delta)^{2} / 2}-1\right)-\varpi\left(e^{-\gamma \theta^{*}+\left(\gamma \delta^{*}\right)^{2} / 2}-1\right) \\
& +\varpi\left(e^{-\gamma \theta^{*}+\gamma \theta-2 \gamma \gamma^{*} \rho_{z, z^{*}} \delta \delta^{*}+(\gamma \delta)^{2} / 2+\left(\gamma \delta^{*}\right)^{2} / 2}-1\right) .
\end{aligned}
$$

Next, we introduce incomplete spanning as described in the main text. The conditional entropy of the perturbed pricing kernel is equal to:

$$
\begin{aligned}
L_{t}\left(M_{t+1} e^{-\eta_{t+1}}\right) & =L_{t}\left(e^{-\gamma \Delta c_{t+1}-\gamma e_{t+1}}\right)=L_{t}\left(e^{-\gamma w_{t+1}}\right)+L_{t}\left(e^{-\gamma z_{t+1}-\gamma d_{t+1}}\right) \\
& =\gamma^{2} \sigma^{2} / 2+\varpi\left(e^{-\gamma\left(\theta+\theta_{d}\right)+\gamma^{2} \delta \delta_{d} \rho_{z, d}+\left(\gamma \delta_{d}\right)^{2} / 2+(\gamma \delta)^{2} / 2}-1\right)+\gamma \varpi\left(\theta+\theta_{d}\right)
\end{aligned}
$$

The entropy of the sum of two Poisson mixtures $\left(L_{t}\left(e^{-\gamma z_{t+1}-\gamma d_{t+1}}\right)\right.$ above $)$ is a generalization of the result presented in Backus, Chernov, and Zin (2011). The co-entropy condition in Proposition 2, $\mu_{t, \eta}=L_{t}\left(M_{t+1} e^{-\eta_{t+1}}\right)-$ $L\left(M_{t+1}\right)$, implies here that:

$$
\begin{aligned}
\gamma \varpi \theta_{d} & =L_{t}\left(M_{t+1} e^{-\eta_{t+1}}\right)-L\left(M_{t+1}\right) \\
& =\varpi\left(e^{-\gamma\left(\theta+\theta_{d}\right)+\gamma^{2} \delta \delta_{d} \rho_{z, e}+\left(\gamma \delta_{d}\right)^{2} / 2+(\gamma \delta)^{2} / 2}-1\right)-\varpi\left(e^{-\gamma \theta+(\gamma \delta)^{2} / 2}-1\right)+\gamma \varpi \theta_{d}
\end{aligned}
$$

Simplifying, we obtain:

$$
0=e^{-\gamma\left(\theta+\theta_{d}\right)+\gamma^{2} \delta \delta_{d} \rho_{z, d}+\left(\gamma \delta_{d}\right)^{2} / 2+(\gamma \delta)^{2} / 2}-e^{-\gamma \theta+(\gamma \delta)^{2} / 2} .
$$

This leads to:

$$
-\gamma\left(\theta+\theta_{d}\right)+\gamma^{2} \delta \delta_{d} \rho_{z, d}+\left(\gamma \delta_{d}\right)^{2} / 2+(\gamma \delta)^{2} / 2=-\gamma \theta+(\gamma \delta)^{2} / 2
$$

This is equivalent to the following restriction on the wedge:

$$
-\gamma \theta_{d}+\gamma^{2} \delta \delta_{d} \rho_{z, d}+\left(\gamma \delta_{d}\right)^{2} / 2=0 .
$$

Next, we turn to the foreign pricing kernel. The conditional entropy of the perturbed pricing kernel is equal to:

$$
\begin{aligned}
L_{t}\left(M_{t+1}^{*} e^{\eta_{t+1}}\right) & =L_{t}\left(e^{-\gamma \Delta c_{t+1}^{*}+\gamma d_{t+1}}\right)=L_{t}\left(e^{-\gamma w_{t+1}^{*}}\right)+L_{t}\left(e^{-\gamma z_{t+1}+\gamma d_{t+1}}\right) \\
& =\gamma^{2} \sigma^{2, *} / 2+\varpi^{*}\left(e^{-\gamma\left(\theta^{*}-\theta_{e}^{*}\right)-\gamma^{2} \delta^{*} \delta_{d} \rho_{z^{*}, d}+\left(\gamma \delta_{d}^{*}\right)^{2} / 2+\left(\gamma \delta^{*}\right)^{2} / 2}-1\right)+\gamma \varpi\left(\theta^{*}\right)-\gamma \varpi\left(\theta_{d}\right)
\end{aligned}
$$

The co-entropy condition in Proposition $2,-\mu_{t, \eta}=L_{t}\left(M_{t+1}^{*} \exp \left(\eta_{t+1}\right)\right)-L\left(M_{t+1}^{*}\right)$, implies here that:

$$
\left[1-e^{\left.\gamma \theta_{d}-\gamma^{2} \delta \delta_{d} \rho_{z^{*}, d}+\left(\gamma \delta_{d}\right)^{2} / 2\right)}\right] \varpi e^{-\gamma \theta^{*}+\left(\gamma \delta^{*}\right)^{2} / 2}=0 .
$$

This is equivalent to the following condition:

$$
\gamma \theta_{d}-\gamma^{2} \delta^{*} \delta_{d} \rho_{z^{*}, d}+\left(\gamma \delta_{d}\right)^{2} / 2=0
$$


Collecting all of the no-arbitrage restrictions, we obtain the conditions first described in Result 1:

$$
\begin{aligned}
-\gamma \theta_{e}+\gamma^{2} \delta \delta_{e} \rho_{z, e}+\left(\gamma \delta_{e}\right)^{2} / 2 & =0 \\
\gamma \theta_{e}-\gamma^{2} \delta^{*} \delta_{e} \rho_{z^{*}, e}+\left(\gamma \delta_{e}\right)^{2} / 2 & =0 \\
\gamma^{2} \delta \delta_{e} \rho_{z, e}-\gamma^{2} \delta^{*} \delta_{e} \rho_{z^{*}, e}+\left(\gamma \delta_{e}\right)^{2} / 2 & =0 .
\end{aligned}
$$

The third condition is implied by the first two conditions.

We turn now to the entropy of the exchange rate. When markets are incomplete, the exchange rate's entropy is given by:

$$
\begin{aligned}
& L_{t}\left(\frac{M_{t+1}^{*} e^{\eta_{t+1}}}{M_{t+1}}\right)=L_{t}\left(e^{-\gamma \Delta c_{t+1}^{*}+\gamma d_{t+1}+\gamma \Delta c_{t+1}}\right), \\
& =L_{t}\left(e^{-\gamma w_{t+1}^{*}}\right)+L_{t}\left(e^{\gamma w_{t+1}}\right)+L_{t}\left(e^{-\gamma z_{t+1}^{*}+\gamma z_{t+1}+\gamma d_{t+1}}\right) \text {, } \\
& =\frac{\gamma^{2} \sigma^{*, 2}}{2}+\frac{\gamma^{2} \sigma^{2}}{2}+\gamma^{*} \varpi^{*} \theta^{*}-\gamma \varpi \theta-\gamma \varpi \theta_{d} \\
& +\varpi\left(e^{\gamma\left(\theta+\theta_{d}-\theta^{*}\right)-\gamma^{2} \delta^{*} \delta_{d} \rho_{z^{*}, d}+\gamma^{2} \delta \delta_{d} \rho_{z, d}-\gamma^{2} \rho_{z, z^{*}} \delta \delta^{*}+\frac{\left(\gamma \delta_{d}\right)^{2}}{2}+\frac{(\gamma \delta)^{2}}{2}+\frac{\left(\gamma \delta^{*}\right)^{2}}{2}}-1\right) .
\end{aligned}
$$

The entropy gap between the complete and incomplete spanning exchange rate is thus:

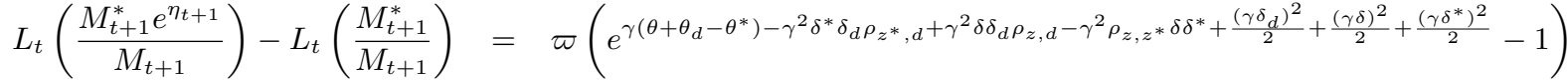

$$
\begin{aligned}
& -\gamma \varpi \theta_{d}-\varpi\left(e^{-\gamma \theta^{*}+\gamma \theta-\gamma^{2} \rho_{z, z^{*}} \delta \delta^{*}+(\gamma \delta)^{2} / 2+\left(\gamma \delta^{*}\right)^{2} / 2}-1\right)
\end{aligned}
$$

Using the no-arbitrage condition on the wedges $\gamma \theta_{d}=\gamma^{2} \delta^{*} \delta_{d} \rho_{z^{*}, d}-\left(\gamma \delta_{d}\right)^{2} / 2=0$, we obtain the following result:

$$
\begin{aligned}
& L_{t}\left(\frac{M_{t+1}^{*} e^{\eta_{t+1}}}{M_{t+1}}\right)-L_{t}\left(\frac{M_{t+1}^{*}}{M_{t+1}}\right)=\varpi\left(e^{\gamma\left(\theta-\theta^{*}\right)+\gamma^{2} \delta \delta_{d} \rho_{z, d}-\gamma^{2} \rho_{z, z^{*}} \delta \delta^{*}+\frac{(\gamma \delta)^{2}}{2}+\frac{\left(\gamma \delta^{*}\right)^{2}}{2}}-1\right) \\
& -\gamma \varpi \theta_{d} \varpi\left(e^{-\gamma \theta^{*}+\gamma \theta-\gamma^{2} \rho_{z, z^{*}} \delta \delta^{*}+\frac{(\gamma \delta)^{2}}{2}+\frac{\left(\gamma \delta^{*}\right)^{2}}{2}}-1\right) .
\end{aligned}
$$

This can be restated as :

$$
\begin{aligned}
\Delta L_{t}=L_{t}^{I M}-L_{t}^{C M} & =L_{t}\left(\frac{M_{t+1}^{*} e^{\eta_{t+1}}}{M_{t+1}}\right)-L_{t}\left(\frac{M_{t+1}^{*}}{M_{t+1}}\right) \\
& =-\gamma \varpi \theta_{d}+\varpi\left(e^{-\gamma \theta^{*}+\gamma \theta-\gamma^{2} \rho_{z, z^{*}} \delta \delta^{*}+\frac{(\gamma \delta)^{2}}{2}+\frac{\left(\gamma \delta^{*}\right)^{2}}{2}}\right)\left(e^{\gamma^{2} \delta \delta_{d} \rho_{z, d}}-1\right) .
\end{aligned}
$$

This is the second part of Result 1. Taking into account the no-arbitrage conditions on the wedge, when the wedge does not have a drift $\left(\theta_{d}=0\right)$ and the two countries share the same parameters $\left(\theta=\theta^{*}, \delta=\delta^{*}\right)$, we obtain:

$$
\Delta L_{t}=\varpi\left(e^{-\gamma^{2} \rho_{z, z^{*}} \delta^{2}+(\gamma \delta)^{2}}\right)\left(e^{\left(-\gamma^{2} \delta_{e}^{2}\right.}-1\right)<0 .
$$

Finally, we turn to the risk premium in levels on a long position in foreign currency, which is given by :

$$
E_{t}\left[r x_{t+1}^{F X}\right]+L_{t}\left(\frac{S_{t+1}}{S_{t}}\right)=L_{t}\left(M_{t+1}\right)-L_{t}\left(M_{t+1}^{*}\right)+\mu_{t, \eta}+L_{t}\left(\frac{M_{t+1}^{*} e^{\eta_{t+1}}}{M_{t+1}}\right) .
$$

Hence, the change in the risk premium from complete to incomplete spanning is given by the change in entropy, $L_{t}^{I M}-L_{t}^{C M}$, plus the drift term: $\gamma \varpi \theta_{d}$. As a result, the change in the risk premium is given by:

$$
\Delta R P_{t}=R P_{t}^{I M}-R P_{t}^{C M}=\varpi\left(e^{-\gamma \theta^{*}+\gamma \theta-\gamma^{2} \rho_{z, z^{*}} \delta \delta^{*}+\frac{(\gamma \delta)^{2}}{2}+\frac{\left(\gamma \delta^{*}\right)^{2}}{2}}\right)\left(e^{\gamma^{2} \delta \delta_{d} \rho_{z, d}}-1\right) .
$$

This is the third part of Result 1. 
Proof of Result 2:

Proof. We need to implement the following conditions:

$$
\begin{aligned}
& \operatorname{covar}_{t}\left(m_{t+1}^{*}, \eta_{t+1}\right)=-\mu_{t, \eta}-\frac{1}{2} \operatorname{var}_{t}\left(\eta_{t+1}\right), \\
& \operatorname{covar}_{t}\left(m_{t+1}, \eta_{t+1}\right)=-\mu_{t, \eta}+\frac{1}{2} \operatorname{var}_{t}\left(\eta_{t+1}\right),
\end{aligned}
$$

Using the expression for the SDF, we obtain the following conditions:

$$
\begin{aligned}
-\sqrt{\gamma^{*}} \sqrt{\left(\gamma^{*}-\lambda^{*}\right)} z_{t}^{*} & =-\left(\psi z_{t}+\psi^{*} z_{t}^{*}\right)-\frac{1}{2}\left((\gamma-\kappa) z_{t}+\left(\gamma^{*}-\kappa^{*}\right) z_{t}^{*}\right) \\
+\sqrt{\gamma} \sqrt{(\gamma-\lambda)} z_{t} & =-\left(\psi z_{t}+\psi^{*} z_{t}^{*}\right)+\frac{1}{2}\left((\gamma-\kappa) z_{t}+\left(\gamma^{*}-\kappa^{*}\right) z_{t}^{*}\right) .
\end{aligned}
$$

These conditions imply that:

$$
\begin{aligned}
\psi^{*} & =\frac{1}{2}\left(\gamma^{*}-\kappa^{*}\right), \\
\psi & =-\frac{1}{2}(\gamma-\kappa) .
\end{aligned}
$$

as well as:

$$
\begin{aligned}
-\sqrt{\gamma^{*}} \sqrt{\left(\gamma^{*}-\lambda^{*}\right)} & =-\psi^{*}-\frac{1}{2}\left(\gamma^{*}-\kappa^{*}\right)=-\left(\gamma^{*}-\kappa^{*}\right), \\
+\sqrt{\gamma} \sqrt{(\gamma-\lambda)} & =-\psi+\frac{1}{2}(\gamma-\kappa)=(\gamma-\kappa),
\end{aligned}
$$

where we have used the expressions for the $\psi$ 's. This delivers the following end result:

$$
\begin{aligned}
\gamma^{*}-\sqrt{\gamma^{*}} \sqrt{\left(\gamma^{*}-\lambda^{*}\right)} & =\kappa^{*}, \\
\gamma-\sqrt{\gamma} \sqrt{(\gamma-\lambda)} & =\kappa .
\end{aligned}
$$

\section{Proof of Result 3:}

Proof. The risk premium in logs on a long position in foreign currency is given by:

$$
\begin{aligned}
E_{t}\left[r x_{t+1}^{F X}\right] & =r_{t}^{f, *}-r_{t}^{f}+E_{t}\left(\Delta s_{t+1}\right)=\frac{1}{2}\left[\operatorname{var}_{t}\left(m_{t+1}\right)-\operatorname{var}_{t}\left(m_{t+1}^{*}+\eta_{t+1}\right)\right] \\
& =\frac{1}{2}\left[(\gamma+2 \psi) z_{t}-\left(\gamma^{*}-2 \psi^{*}\right) z_{t}^{*}\right] . \\
& =\frac{1}{2}\left[(\gamma-(\gamma-\kappa)) z_{t}-\left(\gamma^{*}-\left(\gamma^{*}-\kappa^{*}\right)\right) z_{t}^{*}\right] \\
& =\frac{1}{2}\left[\kappa z_{t}-\kappa^{*} z_{t}^{*}\right]
\end{aligned}
$$

The risk premium in levels on a long position in foreign currency is given by:

$$
\begin{aligned}
E_{t}\left[r x_{t+1}^{F X}\right]+\frac{1}{2} \operatorname{var}_{t}\left[r x_{t+1}^{F X}\right] & =-\operatorname{cov}_{t}\left(m_{t+1}, \Delta s_{t+1}\right) \\
& =\frac{1}{2}\left[(\kappa+\kappa) z_{t}-\left(\kappa^{*}-\kappa^{*}\right) z_{t}^{*}\right] \\
& =\kappa z_{t}
\end{aligned}
$$

Recall that the short rate is given by: $r_{t}=\alpha+\left(\chi-\frac{1}{2} \gamma\right) z_{t}$. Hence, the regression slope coefficient on $r_{t}-r_{t}^{*}$ is

$$
\frac{\operatorname{cov}\left(r x_{t+1}^{F X}, r_{t}-r_{t}^{*}\right)}{\operatorname{var}\left(r_{t}-r_{t}^{*}\right)}=\frac{.5 \kappa\left(\chi-\frac{1}{2} \gamma\right)+.5 \kappa^{*}\left(\chi-\frac{1}{2} \gamma^{*}\right)}{\left(\chi-\frac{1}{2} \gamma\right)^{2}+\left(\chi-\frac{1}{2} \gamma^{*}\right)^{2}}
$$


Hence, in the symmetric case, we end up with:

$$
\frac{.5 \kappa}{\left(\chi-\frac{1}{2} \gamma\right)}
$$

\section{B Three Examples}

This section presents three examples: a simple consumption-based example; a Cox, Ingersoll, and Ross (1985) model with common factors; a consumption-based example with heteroscedasticity. ${ }^{15}$

\section{B.1 A Simple Consumption-Based Example}

In this section, we study in detail the consumption-based example that is mentioned rapidly in the main text.

Complete Markets We start from the complete market benchmark. The model is described in the main text.

Result 4. The complete markets foreign currency risk premium in levels (defined from the perspective of the home investor) is given by:

$$
E_{t}\left[r x_{t+1}^{F X}\right]+L_{t}\left[r x_{t+1}^{F X}\right]=\gamma^{2} \sigma^{2}-\gamma^{2} \rho_{w, w^{*}} \sigma \sigma^{*}
$$

The proof of Result 4 is as follows.

Proof. The entropy of the domestic pricing kernel is given by:

$$
L_{t}\left(M_{t+1}\right)=L_{t}\left(e^{-\gamma \Delta c_{t+1}}\right)=\frac{\gamma^{2} \sigma^{2}}{2}
$$

As a result, the entropy of the exchange rate is:

$$
L_{t}\left(\frac{M_{t+1}^{*}}{M_{t+1}}\right)=L_{t}\left(e^{-\gamma w_{t+1}^{*}+\gamma w_{t+1}}\right)=\frac{\gamma^{2} \sigma^{* 2}}{2}+\frac{\gamma^{2} \sigma^{2}}{2}-\gamma^{2} \rho_{w, w^{*}} \sigma \sigma^{*} .
$$

When markets are complete, the log currency risk premium is given by the difference in the entropy of the domestic and the foreign pricing kernels:

$$
\begin{aligned}
E_{t}\left[r x_{t+1}^{F X}\right] & =-L_{t}\left(M_{t+1}^{*}\right)+L_{t}\left(M_{t+1}\right)=-L_{t}\left(e^{-\gamma \Delta c_{t+1}^{*}}\right)+L_{t}\left(e^{-\gamma \Delta c_{t+1}}\right) \\
& =-L_{t}\left(e^{-\gamma w_{t+1}^{*}}\right)+L_{t}\left(e^{-\gamma w_{t+1}}\right)=-\frac{\gamma^{2, *} \sigma^{*, 2}}{2}+\frac{\gamma^{2} \sigma^{2}}{2} .
\end{aligned}
$$

As a result, the currency risk premium in levels (defined from the perspective of the home investor) is given by:

$$
E_{t}\left[r x_{t+1}^{F X}\right]+L_{t}\left[\frac{S_{t+1}}{S_{t}}\right]=\gamma^{2} \sigma^{2}-\gamma^{2} \rho_{w, w^{*}} \sigma \sigma^{*} .
$$

Likewise, the currency risk premium in levels (defined from the perspective of the foreign investor) is given by:

$$
-E_{t}\left[r x_{t+1}^{F X}\right]+L_{t}\left[\frac{S_{t}}{S_{t+1}}\right]=\gamma^{2} \sigma^{* 2}-\gamma^{2} \rho_{w, w^{*}} \sigma \sigma^{*}
$$

\footnotetext{
${ }^{15}$ Other examples of multi-country term structure models that rely on the complete market assumption to address the carry trade and forward premium puzzle include Frachot (1996), Hodrick and Vassalou (2002), Brennan and Xia (2006), Graveline and Joslin (2011), Sarno, Schneider, and Wagner (2012), and Lustig, Roussanov, and Verdelhan $(2011,2014)$.
} 
Incomplete markets Next, we introduce incomplete spanning. Assume that the wedge takes the form $\eta_{t+1}=\gamma d_{t+1}$, where $d \sim N\left(\mu_{d}, \sigma_{d}^{2}\right)$.

Result 5. The wedge has to satisfy the following conditions:

$$
\begin{aligned}
\mu_{d} & =\frac{\gamma^{2} \sigma_{d}^{2}}{2}+\rho_{w, d} \gamma^{2} \sigma \sigma_{d} \\
-\mu_{d} & =\frac{\gamma^{2} \sigma_{d}^{2}}{2}-\rho_{w^{*}, d} \gamma^{2} \sigma^{*} \sigma_{d} .
\end{aligned}
$$

The change in exchange rate variance from complete to incomplete spanning is given by:

$$
\Delta \operatorname{Var}_{t}=\operatorname{Var}_{t}^{I M}-\operatorname{Var}_{t}^{C M}=-\gamma^{2} \sigma_{d}^{2} .
$$

The change in the currency risk premium (defined from the perspective of the home investor) from complete to incomplete spanning is given by:

$$
\Delta R P_{t}=R P_{t}^{I M}-R P_{t}^{C M}=\rho_{w, d} \gamma^{2} \sigma \sigma_{d} .
$$

The change in the currency risk premium (defined from the perspective of the foreign investor) from complete to incomplete spanning is:

$$
\Delta R P_{t}^{*}=R P_{t}^{* I M}-R P_{t}^{* C M}=-\rho_{w^{*}, d} \gamma^{2} \sigma \sigma_{d}
$$

Result 5 implies that in the symmetric case (when the drift of the wedge is zero), the change in the currency risk premium in level is $\Delta R P_{t}=\Delta R P_{t}^{*}=-.5 \gamma^{2} \sigma_{d}^{2}$. In that case, introducing a wedge decreases the currency risk premium from the perspective of both domestic and foreign agents. The Sharpe ratio declines as well:

$$
S R_{t}^{F X}=\frac{\gamma}{\sqrt{2}} \sqrt{\sigma^{2}(1-\rho)-\frac{\sigma_{d}^{2}}{2}}
$$

The proof of Result 5 is as follows:

Proof. The conditional entropy of the perturbed home pricing kernel is given by:

$$
L_{t}\left(M_{t+1} e^{-\eta_{t+1}}\right)=L_{t}\left(e^{-\gamma \Delta c_{t+1}-\gamma d_{t+1}}\right)=L_{t}\left(e^{-\gamma w_{t+1}-\gamma d_{t+1}}\right)=\frac{\gamma^{2} \sigma^{2}}{2}+\frac{\gamma^{2} \sigma_{d}^{2}}{2}+\rho_{w, d} \gamma^{2} \sigma \sigma_{d} .
$$

Applying Proposition 2, it then implies that the drift of the wedge satisfies:

$$
\mu_{e}=\frac{\gamma^{2} \sigma_{d}^{2}}{2}+\rho_{w, d} \gamma^{2} \sigma \sigma_{d}
$$

The conditional entropy of the perturbed foreign pricing kernel is equal to:

$$
L_{t}\left(M_{t+1}^{*} e^{\eta_{t+1}}\right)=L_{t}\left(e^{-\gamma \Delta c_{t+1}^{*}+\gamma d_{t+1}}\right)=L_{t}\left(e^{-\gamma w_{t+1}^{*}+\gamma d_{t+1}}\right)=\frac{\gamma^{2} \sigma^{2, *}}{2}+\frac{\gamma^{2} \sigma_{d}^{2}}{2}-\rho_{w^{*}, d} \gamma^{2} \sigma \sigma_{d} .
$$

Proposition 2 then implies that the drift of the wedge satisfies:

$$
-\mu_{d}=\frac{\gamma^{2} \sigma_{d}^{2}}{2}-\rho_{w^{*}, d} \gamma^{2} \sigma \sigma_{d}
$$

When markets are incomplete, the entropy of the 'incomplete spanning' exchange rate is given by:

$$
\begin{aligned}
L_{t}\left(\frac{M_{t+1}^{*} e^{\eta_{t+1}}}{M_{t+1}}\right) & =L_{t}\left(e^{-\gamma \Delta c_{t+1}^{*}+\gamma d_{t+1}+\gamma \Delta c_{t+1}}\right)=L_{t}\left(e^{-\gamma w_{t+1}^{*}+\gamma w_{t+1}+\gamma d_{t+1}}\right) \\
& =\frac{\gamma^{2} \sigma^{*, 2}}{2}+\frac{\gamma^{2} \sigma^{2}}{2}-\gamma^{2} \sigma^{*} \sigma_{d} \rho_{w^{*}, d}+\gamma^{2} \sigma \sigma_{d} \rho_{w, d}-\gamma^{2} \rho_{w, w^{*}} \sigma \sigma^{*}+\frac{\gamma^{2} \sigma_{d}^{2}}{2} .
\end{aligned}
$$

By summing the two conditions that define the drift of the wedge, one obtains that:

$$
0=\gamma^{2} \sigma_{d}^{2}+\rho_{w, d} \gamma^{2} \sigma \sigma_{d}-\rho_{w^{*}, d} \gamma^{2} \sigma \sigma_{d} .
$$


The entropy of the 'incomplete spanning' exchange rate is thus simply:

$$
L_{t}\left(\frac{M_{t+1}^{*} e^{\eta_{t+1}}}{M_{t+1}}\right)=\frac{\gamma^{2} \sigma^{*, 2}}{2}+\frac{\gamma^{2} \sigma^{2}}{2}-\gamma^{2} \rho_{w, w^{*}} \sigma \sigma^{*}-\frac{\gamma^{2} \sigma_{d}^{2}}{2} .
$$

The entropy gap between the complete and incomplete spanning exchange rate is then:

$$
\Delta L_{t}=L_{t}\left(\frac{M_{t+1}^{*} e^{\eta_{t+1}}}{M_{t+1}}\right)-L_{t}\left(\frac{M_{t+1}^{*}}{M_{t+1}}\right)=-\frac{\gamma^{2} \sigma_{d}^{2}}{2} .
$$

According to Proposition 5, the risk premium in levels on a long position in foreign currency is given by :

$$
E_{t}\left[r x_{t+1}^{F X}\right]+L_{t}\left(\frac{S_{t+1}}{S_{t}}\right)=L_{t}\left(M_{t+1}\right)-L_{t}\left(M_{t+1}^{*}\right)+\mu_{t, \eta}+L_{t}\left(\frac{M_{t+1}^{*} e^{\eta_{t+1}}}{M_{t+1}}\right) .
$$

The change in the risk premium from complete to incomplete spanning is thus given by the change in entropy, $-.5 \gamma^{2} \sigma_{d}^{2}$, plus the drift term, $\mu_{d}=0.5 \gamma^{2} \sigma_{d}^{2}+\rho_{w, d} \gamma^{2} \sigma \sigma_{d}$. The difference between the risk premium in incomplete and complete markets is:

$$
\Delta R P_{t}=R P_{t}^{I M}-R P_{t}^{C M}=\mu_{t, \eta}+L_{t}\left(\frac{M_{t+1}^{*} e^{\eta_{t+1}}}{M_{t+1}}\right)-L_{t}\left(\frac{M_{t+1}^{*}}{M_{t+1}}\right)=\rho_{w, d} \gamma^{2} \sigma \sigma_{d} .
$$

Similarly, the foreign risk premium in levels on a long position in foreign currency is given by :

$$
-E_{t}\left[r x_{t+1}^{F X}\right]+L_{t}\left(\frac{S_{t}}{S_{t+1}}\right)=-L_{t}\left(M_{t+1}\right)+L_{t}\left(M_{t+1}^{*}\right)-\mu_{t, \eta}+L_{t}\left(\frac{M_{t+1}}{M_{t+1}^{*} e^{\eta_{t+1}}}\right) .
$$

The change in the foreign risk premium from complete to incomplete spanning is given by:

$$
\Delta R P_{t}^{*}=R P_{t}^{* I M}-R P_{t}^{* C M}=-\rho_{w^{*}, d} \gamma^{2} \sigma \sigma_{d} .
$$

Proposition 2 implies that the restrictions on the wedges are given by:

$$
\begin{aligned}
\mu_{d} & =\gamma^{2} \sigma_{d}^{2} / 2+\rho_{w, d} \gamma^{2} \sigma \sigma_{d}, \\
-\mu_{d} & =\gamma^{2} \sigma_{e}^{2} / 2-\rho_{w^{*}, d} \gamma^{2} \sigma^{*} \sigma_{d} .
\end{aligned}
$$

\section{B.2 A Cox, Ingersoll, and Ross (1985) Example with Common Factors}

The stylized model in the main text rules out correlation of interest rates across countries. However, the key insights carry over to a setting with correlated interest rates. To show this result, we use a CIR model with common factors. The Cox, Ingersoll, and Ross (1985) model (denoted CIR) is defined by the following two equations:

$$
\begin{aligned}
-\log M_{t+1} & =\alpha+\chi z_{t}+\varphi z_{t}^{*}+\sqrt{\gamma z_{t}} u_{t+1}+\sqrt{\delta z_{t}^{*}} u_{t+1}^{*} \\
z_{t+1} & =(1-\phi) \theta+\phi z_{t}-\sigma \sqrt{z_{t}} u_{t+1} \\
z_{t+1}^{*} & =(1-\phi) \theta+\phi z_{t}-\sigma \sqrt{z_{t}^{*}} u_{t+1}^{*}
\end{aligned}
$$

where $u_{t+1} \sim \mathbb{N}(0,1)$ and $u_{t+1}^{*} \sim \mathbb{N}(0,1)$ are i.i.d. The foreign pricing kernel is specified as in Equation (30) with the same parameters. However, the foreign country has different loadings:

$$
-\log M_{t+1}=\alpha+\chi^{*} z_{t}+\varphi^{*} z_{t}^{*}+\sqrt{\gamma^{*} z_{t}} u_{t+1}+\sqrt{\delta^{*} z_{t}^{*}} u_{t+1}^{*} .
$$

To give content to the notion that $z_{t}$ is a domestic factor and $z_{t}^{*}$ is a foreign factor, we assume that $\gamma \geq \gamma^{*}$ and that $\delta \leq \delta^{*}$ : the domestic (foreign) pricing kernel is more exposed to the domestic (foreign) shock than the foreign (domestic) pricing kernel. We assume that investors can trade the domestic risk-free and at least two risky 
domestic assets ${ }^{16}$, but they can only trade the foreign risk-free asset. The squared maximum SRs at home and abroad are, respectively, $\operatorname{var}_{t}\left(m_{t+1}\right)=\gamma z_{t}+\delta z_{t}^{*}$, and $\operatorname{var}_{t}\left(m_{t+1}^{*}\right)=\gamma^{*} z_{t}+\delta^{*} z_{t}^{*}$.

We denote the target volatility of the incomplete markets exchange rate can be stated as: $\operatorname{var}_{t}\left(\Delta s_{t+1}\right)=$ $\kappa z_{t}+\kappa^{*} z_{t}^{*}$. We can compute the implied volatility of the incomplete markets exchange rate process using our formula:

$$
\operatorname{var}_{t}\left(\Delta s_{t+1}\right)=\left(\gamma+\gamma^{*}-2 \sqrt{\gamma} \sqrt{\gamma^{*}}\right) z_{t}+\left(\delta+\delta^{*}-2 \sqrt{\delta} \sqrt{\delta^{*}}\right) z_{t}^{*}-\operatorname{var}_{t}\left(\eta_{t+1}\right) .
$$

Then we simply choose the volatility of the noise to be equal to: $\operatorname{var}_{t}\left(\eta_{t+1}\right)=\left(\gamma+\gamma^{*}-\kappa\right) z_{t}+\left(\delta+\delta^{*}-\kappa^{*}\right) z_{t}^{*}$.

Result 6. In the CIR model with country-specific factors, we can define an exchange rate process $S_{t}$ that satisfies $\Delta s_{t+1}=\eta_{t+1}+m_{t+1}^{*}-m_{t+1}$ with variance $\operatorname{var}_{t}\left(\Delta s_{t+1}\right)=\kappa z_{t}+\kappa^{*} z_{t}^{*}$. where $\eta_{t}$ follows:

$$
\begin{aligned}
\eta_{t+1} & =\beta+\psi z_{t}+\psi^{*} z_{t}^{*}-\sqrt{\left(\gamma+\gamma^{*}-2 \sqrt{\gamma} \sqrt{\gamma^{*}}-\lambda\right) z_{t}} u_{t+1}+\sqrt{\left(\delta+\delta^{*}-2 \sqrt{\delta} \sqrt{\delta^{*}}-\lambda^{*}\right) z_{t}^{*}} u_{t+1}^{*} \\
& +\sqrt{(\lambda-\kappa) z_{t}} \epsilon_{t+1}+\sqrt{\left(\lambda^{*}-\kappa^{*}\right) z_{t}^{*}} \epsilon_{t+1}^{*}
\end{aligned}
$$

where $\epsilon_{t+1}$ and $\epsilon_{t+1}^{*}$ are $\sim N(0,1), \kappa \leq \lambda \leq \gamma+\gamma^{*}-2 \sqrt{\gamma} \sqrt{\gamma^{*}}$ and $\kappa^{*} \leq \lambda^{*} \leq \delta+\delta^{*}-2 \sqrt{\delta} \sqrt{\delta^{*}}$. The drift imputed to exchange rates is given by $\mu_{t, \eta}=\beta+\psi z_{t}+\psi^{*} z_{t}^{*}$. where $\epsilon_{t+1}$ and $\epsilon_{t+1}^{*}$ are $\sim N(0,1), \kappa \leq \lambda \leq \gamma$ and $\kappa^{*} \leq \lambda^{*} \leq \gamma^{*}$ satisfies:

$$
\begin{aligned}
\kappa & \left.=-\left(\sqrt{\gamma}+\sqrt{\gamma^{*}}\right) \sqrt{\left(\gamma+\gamma^{*}-2 \sqrt{\gamma} \sqrt{\gamma^{*}}-\lambda\right)}\right)+\gamma+\gamma^{*}-2 \sqrt{\gamma} \sqrt{\gamma^{*}}, \\
\kappa^{*} & \left.=-\left(\sqrt{\delta}+\sqrt{\delta^{*}}\right) \sqrt{\left(\delta+\delta^{*}-2 \sqrt{\delta} \sqrt{\delta^{*}}-\lambda^{*}\right)}\right)+\delta+\delta^{*}-2 \sqrt{\delta} \sqrt{\delta^{*}}, \\
\psi & =-(1 / 2)\left(\sqrt{\gamma}-\sqrt{\gamma^{*}}\right) \sqrt{\gamma+\gamma^{*}-2 \sqrt{\gamma} \sqrt{\gamma^{*}}-\lambda}, \\
\psi^{*} & =-(1 / 2)\left(\sqrt{\delta}-\sqrt{\delta^{*}}\right) \sqrt{\delta+\delta^{*}-2 \sqrt{\delta} \sqrt{\delta^{*}}-\lambda^{*}} .
\end{aligned}
$$

If we allowed domestic investors to trade two foreign risky assets, then the wedges disappear. The additional covariance restrictions in (12) imply that $\kappa=\lambda=\gamma+\gamma^{*}-2 \sqrt{\gamma} \sqrt{\gamma^{*}}$ and $\kappa^{*}=\lambda^{*}=\delta+\delta^{*}-2 \sqrt{\delta} \sqrt{\delta^{*}}$, because the log returns are affine in the shocks. This in turn implies that the wedges are zero $(\eta=0)$.

The proof of Result 6 is as follows:

Proof. Hence, we can write a square root process for $\eta$ :

$$
\begin{aligned}
\eta_{t+1} & =\beta+\psi z_{t}+\psi^{*} z_{t}^{*}-\sqrt{\left(\gamma+\gamma^{*}-2 \sqrt{\gamma} \sqrt{\gamma^{*}}-\lambda\right) z_{t}} u_{t+1}+\sqrt{\left(\delta+\delta^{*}-2 \sqrt{\delta} \sqrt{\delta^{*}}-\lambda^{*}\right) z_{t}^{*}} u_{t+1}^{*} \\
& +\sqrt{(\lambda-\kappa) z_{t}} \epsilon_{t+1}+\sqrt{\left(\lambda^{*}-\kappa^{*}\right) z_{t}^{*}} \epsilon_{t+1}^{*}
\end{aligned}
$$

where $\epsilon_{t+1}$ and $\epsilon_{t+1}^{*}$ are $\sim N(0,1), \kappa \leq \lambda \leq \gamma$ and $\kappa^{*} \leq \lambda^{*} \leq \gamma^{*}$. The drift imputed to exchange rates is given by $\mu_{t, \eta}=\beta+\psi z_{t}+\psi^{*} z_{t}^{*}$.

To ensure that the Euler equations for the risk-free are satisfied, we also need to implement the following conditions:

$$
\begin{aligned}
\operatorname{covar}_{t}\left(m_{t+1}^{*}, \eta_{t+1}\right) & =-\mu_{t, \eta}-\frac{1}{2} \operatorname{var}_{t}\left(\eta_{t+1}\right), \\
\operatorname{covar}_{t}\left(m_{t+1}, \eta_{t+1}\right) & =-\mu_{t, \eta}+\frac{1}{2} \operatorname{var}_{t}\left(\eta_{t+1}\right)
\end{aligned}
$$

\footnotetext{
${ }^{16}$ If they can trade two different longer maturity bonds, then the domestically traded assets span all of the shocks.
} 
Using the expressions for the log SDFs and $\eta$, these expressions can be restated as follows:

$$
\begin{aligned}
& -\sqrt{\gamma^{*}} \sqrt{\left(\gamma+\gamma^{*}-2 \sqrt{\gamma} \sqrt{\gamma^{*}}-\lambda\right)} z_{t}-\sqrt{\delta *} \sqrt{\left(\delta+\delta^{*}-2 \sqrt{\delta} \sqrt{\delta^{*}}-\lambda^{*}\right)} z_{t}^{*} \\
& =-\left(\psi z_{t}+\psi^{*} z_{t}^{*}\right)-\frac{1}{2}\left(\left(\gamma+\gamma^{*}-2 \sqrt{\gamma} \sqrt{\gamma^{*}}-\kappa\right) z_{t}+\left(\delta+\delta^{*}-2 \sqrt{\delta} \sqrt{\delta^{*}}-\kappa^{*}\right) z_{t}^{*}\right), \\
& +\sqrt{\gamma} \sqrt{\left(\gamma+\gamma^{*}-2 \sqrt{\gamma} \sqrt{\gamma^{*}}-\lambda\right)} z_{t}+\sqrt{\delta} \sqrt{\left(\delta+\delta^{*}-2 \sqrt{\delta} \sqrt{\delta^{*}}-\lambda\right)} z_{t}^{*} \\
& =-\left(\psi z_{t}+\psi^{*} z_{t}^{*}\right)+\frac{1}{2}\left(\left(\gamma+\gamma^{*}-2 \sqrt{\gamma} \sqrt{\gamma^{*}}-\kappa\right) z_{t}+\left(\delta+\delta^{*}-2 \sqrt{\delta} \sqrt{\delta^{*}}-\kappa^{*}\right) z_{t}^{*}\right) .
\end{aligned}
$$

By collecting the terms in $z_{t}$ and $z_{t}^{*}$, we obtain the following four equations that need to be solved for 4 unknowns:

$$
\begin{aligned}
& -\sqrt{\gamma^{*}} \sqrt{\left(\gamma+\gamma^{*}-2 \sqrt{\gamma} \sqrt{\gamma^{*}}-\lambda\right)}=-(\psi)-\frac{1}{2}\left(\gamma+\gamma^{*}-2 \sqrt{\gamma} \sqrt{\gamma^{*}}-\kappa\right), \\
& -\sqrt{\delta^{*}} \sqrt{\left(\delta+\delta^{*}-2 \sqrt{\delta} \sqrt{\delta^{*}}-\lambda^{*}\right)}=-\left(\psi^{*}\right)-\frac{1}{2}\left(\delta+\delta^{*}-2 \sqrt{\delta} \sqrt{\delta^{*}}-\kappa^{*}\right) . \\
& +\sqrt{\gamma} \sqrt{\left(\gamma+\gamma^{*}-2 \sqrt{\gamma} \sqrt{\gamma^{*}}-\lambda\right)}=-(\psi)+\frac{1}{2}\left(\gamma+\gamma^{*}-2 \sqrt{\gamma} \sqrt{\gamma^{*}}-\kappa\right) \\
& +\sqrt{\delta} \sqrt{\left(\delta+\delta^{*}-2 \sqrt{\delta} \sqrt{\delta^{*}}-\kappa\right)}=-\left(\psi^{*}\right)+\frac{1}{2}\left(\delta+\delta^{*}-2 \sqrt{\delta} \sqrt{\delta^{*}}-\kappa^{*}\right) .
\end{aligned}
$$

By adding the 1st and 3rd, and the 2nd and 4th equation, we obtain the following expression for the drift terms:

$$
\begin{aligned}
& \left.\left(\sqrt{\gamma}-\sqrt{\gamma^{*}}\right) \sqrt{\gamma+\gamma^{*}-2 \sqrt{\gamma} \sqrt{\gamma^{*}}-\lambda}=-2 \psi\right), \\
& \left(\sqrt{\delta}-\sqrt{\delta^{*}}\right) \sqrt{\delta+\delta^{*}-2 \sqrt{\delta} \sqrt{\delta^{*}}-\lambda^{*}}=-2 \psi^{*} .
\end{aligned}
$$

By substituting for $\psi$ and $\psi^{*}$ in the original four equations, we obtain the following conditions:

$$
\begin{aligned}
+\sqrt{\gamma} \sqrt{\left(\gamma+\gamma^{*}-2 \sqrt{\gamma} \sqrt{\gamma^{*}}-\lambda\right)} & =+\frac{1}{2}\left(\sqrt{\gamma}-\sqrt{\gamma^{*}}\right) \sqrt{\left(\gamma+\gamma^{*}-2 \sqrt{\gamma} \sqrt{\gamma^{*}}-\lambda\right)}+\frac{1}{2}\left(\gamma+\gamma^{*}-2 \sqrt{\gamma} \sqrt{\gamma^{*}}-\kappa\right), \\
-\sqrt{\delta^{*}} \sqrt{\left(\delta+\delta^{*}-2 \sqrt{\delta} \sqrt{\delta^{*}}-\lambda^{*}\right)} & =+\frac{1}{2}\left(\sqrt{\delta}-\sqrt{\delta^{*}}\right) \sqrt{\left(\delta+\delta^{*}-2 \sqrt{\delta} \sqrt{\delta^{*}}-\lambda^{*}\right)}+\frac{1}{2}\left(\delta+\delta^{*}-2 \sqrt{\delta} \sqrt{\delta^{*}}-\kappa^{*}\right) .
\end{aligned}
$$

These conditions can be solved for $\kappa$ and $\kappa^{*}$ :

$$
\begin{aligned}
\kappa & =-2 \sqrt{\gamma} \sqrt{\left(\gamma+\gamma^{*}-2 \sqrt{\gamma} \sqrt{\gamma^{*}}-\lambda\right)}+\left(\sqrt{\gamma}-\sqrt{\gamma^{*}}\right) \sqrt{\left(\gamma+\gamma^{*}-2 \sqrt{\gamma} \sqrt{\gamma^{*}}-\lambda\right)}+\left(\gamma+\gamma^{*}-2 \sqrt{\gamma} \sqrt{\gamma^{*}}\right), \\
\kappa^{*} & =+2 \sqrt{\delta^{*}} \sqrt{\left(\delta+\delta^{*}-2 \sqrt{\delta} \sqrt{\delta^{*}}-\lambda^{*}\right)}+\left(\sqrt{\delta}-\sqrt{\delta^{*}}\right) \sqrt{\left(\delta+\delta^{*}-2 \sqrt{\delta} \sqrt{\delta^{*}}-\lambda^{*}\right)}+\left(\delta+\delta^{*}-2 \sqrt{\delta} \sqrt{\delta^{*}}\right) .
\end{aligned}
$$

These conditions imply that:

$$
\begin{aligned}
\kappa & \left.=-\left(\sqrt{\gamma}+\sqrt{\gamma^{*}}\right) \sqrt{\left(\gamma+\gamma^{*}-2 \sqrt{\gamma} \sqrt{\gamma^{*}}-\lambda\right)}\right)+\gamma+\gamma^{*}-2 \sqrt{\gamma} \sqrt{\gamma^{*}}, \\
\kappa^{*} & \left.=-\left(\sqrt{\delta}+\sqrt{\delta^{*}}\right) \sqrt{\left(\delta+\delta^{*}-2 \sqrt{\delta} \sqrt{\delta^{*}}-\lambda^{*}\right)}\right)+\delta+\delta^{*}-2 \sqrt{\delta} \sqrt{\delta^{*}} .
\end{aligned}
$$

Result 7. The risk premium in logs on a long position in foreign currency is:

$$
\begin{aligned}
E_{t}\left[r x_{t+1}^{F X}\right] & =\frac{1}{2}\left[\gamma-\gamma^{*}-\left(\sqrt{\gamma}-\sqrt{\gamma^{*}}\right) \sqrt{\gamma+\gamma^{*}-2 \sqrt{\gamma} \sqrt{\gamma^{*}}-\lambda}\right] z_{t} \\
& +\frac{1}{2}\left[\delta-\delta^{*}-\left(\sqrt{\delta}-\sqrt{\delta^{*}}\right) \sqrt{\delta+\delta^{*}-2 \sqrt{\delta} \sqrt{\delta^{*}}-\lambda^{*}}\right] z_{t}^{*}
\end{aligned}
$$


The risk premium in levels on a long position in foreign currency is given by:

$$
\begin{aligned}
E_{t}\left[r x_{t+1}^{F X}\right]+\frac{1}{2} \operatorname{var}_{t}\left[r x_{t+1}^{F X}\right] & =\left[\gamma-\sqrt{\gamma} \sqrt{\left(\gamma+\gamma^{*}-2 \sqrt{\gamma} \sqrt{\gamma^{*}}-\lambda\right)}-\sqrt{\gamma} \sqrt{\gamma^{*}}\right] z_{t} \\
& +\left[\delta-\sqrt{\delta} \sqrt{\left(\delta+\delta^{*}-2 \sqrt{\delta} \sqrt{\delta^{*}}-\lambda^{*}\right)}-\sqrt{\delta} \sqrt{\delta^{*}}\right] z_{t}^{*} .
\end{aligned}
$$

These expressions can readily be compared to the complete markets log currency risk premium, $\frac{1}{2}\left[\left(\gamma-\gamma^{*}\right) z_{t}+\left(\delta-\delta^{*}\right) z_{t}^{*}\right]$, and the complete markets risk premium in levels, $\left(\gamma-\sqrt{\gamma} \sqrt{\gamma^{*}}\right) z_{t}+\left(\delta-\sqrt{\delta} \sqrt{\delta^{*}}\right) z_{t}^{*}$. Clearly, this establishes that the incomplete markets risk premium in levels is always smaller than the complete markets risk premium. In addition, there is less return predictability as well.

The proof of Result 7 is as follows:

Proof. Note that the risk premium in logs is given by

$$
\begin{aligned}
E_{t}\left[r x_{t+1}^{F X}\right] & =r_{t}^{f, *}-r_{t}^{f}+E_{t}\left(\Delta s_{t+1}\right)=\frac{1}{2}\left[\operatorname{var}_{t}\left(m_{t+1}\right)-\operatorname{var}_{t}\left(m_{t+1}^{*}+\eta_{t+1}\right)\right] \\
& \left.=\frac{1}{2}\left[\left(\gamma-\gamma^{*}+2 \psi\right) z_{t}+\left(\delta-\delta^{*}+2 \psi^{*}\right) z_{t}^{*}\right)\right] \\
& =\frac{1}{2}\left[\gamma-\gamma^{*}-\left(\sqrt{\gamma}-\sqrt{\gamma^{*}}\right) \sqrt{\gamma+\gamma^{*}-2 \sqrt{\gamma} \sqrt{\gamma^{*}}-\lambda}\right] z_{t} \\
& +\frac{1}{2}\left[\delta-\delta^{*}-\left(\sqrt{\delta}-\sqrt{\delta^{*}}\right) \sqrt{\delta+\delta^{*}-2 \sqrt{\delta} \sqrt{\delta^{*}}-\lambda^{*}}\right] z_{t}^{*}
\end{aligned}
$$

The risk premium in levels on a long position in foreign currency is given by:

$$
\begin{aligned}
& E_{t}\left[r x_{t+1}^{F X}\right]+\frac{1}{2} \operatorname{var}_{t}\left[r x_{t+1}^{F X}\right]=-\operatorname{cov}_{t}\left(m_{t+1}, \Delta s_{t+1}\right) \\
& \left.=\frac{1}{2}\left[\left(\gamma-\gamma^{*}+2 \psi+\kappa\right) z_{t}+\left(\delta-\delta^{*}+2 \psi^{*}+\kappa^{*}\right) z_{t}^{*}\right)\right] \\
& =\frac{1}{2}\left[\gamma-\gamma^{*}+\kappa-\left(\sqrt{\gamma}-\sqrt{\gamma^{*}}\right) \sqrt{\gamma+\gamma^{*}-2 \sqrt{\gamma} \sqrt{\gamma^{*}}-\lambda}\right] z_{t} \\
& +\frac{1}{2}\left[\delta-\delta^{*}+\kappa^{*}-\left(\sqrt{\delta}-\sqrt{\delta^{*}}\right) \sqrt{\delta+\delta^{*}-2 \sqrt{\delta} \sqrt{\delta^{*}}-\lambda^{*}}\right] z_{t}^{*}, \\
& =\frac{1}{2}\left[\gamma-\gamma^{*}-2 \sqrt{\gamma} \sqrt{\left(\gamma+\gamma^{*}-2 \sqrt{\gamma} \sqrt{\gamma^{*}}-\lambda\right)}+\left(\gamma+\gamma^{*}-2 \sqrt{\gamma} \sqrt{\gamma^{*}}\right)\right] z_{t} \\
& +\frac{1}{2}\left[\delta-\delta^{*}+2 \sqrt{\delta^{*}} \sqrt{\left(\delta+\delta^{*}-2 \sqrt{\delta} \sqrt{\delta^{*}}-\lambda^{*}\right)}+\left(\delta+\delta^{*}-2 \sqrt{\delta} \sqrt{\delta^{*}}\right)\right] z_{t}^{*} \\
& =\left[\gamma-\sqrt{\gamma} \sqrt{\left(\gamma+\gamma^{*}-2 \sqrt{\gamma} \sqrt{\gamma^{*}}-\lambda\right)}-\sqrt{\gamma} \sqrt{\gamma^{*}}\right] z_{t} \\
& +\left[\delta-\sqrt{\delta} \sqrt{\left(\delta+\delta^{*}-2 \sqrt{\delta} \sqrt{\delta^{*}}-\lambda^{*}\right)}-\sqrt{\delta} \sqrt{\delta^{*}}\right] z_{t}^{*}
\end{aligned}
$$

Result 8. The Fama slope coefficient in a regression of log currency excess returns on $f_{t}-s_{t}=r_{t}-r_{t}^{*}$ is

$$
\begin{aligned}
& \frac{\operatorname{cov}\left(r x_{t+1}^{F X}, f_{t}-s_{t}\right)}{\operatorname{var}\left(f_{t}-s_{t}\right)} \\
= & \frac{.5\left(\gamma-\gamma^{*}-\left(\sqrt{\gamma}-\sqrt{\gamma^{*}}\right) \sqrt{\left.\gamma+\gamma^{*}-2 \sqrt{\gamma} \sqrt{\gamma^{*}}-\lambda\right)\left(\left(\chi-\frac{1}{2} \gamma\right)-\left(\chi^{*}-\frac{1}{2} \gamma^{*}\right)\right)}\right.}{\left(\left(\chi-\frac{1}{2} \gamma\right)-\left(\chi^{*}-\frac{1}{2} \gamma^{*}\right)\right)^{2}+\left(\left(\phi-\frac{1}{2} \delta\right)-\left(\phi^{*}-\frac{1}{2} \delta^{*}\right)\right)^{2}} \\
+ & \frac{.5\left(\delta-\delta^{*}-\left(\sqrt{\delta}-\sqrt{\delta^{*}}\right) \sqrt{\delta+\delta^{*}-2 \sqrt{\delta} \sqrt{\delta^{*}}-\lambda^{*}}\right)\left(\left(\phi-\frac{1}{2} \delta\right)-\left(\phi^{*}-\frac{1}{2} \delta^{*}\right)\right)}{\left(\left(\chi-\frac{1}{2} \gamma\right)-\left(\chi^{*}-\frac{1}{2} \gamma^{*}\right)\right)^{2}+\left(\left(\phi-\frac{1}{2} \delta\right)-\left(\phi^{*}-\frac{1}{2} \delta^{*}\right)\right)^{2}}
\end{aligned}
$$


In the relevant region of the parameter space, $\left(\chi-\frac{1}{2} \gamma\right)-\left(\chi^{*}-\frac{1}{2} \gamma^{*}\right)<0$ and $\left(\phi-\frac{1}{2} \delta\right)-\left(\phi^{*}-\frac{1}{2} \delta^{*}\right)>0$. Then the interest rate spread $r_{t}-r_{t}^{*}$ decreases (increases) when $z_{t}$ increases ( $z_{t}^{*}$ decreases) -the precautionary motive dominates. This is needed to account for U.I.P. deviations in the data. As a benchmark, we note that the complete markets slope coefficient is given by:

$$
=\frac{.5(\gamma)\left(\left(\chi-\frac{1}{2} \gamma\right)-\left(\chi^{*}-\frac{1}{2} \gamma^{*}\right)\right)+.5(\delta)\left(\left(\phi-\frac{1}{2} \delta\right)-\left(\phi^{*}-\frac{1}{2} \delta^{*}\right)\right)}{\left(\left(\chi-\frac{1}{2} \gamma\right)-\left(\chi^{*}-\frac{1}{2} \gamma^{*}\right)\right)^{2}+\left(\left(\phi-\frac{1}{2} \delta\right)-\left(\phi^{*}-\frac{1}{2} \delta^{*}\right)\right)^{2}}
$$

Recall that $\gamma \geq \gamma^{*}$ and $\delta \leq \delta^{*}$. As a result, the first term now decreases in absolute value relative to the complete markets case. The second term decreases as well in absolute value. Even in the model with common factors, the slope coefficients in the predictability regression are pushed closer to zero by the incomplete spanning and we get closer to U.I.P.

The proof of Result 8 is as follows:

Proof. Recall that the short rate is given by: $r_{t}=\alpha+\left(\chi-\frac{1}{2} \gamma\right) z_{t}+\left(\phi-\frac{1}{2} \delta\right) z_{t}^{*}$. Hence, the regression slope coefficient on $f_{t}-s_{t}=r_{t}-r_{t}^{*}$ is

$$
\begin{aligned}
& \frac{\operatorname{cov}\left(r x_{t+1}^{F X}, f_{t}-s_{t}\right)}{\operatorname{var}\left(f_{t}-s_{t}\right)}= \\
& \frac{.5\left(\gamma-\gamma^{*}-\left(\sqrt{\gamma}-\sqrt{\gamma^{*}}\right) \sqrt{\left.\gamma+\gamma^{*}-2 \sqrt{\gamma} \sqrt{\gamma^{*}}-\lambda\right)}\left(\left(\chi-\frac{1}{2} \gamma\right)-\left(\chi^{*}-\frac{1}{2} \gamma^{*}\right)\right)\right.}{\left(\left(\chi-\frac{1}{2} \gamma\right)-\left(\chi^{*}-\frac{1}{2} \gamma^{*}\right)\right)^{2}+\left(\left(\phi-\frac{1}{2} \delta\right)-\left(\phi^{*}-\frac{1}{2} \delta^{*}\right)\right)^{2}} \\
+ & \frac{.5\left(\delta-\delta^{*}-\left(\sqrt{\delta}-\sqrt{\delta^{*}}\right) \sqrt{\delta+\delta^{*}-2 \sqrt{\delta} \sqrt{\delta^{*}}-\lambda^{*}}\right)\left(\left(\phi-\frac{1}{2} \delta\right)-\left(\phi^{*}-\frac{1}{2} \delta^{*}\right)\right)}{\left(\left(\chi-\frac{1}{2} \gamma\right)-\left(\chi^{*}-\frac{1}{2} \gamma^{*}\right)\right)^{2}+\left(\left(\phi-\frac{1}{2} \delta\right)-\left(\phi^{*}-\frac{1}{2} \delta^{*}\right)\right)^{2}}
\end{aligned}
$$

\section{B.3 A Consumption-Based Example with Heteroscedasticity}

To develop some economic intuition for the dynamics of these wedges, we look at a version of the two-country Lucas (1982) model with heteroskedastic consumption growth. This model produces time-varying risk premia. We use $\delta$ to denote the rate of time preference and $\gamma$ to denote the coefficient of relative risk aversion. The real stochastic discount factor is thus given by:

$$
\begin{aligned}
-\log M_{t+1} & =-\left(\log \delta-\gamma \mu_{g}\right)+\gamma \sigma_{g, t} e_{t+1}, \\
\sigma_{g, t}^{2} & =(1-\phi) \theta+\phi \sigma_{g, t}^{2}-\sigma_{g, t} e_{t+1}, \\
-\log M_{t+1}^{*} & =-\left(\log \delta-\gamma \mu_{g}\right)+\gamma \sigma_{g, t}^{*} e_{t+1}^{*}, \\
\sigma_{g, t}^{2, *} & =(1-\phi) \theta+\phi \sigma_{g, t}^{2, *}-\sigma_{g, t}^{*} e_{t+1}^{*}
\end{aligned}
$$

where $\Delta c_{t+1}=\mu_{g}+\sigma_{g, t} e_{t+1}$, and $\Delta c_{t+1}=\mu_{g}+\sigma_{g, t}^{*} e_{t+1}^{*}$. The consumption growth innovations $e_{t+1} \sim \mathbb{N}(0,1)$ and $e_{t+1}^{*} \sim \mathbb{N}(0,1)$ are i.i.d. as well as uncorrelated across countries. When markets are complete, the exchange rate variance is thus $\operatorname{var}_{t}\left(\Delta s_{t+1}\right)=\gamma^{2} \sigma_{g, t}^{2}+\gamma^{2, *} \sigma_{g, t}^{2, *}$. Domestic investors can invest in the domestic risk-free and at least one domestic risky asset (e.g. a longer maturity real zero-coupon bond), and the foreign risk-free, but they cannot invest in foreign risky assets. Hence, only the domestic shocks are spanned.

In this model, we can back out the dynamic process for the wedges that satisfy the necessary conditions of Proposition 1. It turns out that all the wedges take the form:

$$
\begin{aligned}
\eta_{t+1}=\psi \sigma_{g, t}+\psi^{*} \sigma_{g, t}^{*} & -\sqrt{\left(\gamma^{2}-\lambda\right)} \sigma_{g, t} e_{t+1}+\sqrt{\left(\gamma^{2}-\lambda^{*}\right)} \sigma_{g, t}^{*} e_{t+1}^{*} \\
& +\sqrt{(\lambda-\kappa)} \sigma_{g, t} \epsilon_{t+1}+\sqrt{\left(\lambda-\kappa^{*}\right)} \sigma_{g, t}^{*} \epsilon_{t+1}^{*}
\end{aligned}
$$

where $\epsilon_{t+1}$ and $\epsilon_{t+1}^{*}$ are standard i.i.d. Gaussian shocks uncorrelated with the consumption growth innovations $e_{t+1}$ and $e_{t+1}^{*}$. These shocks are the unspanned component of the exchange rate changes. The parameters $\kappa$ and $\kappa^{*}$ govern the volatility of the exchange rate when markets are incomplete: $\operatorname{var}_{t}\left(\Delta s_{t+1}\right)=\kappa \sigma_{g, t}^{2}+\kappa^{*} \sigma_{g, t}^{2, *}$. These 
wedges only affect exchange rates, and as a result, the returns on foreign investments. The returns on domestic investments remain unchanged.

The parameters $\kappa$ and $\kappa^{*}$ are the only two degrees of freedom in the law of motion of the wedge. The other parameters that describe the wedge are implied. The drift term (denoted $\mu_{t, \eta}$ in Proposition 1 and here equal to $\psi \sigma_{g, t}+\psi^{*} \sigma_{g, t}^{*}$ ) is governed by the consumption growth volatilities; it is determined by the no-arbitrage conditions, which imply that $\psi=-\frac{1}{2}\left(\gamma^{2}-\kappa\right)$, and $\psi^{*}=\frac{1}{2}\left(\gamma^{2}-\kappa^{*}\right)$. The unexpected component of the wedge depends on the parameters $\lambda$ and $\lambda^{*}$, which have to satisfy the following restrictions: $\kappa \leq \lambda \leq \gamma^{2}$ and $\kappa^{*} \leq \lambda^{*} \leq \gamma^{2}$, and are implicitly defined by the following conditions: $\kappa=\gamma^{2}-\sqrt{\gamma^{2}} \sqrt{\gamma^{2}-\lambda}, \kappa^{*}=\gamma^{2}-\sqrt{\gamma^{2}} \sqrt{\gamma^{2}-\lambda^{*}}$.

In this example, the domestic investor cannot invest in any foreign risky asset. If we allow the foreign investor to do so, then we need to impose the additional covariance restrictions in condition (12). These conditions imply that $\eta$ is orthogonal to $e_{t+1}$ and $e_{t+1}^{*}$, because the log return on the domestic (foreign) risky asset is affine in the domestic (foreign) innovation, which in turn implies $\kappa=\lambda=\gamma^{2}$ and $\kappa^{*}=\lambda^{*}=\gamma^{*, 2}$. We are back in the case of complete markets: $\eta_{t+1}=0$.

In the two-country Lucas (1982) model, incomplete spanning reduces the exchange rate's exposure to the consumption growth innovations. Instead, the exchange rates are now exposed to shocks uncorrelated with aggregate consumption growth in either country. In the following sections, we study the impact of incomplete spanning on each of the key three exchange rate puzzles without restricting ourselves to the Lucas (1982) model. We start with the Brandt, Cochrane, and Santa-Clara (2006) puzzle.

The two-country Lucas (1982) model with heteroskedastic consumption growth provides a simple laboratory for understanding the effects of incompleteness. In that model, the complete markets risk premium in logs on a long position in foreign currency is: $E_{t}\left[r x_{t+1}^{F X}\right]=\frac{1}{2} \gamma^{2}\left[\sigma_{g, t}^{2}-\sigma_{g, t}^{2, *}\right]$, while the complete markets risk premium in levels is given by: $E_{t}\left[r x_{t+1}^{F X}\right]+\frac{1}{2} \operatorname{var}_{t}\left[r x_{t+1}^{F X}\right]=\gamma^{2} \sigma_{g, t}^{2}$. In the incomplete spanning economy, the risk premium in logs on a long position in foreign currency is $E_{t}\left[r x_{t+1}^{F X}\right]=\frac{1}{2} \kappa\left[\sigma_{g, t}^{2}-\sigma_{g, t}^{2, *}\right]$, while the risk premium in levels on a long position in foreign currency is given by: $E_{t}\left[r x_{t+1}^{F X}\right]+\frac{1}{2} \operatorname{var}_{t}\left[r x_{t+1}^{F X}\right]=\kappa \sigma_{g, t}^{2}$. The incomplete markets model behaves as if risk aversion $\gamma$ was effectively reduced to $\sqrt{\kappa}$. There is also less return predictability in the incomplete spanning economy. The Fama slope coefficient in a regression of log currency excess returns on $f_{t}-s_{t}=r_{t}-r_{t}^{*}$ is $-2 \kappa / \gamma^{2}$. Hence, the slope coefficient falls below 2 , its complete markets value, in absolute value. The percentage reduction in the slope coefficient is twice the percentage reduction in volatility $2 \log \left(\sqrt{\frac{\kappa}{\gamma^{2}}}\right)$.

\section{Exchange Rate Entropy}

Table 2 reports summary statistics on exchange rate entropy. At the quarterly frequency, the entropy and halfvolatility are essentially the same, as if exchange rate changes were normally distributed. 
Table 2: Exchange Rate Entropy

\begin{tabular}{ccccc}
\hline \hline & Cross-country Mean & Cross-country Std & Cross-country Min & Cross-country Max \\
$L(\Delta s)$ & 0.64 & 0.15 & 0.19 & 0.80 \\
& $(0.05)$ & $(0.02)$ & $(0.03)$ & $(0.08)$ \\
$\frac{1}{2} \sigma_{\Delta s}^{2}$ & 0.64 & 0.15 & 0.19 & 0.81 \\
& $(0.05)$ & $(0.02)$ & $(0.03)$ & $(0.08)$ \\
$L(\Delta q)$ & 0.63 & 0.15 & 0.19 & 0.81 \\
& $(0.05)$ & $(0.02)$ & $(0.03)$ & $(0.08)$ \\
$\frac{1}{2} \sigma_{\Delta q}^{2}$ & 0.63 & 0.16 & 0.19 & 0.82 \\
& $(0.05)$ & $(0.02)$ & $(0.03)$ & $(0.08)$ \\
\hline \hline
\end{tabular}

Notes: The table reports summary statistics on exchange rate entropy and volatility. The entropy, denoted $L(\Delta s)$, is measured as the log of the mean change in exchange rate minus the mean of the log change in exchange rate: $L(\Delta s)=$ $\log E\left(e^{\Delta s}\right)-E(\log \Delta s)$. The volatility is measured as half the variance of the log change in exchange rates. Similar moments are defined for real exchange rates. The table presents the cross-country mean of the bilateral nominal and real exchange rate volatilities, along with the cross-country standard deviation of the bilateral exchange rate volatilities and the corresponding minimum and maximum values across countries. Similar statistics are reported for entropies. Moments are annualized (multiplied by 4) and reported in percentages. Data are quarterly, over the 1973.IV - 2014.IV period. The panel consists of 15 countries: Australia, Belgium, Canada, Denmark, France, Germany, Italy, Japan, Netherlands, New Zealand, Norway, Sweden, Switzerland, U.K., and U.S. The standard errors (reported between brackets) were generated by block-bootstrapping 10,000 samples, each block containing 2 quarters. 